LESLY ALEJANDRA GONZALEZ CAMACHO

SISTEMA DE RECOMENDAÇÃO BASEADO NA RELAÇÃO DE AMIZADE ENTRE USUÁRIOS DE REDES SOCIAIS NUM CENÁRIO DE COLD-START 
LESLY ALEJANDRA GONZALEZ CAMACHO

\title{
SISTEMA DE RECOMENDAÇÃO BASEADO NA RELAÇÃO DE AMIZADE ENTRE USUÁRIOS DE REDES SOCIAIS NUM CENÁRIO DE COLD-START
}

\author{
Dissertação apresentada à Escola Po- \\ litécnica da Universidade de São Paulo para \\ obtenção do Título de Mestre em Ciências.
}




\section{SISTEMA DE RECOMENDAÇÃO BASEADO NA RELAÇÃO DE AMIZADE ENTRE USUÁRIOS DE REDES SOCIAIS NUM CENÁRIO DE COLD-START}

\section{VERSÃO CORRIGIDA}

Dissertação apresentada à Escola Politécnica da Universidade de São Paulo para obtenção do Título de Mestre em Ciências.

Área de Concentração:

Engenharia de Computação

Orientador:

Profa. Dra. Solange Nice Alves de Souza 
Autorizo a reprodução e divulgação total ou parcial deste trabalho, por qualquer meio convencional ou eletrônico, para fins de estudo e pesquisa, desde que citada a fonte.

Este exemplar foi revisado e corrigido em relação à versão original, sob responsabilidade única do autor e com a anuência de seu orientador.

São Paulo, 16 de outubro de 2020

Assinatura do autor:

Assinatura do orientador:

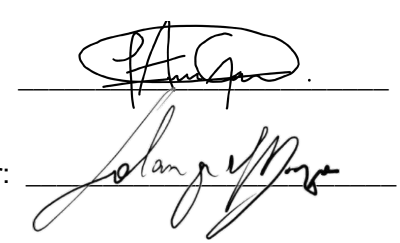

Gonzalez Camacho, Lesly Alejandra

Sistema de Recomendação baseado na relação de amizade entre usuários de redes sociais num cenário de cold-start / L. A. Gonzalez Camacho -versão corr. -- São Paulo, 2020.

$100 \mathrm{p}$.

Dissertação (Mestrado) - Escola Politécnica da Universidade de São Paulo. Departamento de Engenharia de Computação e Sistemas Digitais.

1.Redes sociais-Mineração de dados 2.Aprendizado Computacional 3.Sistemas de Recomendação-Música 4.Influência social I.Universidade de São Paulo. Escola Politécnica. Departamento de Engenharia de Computação e Sistemas Digitais II.t. 
A meus pais Magdalena e Jorge, e ao meu irmão Alexis que são a força da minha vida. 


\section{AGRADECIMENTOS}

Gostaria de agradecer principalmente a minha Orientadora a Profa. Solange, por ter acreditado em mim e ter me incentivado a alcançar grandes objetivos. Os seus aportes, ensinos e conselhos foram fundamentais para a realização dessa pesquisa, sem ela esta trabalho não teria sido possível.

A Profa. Lucia Filgueiras, pela sua valiosa ajuda e ensino para desenvolver o projeto para o comitê de ética.

A Profa. Cristina Borda, pela grande ajuda e diponibilidade na revisão dos artigos em inglês que foram publicados durante o desenvolvimento desta pesquisa.

Ao colega João Kersul, por todas as discussões sobre Sistemas de Recomendação, pela ajuda e suporte técnico que foi muito importante para o desenvolvimento desse trabalho.

Ao meu namorado Lucas, pelos conselhos e suporte técnico sobre engenharia de software que ajudaram também ao desenvolvimento desse trabalho, mas especialmente agradeço pelo amor, apoio e incentivo incondicional nos momentos difíceis durante parte do mestrado.

À Fundação de Amparo à Pesquisa do Estado de São Paulo (FAPESP) (Processos: \# 2014/04851-8 e \# 2017/04658-1), pelo financiamento do projeto de pesquisa, tornando possível a produção dessa dissertação.

Ao Itaú Unibanco S.A, pela concessão de bolsa de mestrado por meio do Programa de Bolsa Itaú no Centro de Ciência de Dados $\left(C^{2} D\right)$

Ao Centro de Ciência de Dados e ao Laboratório de Tecnologia de Software - LTS, por todas as facilidades dadas para o desenvolvimento da pesquisa.

Aos colegas do Centro de Ciência de Dados e do Laboratório de Tecnologia de Software - LTS, pelos conhecimentos compartilhados em diferentes ocasiões.

As pessoas que ajudaram como voluntários no experimento, muitos deles colegas de trabalho e amigos que fiz durante minha estadia no Brasil.

A todos meus amigos que me acompanharam durante o Mestrado, em especial a: Renata Brasil, Daniela Brasil, Leiviane Barbosa, Isaac Gonzales, Walter Campos, Carlos Rebolledo, Roberto Rangel, Pedro Bispo, Daniele Santana e Danielly Bezerra. Muito obrigada por terem me acolhido sempre e praticamente terem se tornado minha família aqui no Brasil.

A meus pais e a meu irmão, pelo amor infinito, pelo exemplo e pelo apoio constante para alcançar este objetivo. Tudo o que eu sou é graças a eles. 


\section{RESUMO}

Sistemas de Recomendação têm ganhado importância e visibilidade principalmente em aplicações de e-commerce e transmissão de música e vídeos, nas quais a quantidade de itens que o usuário pode escolher é muito grande. Isso porque ao diminuir as opções aos itens de maior interesse, facilita a escolha por parte do usuário. Situações de coldstart (usuário novo no sistema) dificultam a recomendação devido à falta de informações sobre preferências do usuário. Dados de redes sociais podem ser utilizadas como fonte de informação para reduzir o impacto de cold-start. Neste cenário, identificar o grupo de amigos com maior afinidade e os amigos mais influentes podem melhorar a recomendação. Propõe-se nesta pesquisa a utilização de dados de redes sociais como principal fonte de informação externa para recomendar itens para usuários cold-start. Mais especificamente, a partir da entrada do novo usuário no sistema, por meio das credenciais da sua rede social, identifica-se seu grupo de amigos e, dentre estes, os de maior influência, para que mediante as informações de preferências deste(s) usuário(s) influente(s), se recomendem itens (músicas) ao usuário cold-start. Revisões da literatura mostraram que o modelo de fatoração de matriz e grafos tem sido as principais técnicas empregada, respectivamente, no processo de recomendação e na modelagem das interações em redes sociais. Para validar a proposta, utilizou-se um experimento controlado, no qual teve-se a efetiva participação de 20 usuários. Uma rede social, construída especialmente para a proposta, reteve informações sobre a interação entre amigos na rede social, e também, o acesso dos mesmos a um serviço de streaming de música. Nos testes foram elaboradas duas listas de recomendação, com a finalidade de comparar os resultados, uma considerando o modelo de recomendação proposto e outro sem. Os usuários avaliaram a recomendação, dando notas de 1 a 5 para cada música recomendada. A assertividade do modelo foi computada utilizando a métrica de Root Mean Squared Error (RMSE), apresentando resultado de 1,57, o que mostra que a predição da recomendação foi muito próxima aos valores dados pelos usuários. Os resultados também evidenciaram que o modelo proposto pode ser empregado para melhorar a recomendação de qualquer usuário e não apenas coldstarts. Assim, considerou-se que o modelo proposto é bastante adequado para melhoria da recomendação. Obteve-se a autorização de um comitê de ética para a realização dos experimento.

Palavras-Chave - Sistema de recomendação, filtragem colaborativa, redes sociais, cold-start, influência social, fatoração de matriz. 


\section{ABSTRACT}

Recommender systems have gained importance and visibility especially in e-commerce applications and stream music and videos, in which the amount of items that the user can choose is very large. This is because by reducing the options to the items of greatest interest, it facilitates the user's choice. Cold-start situations (new user in the system) hinder the recommendation due to the lack of information about the user's preferences. Social networking data can be used as a source of information to reduce the cold-start impact. In this scenario, identifying the group of friends with the greatest affinity and the most influential friends can improve the recommendation. It is proposed in this research the use of data from social networks as the main source of external information to recommend items to cold-start users. More specifically, from the entry of the new user into the system, through the credentials of his/her social network, his/her group of friends is identified and, among these, the most influential, so that through the preference information of these (s) influential users, items (songs) are recommended to the coldstart user. Literature reviews have shown that the matrix factorization model and graphs have been the most used techniques, respectively, in the recommendation process and for modeling interactions in social networks. To validate the proposal, we used a controlled experiment, which had the effective participation of 20 members. A social network, built especially for the proposal, retained information about the interaction between friends on the social network, and also, their access to a music streaming service. In the tests, two lists of recommendations were created with the purpose of comparing the results, one considering the proposed recommendation model and the other without. Users rated each recommended song giving the scoring 1 to 5. The assertiveness of the model computed using the Root Mean Squared Error (RMSE) metric was 1.57, showing that the prediction of the recommendation was very close to the values given by users. The results also showed that the proposed model can be used to improve the recommendation of any user and not just cold-starts. Thus, it was considered that the proposed model is quite adequate to improve the recommendation. The experiment was made with a permission of ethic committee.

Keywords - Recommender system, collaborative filtering, social network, cold-start, social influence, matrix factorization. 


\section{LISTA DE FIGURAS}

$1 \quad$ Divisão dos principais modelos em RS . . . . . . . . . . . . . . . . . . . 22

2 Exemplo de abordagem por vizinhança . . . . . . . . . . . . . . . . 23

$3 \quad$ Exemplo de abordagem por fator latente . . . . . . . . . . . . . . . . . . . 24

4 Transformação das características de usuários e itens num espaço de fator latente para predizer as avaliações dos usuários aos itens . . . . . . . . . . 24

5 Esquema para avaliação explicita e avaliação implícita . . . . . . . . . . . . 26

$6 \quad$ Diagrama de Fluxo da RSL $\ldots \ldots \ldots \ldots$

7 Relação geral entre o serviço de música, a rede social e o Sistema de Recomendação . . . . . . . . . . . . . . . . . . . . . . 47

$8 \quad$ Arquitetura do RS proposto . . . . . . . . . . . . . . . . 56

$9 \quad$ processo de recomendação do RS proposto $\ldots \ldots$. . . . . . . . . . . . . . 57

$10 \quad$ Distribuição das avaliações com influência social . . . . . . . . . . . . . . . 67

11 Distribuição das avaliações com influência social dos usuários mais ativos na rede social . . . . . . . . . . . . . . . . . . . . . . . . 69

12 inicio . . . . . . . . . . . . . . . . . . . 86

13 Acesso com Spotify . . . . . . . . . . . . . . . . . . . . . . 86

14 Acesso com Mastodon . . . . . . . . . . . . . . . . . . . . . . . . 87

15 Geração de Recomendação . . . . . . . . . . . . . . . . . . . . 87

16 Recomendação das músicas $\ldots \ldots$. . . . . . . . . . . . . . . . . . 88

17 Avaliação das músicas pelo usuário . . . . . . . . . . . . . . . . . . . 88 


\section{LISTA DE TABELAS}

$1 \quad$ Questões de pesquisa para RSL . . . . . . . . . . . . . . . . . . . 37

$2 \quad$ Critérios de inclusão e exclusão para a RSL $\ldots$. . . . . . . . . . . . . . 37

$4 \quad$ Similarity measures employed in the main papers . . . . . . . . . . . . . . 39

5 Evaluation measures used in the main papers . . . . . . . . . . . . . . 40

$6 \quad$ Criterios de inclusão e exclusão ～. . . . . . . . . . . . . . . . . . . . . 43

$7 \quad$ Número de artigos encontrados e selecionados . . . . . . . . . . . . . . . . 43

8 Técnicas usadas para calcular a influência social . . . . . . . . . . . . . . . 44

$9 \quad$ Tipos de dados de redes sociais usados para calcular a influência social . 45

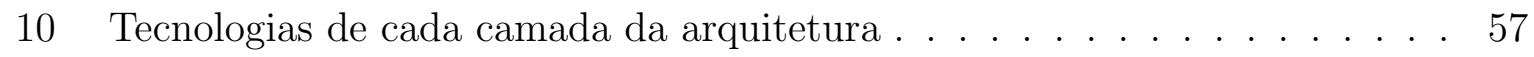

11 Detalhamento de informações do dataset Last.fm . . . . . . . . . . . . . 60

12 Exemplo de cálculo de fatores de influência . . . . . . . . . . . . . . . . . 63

13 Exemplo recomendação considerando influência social e avaliação das músicas

13 Exemplo recomendação considerando influência social e avaliação das músicas

14 Resultado do cálculo dos fatores de influência para cada usuário cold-start 89

14 Resultado do cálculo dos fatores de influência para cada usuário cold-start 90

14 Resultado do cálculo dos fatores de influência para cada usuário cold-start 91

14 Resultado do cálculo dos fatores de influência para cada usuário cold-start 92

15 Resultados das predições e avaliações das músicas considerando a influência social . . . . . . . . . . . . . . . . . . . . . . . 93

15 Resultados das predições e avaliações das músicas considerando a influência social . . . . . . . . . . . . . . . . . . . . . . . . . 94

15 Resultados das predições e avaliações das músicas considerando a influência social . . . . . . . . . . . . . . . . . . . . . 95 
15 Resultados das predições e avaliações das músicas considerando a influência social . . . . . . . . . . . . . . . . . . . . . . . . 96

15 Resultados das predições e avaliações das músicas considerando a influência social . . . . . . . . . . . . . . . . . . . . . . 97

15 Resultados das predições e avaliações das músicas considerando a influência social . . . . . . . . . . . . . . . . . . . . . . . . 98

15 Resultados das predições e avaliações das músicas considerando a influência social 


\section{LISTA DE SIGLAS}

ALS

API

CB

CB-RS

$\mathrm{CF}$

CF-RS

LGPD

MAE

$\mathrm{MF}$

RMSE

$\mathrm{RS}$

RSL
Alternating Least Squares

Application Programming Interface (Interface de Programação de Aplicações)

Content Based (Baseado em Conteudo)

Content Based Recommender System (Sistemas de recomendação baseado em conteudo)

Collaborative Filtering (Filtragem colaborativo)

Collaborative Filtering Recommender System (Sistemas de recomendação baseado em filtragem colaborativa)

Ley Geral de Proteção de Dados

Mean Absolute Error

Matrix Factorization(Fatoração de Matriz)

Root Mean Squared Error

Recommender Systems (Sistemas de recomendação)

Revisão Sistematica da Literatura 


\section{SUMÁRIO}

\begin{tabular}{lll}
\hline 1 & Introdução & 14
\end{tabular}

1.1 Objetivo . . . . . . . . . . . . . . . . . . . . 15

1.2 Contribuição $\ldots \ldots \ldots \ldots \ldots \ldots \ldots$

1.3 Metodologia . . . . . . . . . . . . . . . . . . . . . 17

1.4 Organização do trabalho $\ldots \ldots \ldots \ldots \ldots$. . . . . . . . . . . . . . 19

$\begin{array}{lll}2 & \text { Contextualização Teórica } & 20\end{array}$

2.1 Introdução . . . . . . . . . . . . . . . . . . . . . . . 20

2.2 Sistemas de Recomendação . . . . . . . . . . . . . . . . . . 20

2.3 Fatoração de Matriz $\ldots \ldots \ldots \ldots$. . . . . . . . . . . . . . 21

2.3 .1 Especificação de uma Fatoração de Matriz Básica . . . . . . . . . . . 24

2.4 Avaliações de itens em RS . . . . . . . . . . . . . . . . . . 25

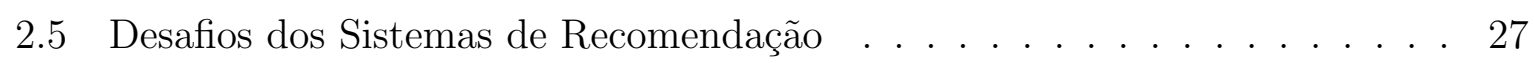

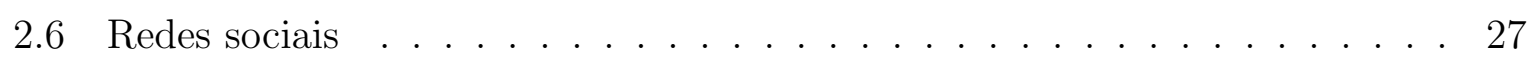

2.6 .1 Influência social . . . . . . . . . . . . . . . . . . . . . . . . . . 28

2.7 Medidas de similaridade $\ldots \ldots \ldots \ldots$. . . . . . . . . . . . . 30

2.8 Medidas de avaliação $\ldots \ldots \ldots$. . . . . . . . . . . . . . . . 31

3 Resultados da Revisão Sistemática da Literatura sobre uso de dados de redes sociais para melhoria da recomendação em cenários de cold-start 34

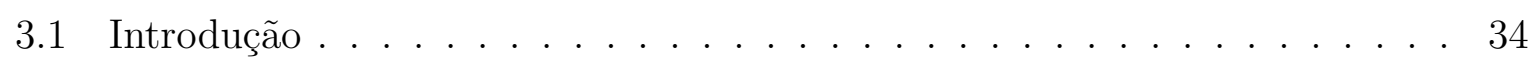

3.2 Principais aspectos dos artigos selecionados . . . . . . . . . . . . . . 36

3.3 Principais técnicas empregadas no processo de recomendação . . . . . . . . 37

3.4 Conclusão da RSD $\ldots \ldots \ldots \ldots \ldots$. . . . . . . . . . . . . . . . . . . . . 41 
4 Resultados da RSL sobre influência social em redes sociais

4.1 Introdução $\ldots \ldots \ldots \ldots$. . . . . . . . . . . . . . . . . . . . . . 42

4.2 Principais aspectos dos artigos mais relevantes . . . . . . . . . . . . . . . . 42

4.3 Conclusões $\ldots \ldots \ldots \ldots$. . . . . . . . . . . . . . . . . . . . . . . 44

5 Sistema de Recomendação Proposto 46

5.1 Introdução . . . . . . . . . . . . . . . . . . . . . . 46

5.2 Características do Sistema de Recomendação . . . . . . . . . . . . . . . . . 46

$5.2 .1 \quad$ Friendly Group Factor $\ldots \ldots$. . . . . . . . . . . . . . . . 48

5.2 .2 Representação da função de preferência de usuário . . . . . . . . . . . 49

5.2 .3 Processo da recomendação . . . . . . . . . . . . . . . . . 54

5.3 Arquitetura e implementação . . . . . . . . . . . . . . . . . . 55

$5.3 .1 \quad$ Fluxo dos dados da recomendação . . . . . . . . . . . . . . . . . . 57

6 Testes e Resultados no ambiente controlado 59

6.1 Introdução $\ldots \ldots \ldots \ldots \ldots \ldots$. . . . . . . . . . . . . . . . . . 59

6.2 Dados para o treinamento do RS . . . . . . . . . . . . . . . . 59

6.2 .1 Dataset da Plataforma de serviço de música . . . . . . . . . . . . . 59

$6.2 .2 \quad$ Dataset das preferências individuais musicais . . . . . . . . . . . . 60

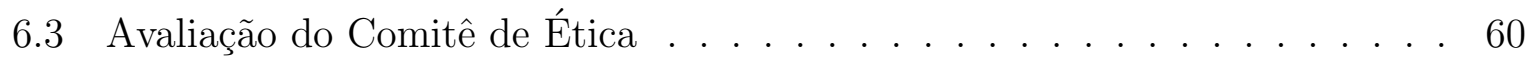

6.4 Rede social SocialTracks Mastodon . . . . . . . . . . . . . . . . . . 61

$6.4 .1 \quad \mathrm{O}$ experimento controlado . . . . . . . . . . . . . . 61

6.5 Fatores de influência . . . . . . . . . . . . . . . . . . . . . 62

6.6 Recomendações . . . . . . . . . . . . . . . . . . . . . . . . . . . 64

\begin{tabular}{lll}
\hline 7 & Conclusões & 70
\end{tabular}

\begin{tabular}{ll}
\hline Referências Bibliográficas & 72
\end{tabular} 
Apêndice A - TERMO DE CONSENTIMENTO LIVRE E ESCLARE-

CIDO (TCLE)

\begin{tabular}{ll}
\hline Apêndice B - Experimento & 86
\end{tabular}

\begin{tabular}{ll}
\hline Apêndice C - Cálculo de Fatores de Influência & 89
\end{tabular}

\begin{tabular}{|ll}
\hline Apêndice D - Resultados Finais & 93
\end{tabular} 


\section{INTRODUÇÃO}

Nos últimos tempos o número de serviços digitais e seus usuários têm aumentado rapidamente, devido em parte, a popularidade dos serviços de computação em nuvem, que ao oferecer uma arquitetura computacional flexível permite suportar cada vez mais modernas aplicações (Deng et al., 2014). Com a prevalência das redes sociais, dispositivos móveis e sistemas orientado a serviços de grande escala, tem-se experimentado a geração de enormes quantidades de dados, que por sua vez sobrecarrega usuários com grande volume de informações, dificultando encontrar serviços que atendam suas preferências Almohsen and Al-Jobori, 2015; Deng et al., 2014). Como resultado, Sistemas de Recomendação (RS, Recommender Systems) têm um papel cada vez mais importante, na medida que lidam com a sobrecarga de serviços/produtos, sugerindo os mais adequados e ainda não adquiridos pelos usuários, mas que poderiam ser considerados altamente relevantes para eles (Deng et al., 2014; Maniktala et al., 2016).

Existem diferentes abordagens em RS, que geralmente são classificadas em: Filtragem Colaborativa (CF, Collaborative Filtering), Baseado em Conteúdo (CB, Content-Based) (De-Campos et al., 2010, Huang et al., 2016), Demográficos e Híbridos. Os CF-RS, tentam identificar grupos de pessoas com gostos semelhantes aos do usuário, para recomendar a este os itens que essas pessoas gostam. Por outro lado, os CB- RS, determinam as preferências do usuário e recomendam itens semelhantes aos previamente preferidos ou navegados por ele. A Filtragem Demográfica é basada no principio que usuários com atributos em comum, tais como idade, sexo, nível educativo, entre outros, têm preferencias em comum. A Filtragem Híbrida combina duas ou mais abordagens de filtragem para processar recomendações. (Bobadilla et al., 2013; Jain et al., 2015).

Quando um usuário acessa pela primeira vez um RS, não existem informações sobre avaliações a itens por parte desse usuário. Assim, o sistema não consegue avaliar suas preferências (Khalid et al., 2014) e não consegue recomendar itens relevantes para esse usuário. Esse problema é conhecido como usuário cold-start e, por não existir uma solução que atenda as diferentes necessidades, é um assunto que, apesar dos avanços em RS, ainda 
permanecem em aberto (Al-Hassan et al., 2015; Bobadilla et al., 2012; Huang et al., 2016).

Vários trabalhos têm sido propostos para melhorar a recomendação em situações de cold-start, tendo várias técnicas sido propostas, como o uso de aprendizado de máquina, teoria de aproximação e várias heurísticas aplicadas a diferentes domínios de recomendação (De-Campos et al., 2010). Vários trabalhos abordam recomendação de filmes (Christou et al., 2016; Moreno et al., 2016), sítios de interesse (Khalid et al., 2014; Yin et al., 2015), programas de TV (Zhang et al., 2013), noticias online (Lin et al., 2014) e grupos de estudo virtual (Salehi et al. 2013), dentre outros. Para diminuir a dispersão dos dados e mitigar o problema de cold-start, geralmente são exploradas diversas fontes para incrementar a informação sobre os usuários ou itens (Barjasteh et al., 2015; CHEN et al., 2016; Jain et al., 2015; Lian et al., 2016; Mohammadi and Andalib, 2017; Wang et al., 2016; Xiushan and Dongfeng, 2017; Zhang, Jia Dong et al., 2017).

As redes sociais são uma fonte de informação, que ao permitir uma participação mais ampla e abundante dos usuários na web, disponibilizam rica informação de feedback dos usuários, históricos de interação e relacionamentos sociais. Tais informações são de grande utilidade para estabelecer preferências de usuário em relação a serviços e produtos, relações de confiança entre os usuários, relações de influência de usuários sobre outros, dentre outras. Usar tais informações em RS podem tornar as recomendações mais precisas, principalmente em cenários de cold-start (Deng et al., 2014). Dado o espectro de possibilidade, algumas pesquisas têm empregado redes sociais como fonte de dados para melhorar a recomendação (Ha et al., 2013; Jiang et al., 2015; Lian et al., 2016; Liu et al., 2013; Rosli et al., 2015; Wang et al., 2016; Xiushan and Dongfeng, 2017; Zhang et al., 2013; Zhang, Jia Dong et al., 2017; Zhao et al., 2016).

\subsection{Objetivo}

Criar um modelo de Recomendação para usuários cold-start usando dados extraídos de redes sociais. No modelo identifica-se no conjunto de amigos, os mais próximos e, dentre estes, os de maior influência ao usuário cold-start (alvo da recomendação), recomendando produtos adequados com base nas informações dos amigos mais influentes. Esta abordagem pode também ser aplicada em usuários que não são cold-start.

Propõe-se uma função de influência social, que calcula a influência com base na identificação (i) dos amigos que tem relacionamento mais forte de amizade com o usuário alvo da recomendação, (ii) dos amigos mais influentes ao usuário alvo e (iii) dos amigos com 
preferências mais semelhantes ao usuário alvo.

Faz parte do objetivo criar um ambiente de implementação para testar o modelo de recomendação proposto. O teste envolve usuários reais, sendo necessário sua aprovação por um comitê ética.

\subsection{Contribuição}

Resultados de pesquisa recente ( Prando, 2016$)$ mostraram que o uso de informações extraídas das redes sociais do próprio usuário ajudam na recomendação para o caso de cold-start. Tais resultados evidenciaram que o uso de dados extraídos de redes sociais são fonte para conseguir informações sobre usuários novos, para os quais não se tem nenhuma informação disponível para recomendação. Assim, acredita-se que aumentar o espectro da coleta de dados das redes sociais melhorará significativamente os resultados da pesquisa anterior. Em outras palavras, espera-se melhorar a precisão das recomendações a partir da adição de dados extraídos dos relacionamentos sociais do usuário.

Adicionalmente, Jiang et al. (2015); Xiushan and Dongfeng (2017); Zhang et al. (2013); Zhang, Jia Dong et al. (2017); Zhao et al. (2016) e Rosli et al. (2015) mostram que pessoas que compartilham interesses similares tendem a estar mais conectadas e a interagir umas com outras. Xiushan and Dongfeng (2017) por exemplo, calcula a confiança implícita baseado nos comportamentos de interação do usuário nas redes sociais (número de retweets, menções, comentários que os usuários fazem com outras pessoas) para determinar diferentes graus de confiança do usuário com os seus amigos e melhorar a recomendação de itens. Rosli et al. (2015), coleta as curtidas que o usuário e seus amigos (likes, co-likes) deram em páginas sobre filmes no Facebook, para determinar o perfil do usuário e melhorar a recomendação de filmes.

Assim, este trabalho estende as propostas de Prando et al. (2017) e Contratres et al. (2018), extraindo as informações das redes sociais como fonte de informação para identificação das preferências do usuário cold-start. Diferentemente de (Contratres et al., 2018; Prando et al., 2017), identifica-se o conjunto de amigos que são mais próximos e, dentre estes, os que mais influenciam o usuário cold-start para basear as recomendações segundo as preferências desses amigos e assim diminuir os problemas causados pela escassez dos dados em cenários cold-sart.

Para o acesso as informações da rede social, segue-se a mesma estratégia de Prando et al. (2017) e Contratres et al. (2018), na qual o novo usuário ao interagir com o e- 
commerce, ou site de serviços, fornece suas credencias da rede social. Assim, como nos trabalhos prévios, tem-se acesso aos dados postados pelo usuário alvo da recomendação. Além disso, pode-se identificar a rede de amigos e, dentre esses, os mais próximos.

Neste trabalho pretende-se fazer recomendação de itens, avaliando por meio das informações das redes sociais a força da amizade e o grau de influência que certas pessoas tem sobre o usuário-alvo para estimar suas preferências por determinados itens.

\subsection{Metodologia}

O desenvolvimento desse trabalho foi dividido da seguinte forma:

- Levantamento e análise de referências bibliográfica: Nesta parte foram realizadas duas Revisões Sistemática da Literatura: uma relacionada com RS, CF e redes sociais que ressaltaram o problema com relação à escassez de dados e o problema de cold-start; e a outra relacionada a influência social em redes sociais. Com estas revisões, cujos processos foram baseadas na proposta de Kitchenham and Charters (2007) para RSL em Engenharia da Computação, pretendeu-se incrementar a qualidade da pesquisa. Para tal, compilou-se os trabalhos mais relevantes entre os anos de 2011 e 2019, encontrados nas bases de pesquisa empregadas nas revisões, sobre as técnicas mais atuais para contornar o cenário de cold-start.

- Análise de uso de redes sociais em RS: Nesta etapa, foi analisada que tipo de informação é trocada dentro das redes sociais e quais informações podem ser coletadas a partir do acesso com as credenciais do usuário nas redes sociais para identificar os amigos mais influentes ao usuário. Como as redes sociais têm enfoques e políticas diferentes para se ter acesso aos dados dos usuários, foi preciso entender cada uma das mais utilizadas como Facebook e Twitter. Levantou-se também ambientes para a geração de redes sociais para a implementação de um experimento controlado para coleta de dados.

- Levantamento da base de dados a ser utilizada: Nesta etapa foram definidas as bases de dados utilizadas no experimento especificando o domínio do RS. Incluiuse também, a extração dos dados das redes sociais, visando encontrar os amigos mais influentes ao usuário recém cadastrado que fazem uso do nosso RS para inferir a recomendação de itens relevantes para o usuário novo.

- Especificação do modelo de RS: Esta etapa compreendeu a definição de algorit- 
mos empregados para execução do RS. Tais algoritmos foram escolhidos com base no resultado da RSL (Gonzalez-Camacho and Alves-Souza, 2018)

- Avaliação do RS: Para a avaliação do RS, empregou-se as técnicas mais utilizadas em trabalhos prévios, a qual foi: Root Mean Square Error (RMSE). O resultado da RSL também guiou a escolha da técnica que foi empregada.

- Identificação do grupo de amigos: Foram estabelecidas métricas para avaliar o grupo de amigos mais influentes sobre o usuário recém cadastrado no sistema.

- Elaboração e submissão do projeto a Comitê de Ética: como a pesquisa incluiu o uso de dados extraídos de redes sociais do perfil das pessoas participantes, de acordo com a Resolução CNS 510/2016, foi necessário a avaliação do uso desses dados pelo comitê de ética. Assim, um projeto foi elaborado e submetido à Plataforma Brasil, tendo sido o projeto analisado pelo comitê de ética da Escola de Artes, Ciências e Humanidades (EACH) da USP.

- Arquitetura e organização do sistema proposto: Foi definida a estrutura do RS e como seria a conexão com os dados dos usuários. Além de decidir como a aplicação exemplo (que permitiu a interação do usuário com o RS) se comunicaria com o RS.

- Ambiente de teste: Os testes foram realizado em um ambiente controlado, com o uso de uma rede social criada especialmente para a pesquisa.

Para o ambiente controlado foram convidadas um grupo de pessoas (Douglas Rodrigues Oliveira et al., 2012) que se cadastraram e usaram a rede social "SocialTracks Mastodon", postando informações e interagindo com amigos. As informações de cadastro dessas pessoas, bem como seu histórico de uso/compra de itens foram armazenados e utilizados para fazer a recomendação para um usuário cold-start.

Para simular a interação com o site de serviço de streaming de música, empregou-se a mesma estratégia seguida nos trabalhos prévios de Prando et al. 2017) e Contratres et al. (2018) que consiste na implementação de um formulário acessado pela web que simula a interação com o e-commerce. Os trabalhos Prando et al. (2017) e Contratres et al. (2018) estão vinculados à pesquisa principal "Big Data e Business Intelligence no contexto do uso de dados de redes sociais como solução para cenário de cold-start em sistemas de recomendação", a qual a pesquisa aqui apresentada também é parte. 
Nos testes foram elaboradas duas listas, com a finalidade de comparação dos resultados, uma consideraando o modelo de recomendação proposto e outro sem.

- Validação dos resultados: Nesta última etapa, discutiu-se a assertividade da recomendação apresentando os resultados obtidos aos usuários cadastrados no sistema, os quais avaliaram a recomendação dando notas de 1 a 5 , representando o quanto eles gostaram do produto recomendado. Para avaliar se realmente a influência social melhora a recomendação, avaliou-se se havia alteração no resultado da recomendação em relação ao uso apenas dos dados dos amigos mais próximos.

\subsection{Organização do trabalho}

Este trabalho está organizado da seguinte forma: seção 2, Fundamentação Teórica, apresenta uma revisão da literatura contendo as principais contribuições sobre RS, CF e redes sociais, além de expor os principais algoritmos usados em RS baseados em CF. As seções 3 e 4 apresentam os principais resultados obtidos com as RSL. A seção 5 corresponde ao detalhamento do sistema de recomendação proposto. A seção 6 descreve o experimento e os resultados dos testes realizados. Na Seção 7 tem-se as conclusões do trabalho. 


\section{CONTEXTUALIZAÇÃO TEÓRICA}

\subsection{Introdução}

Nesse capítulo são apresentados os conceitos sobre sistemas de recomendação, as técnicas mais utilizadas baseadas em filtragem colaborativa e os principais problemas nas recomendações. Também, são apresentados conceitos sobre redes sociais, algoritmos de aprendizado de máquina incluindo uma revisão sobre os algoritmos mais utilizados nos RS.

\subsection{Sistemas de Recomendação}

Segundo Al-Hassan et al. (2015), RS são ferramentas que filtram informação personalizada, que são efetivamente usadas para predição automática e identificação de um conjunto de itens interessantes para o usuário. Devido ao grande volume de dados que são gerados diariamente, é cada vez mais difícil que usuários encontrem itens que realmente sejam de seu interesse (Lalwani et al., 2015). Na maioria dos casos, os usuários não sabem claramente o que precisam, ou desconhecem a existência de algum produto/serviço que potencialmente consiga atender sua necessidade (Deng et al., 2014). É por isso que os RS têm um papel muito importante para sugerir informação relevante ao usuário, permitindo que estes tenham uma experiência positiva no momento de realizar uma compra, ou adquirir um produto, dentro de um e-commerce ou um serviço de streaming.

Geralmente um RS recomenda itens aprendendo sobre o perfil do usuário, considerando as atividades anteriores do usuário e o tipo de itens disponíveis no sistema. Diferentes abordagens têm sido utilizadas pelas plataformas de e-commerce para recomendar produtos aos seus usuários (Thilagam, 2016). Dentre as principais abordagens usadas nos RS, na literatura se destacam: a filtragem Baseada em Conteúdo (CB), a Filtragem Colaborativa (CF) e a Filtragem Hibrida.

Os Sistemas de Recomendação Baseado em Conteúdo (CB-RS, Content Based Re- 
commender System), geralmente avaliam o conjunto de itens favoritos, ou que foram procurados pelo usuário no passado, para determinar as suas preferencias e gerar recomendações de itens similares aos previamente procurados. Uma vez que esse tipo de RS somente considera como base para a recomendação o comportamento de compra anterior do próprio usuário, geralmente se mostra desvantajoso para descobrir novos de itens. (Huang et al., 2016).

Por outro lado, para construir um Sistema de Recomendação por Filtragem Colaborativa (CF-RS, Collaborative Filtering Recommender System), o sistema define clusters de usuários com preferências similares. Os usuários em cada cluster são chamados de vizinhos (Neighbors) e exibem um comportamento de compra/avaliação de itens semelhantes, que pode ser usado para predizer os comportamentos futuros de compra/avaliação dos itens.

A maior diferença entre CB-RS e CF-RS é que em CF as preferências do usuário são determinadas por meio dos hábitos de compra dos seus vizinhos, enquanto os sistemas por CB somente se baseiam nos dados individuais do próprio usuário para recomendar itens (Huang et al. 2016) a este. Na CF itens que tem poucas avaliações podem ser recomendados em função dos feedbacks de outros usuários. Além disso, as recomendações colaborativas são baseadas nas avaliações dos itens feitas pelos vizinhos, e não no conteúdo, ou descrição, do item, permitindo identificar itens melhor qualificados. Também, sistemas por CF conseguem recomendar itens com conteúdo muito diferente, caso outros usuários já tenham mostrado interesse por tais itens (Desrosiers and Karypis, 2011).

Os sistemas Híbridos se baseiam na combinação de duas ou mais técnicas, usando as vantagens de uma que possa suprir as deficiências da outra e que permita melhorar os resultados de recomendação (Ricci et al., 2011).

\subsection{Fatoração de Matriz}

Os CF-RS se dividem em dois principais modelos: Métodos de Vizinhança (Neighborhood Methods) e Modelos de Fator Latente (Latent Factor Models) como se observa na figura 1 (Ricci et al., 2011).. Os Métodos de Vizinhança estão focados em calcular o relacionamento entre itens ou entre usuários. As abordagens orientadas a itens avaliam a preferência do usuário por um item baseado nas avaliações (ratings) dos itens "vizinhos" para o mesmo usuário. Os vizinhos de um item são outros itens que têm avaliações semelhantes feitas pelo mesmo usuário (Koren et al. 2009). Por outro lado, o método de vizinhança baseado em usuário, encontra a avaliação (ratings) mais provável a um item $I$ 
por um usuário $U$, baseada nas avaliações dadas a $I$ pelos usuários mais semelhantes a $U$ (Desrosiers and Karypis, 2011). A semelhança entre usuários ou entre itens é determinada segundo alguma medida de similaridade, as quais são explicadas na seção 2.6.

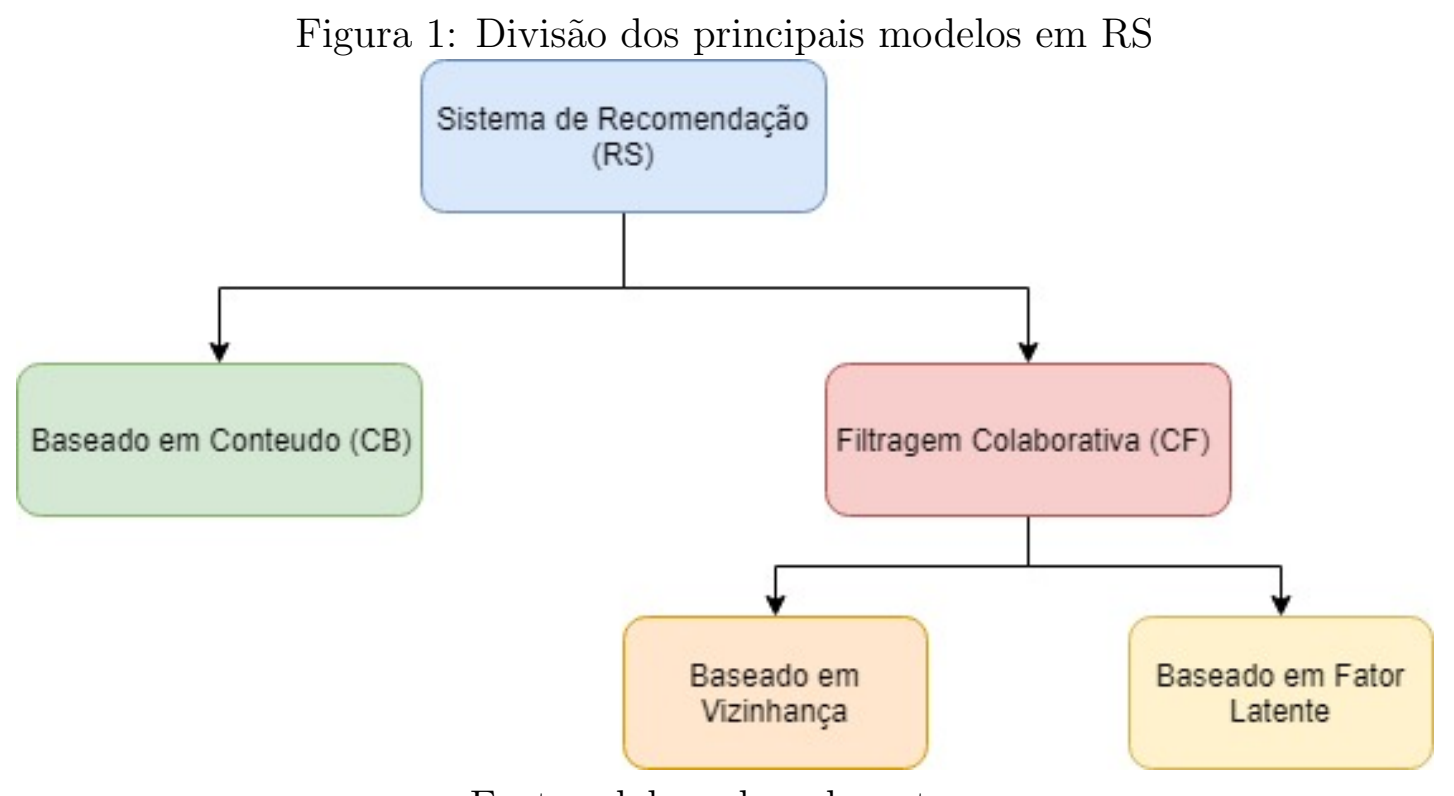

Fonte: elaborado pelo autor

A Figura 2, ilustra como basicamente um algoritmo baseado em vizinhança, no qual são observadas as preferências do usuário Joe e comparado com as preferências dos seus vizinhos mais próximos, para determinar os itens a serem recomendados, baseado nas avaliações dos seus vizinhos feitas a outros itens. A Figura 2 mostra os filmes que Joe e seus amigos assistiram. Observe que tanto Joe quanto os amigos assistiram os mesmos três filmes e, além disso, os três amigos assistiram mais outros filmes, sendo um em comum. Este seria considerado melhor (\#1, o primeiro no ranqueamento) para recomendação a Joe.

Em contraste com os CF-RS baseados em métodos de vizinhança, que usam as classificações armazenadas diretamente na previsão, os modelos de Fator Latente usam essas classificações para aprender um modelo preditivo. A ideia é poder modelar as interações entre usuário-itens com fatores que representam características latentes dos usuários e itens no sistema, como por exemplo, a classe de preferência de usuários e a classe de categoria de itens (Desrosiers and Karypis, 2011).

Os Modelos de Fator Latente são uma alternativa que tentam explicar as avaliações (ratings) caracterizando os itens e usuários em $n$ Fatores, inferidos a partir dos padrões de avaliação. Cada Fator mede o quanto o usuário gosta de um item a partir da pontuação alta no fator do item correspondente. Para o domínio de filmes, por exemplo, os fatores descobertos podem medir dimensões óbvias, como comédia versus drama, romântica ver- 
Figura 2: Exemplo de abordagem por vizinhança

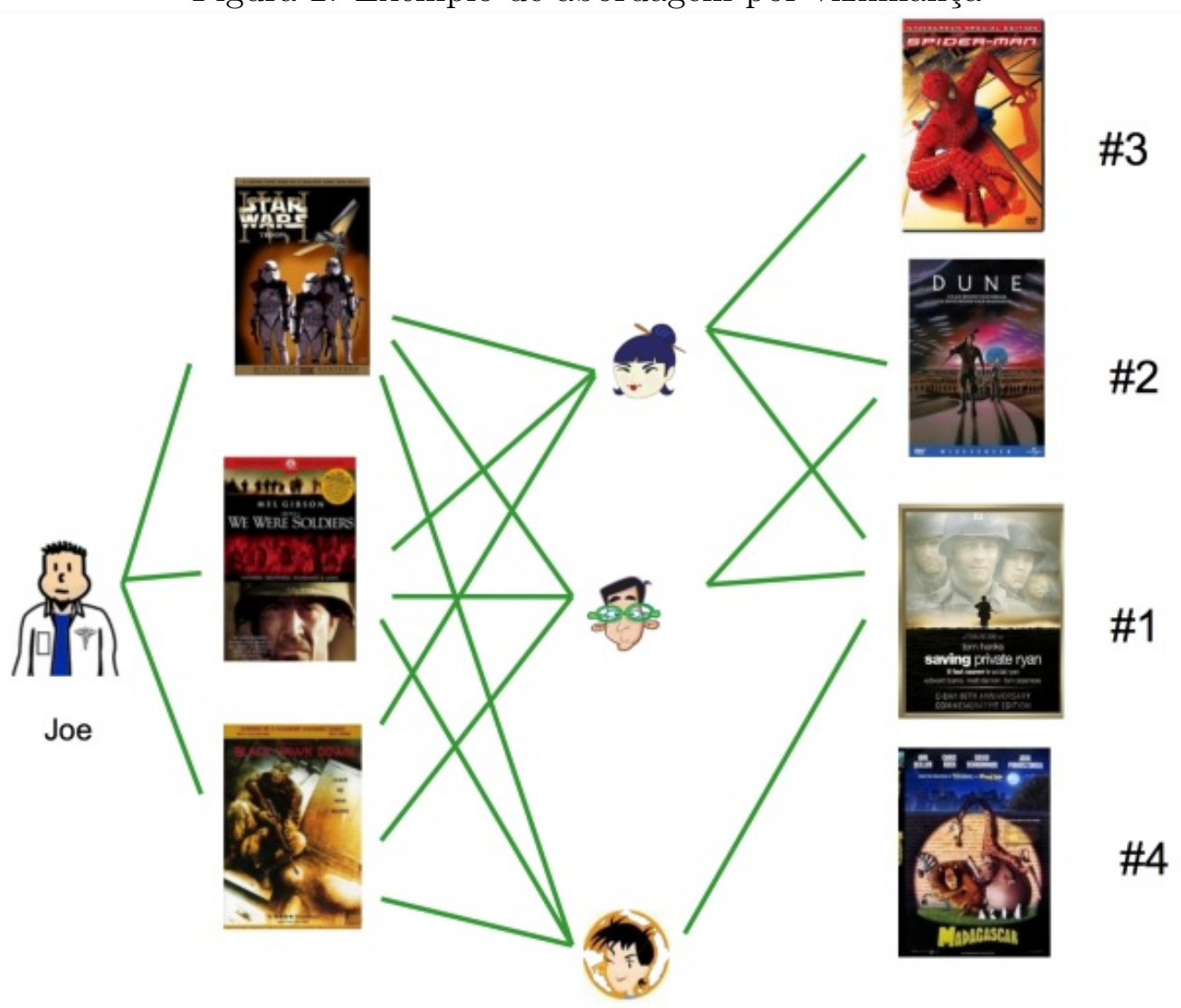

Fonte: Koren et al. (2009)

sus ação, filmes especializados para mulheres ou para crianças, entre outras (Koren et al., 2009).

A Figura 3 é um exemplo da abordagem de fator latente. Nela se pode observar que tanto usuários como itens são caracterizados num plano de duas dimensões femininomasculino, sério-escapista.

Fatoração de Matriz (MF, Matrix Factorization) é uma das concepções mais bem sucedidas dos modelos de Fator Latente. Segundo Koren et al. (2009), MF caracteriza tanto itens como usuários como vectores de fatores inferidos a partir dos comportamentos das avaliações dos itens. A alta correspondência entre um item e os fatores do usuário geram a recomendação. Para Desrosiers and Karypis (2011); Zhang et al. (2013) o modelo de MF transforma as características de usuários e itens dentro de um espaço de fator latente e prediz as avaliações (ratings) de usuários em relação aos itens, como se observa na Figura 4

A MF têm-se tornado muito populares nos últimos anos, porque combina boa escalabilidade com precisão preditiva. Além disso, oferecem muita flexibilidade para modelar 
várias situações da vida real (Koren et al., 2009).

Figura 3: Exemplo de abordagem por fator latente

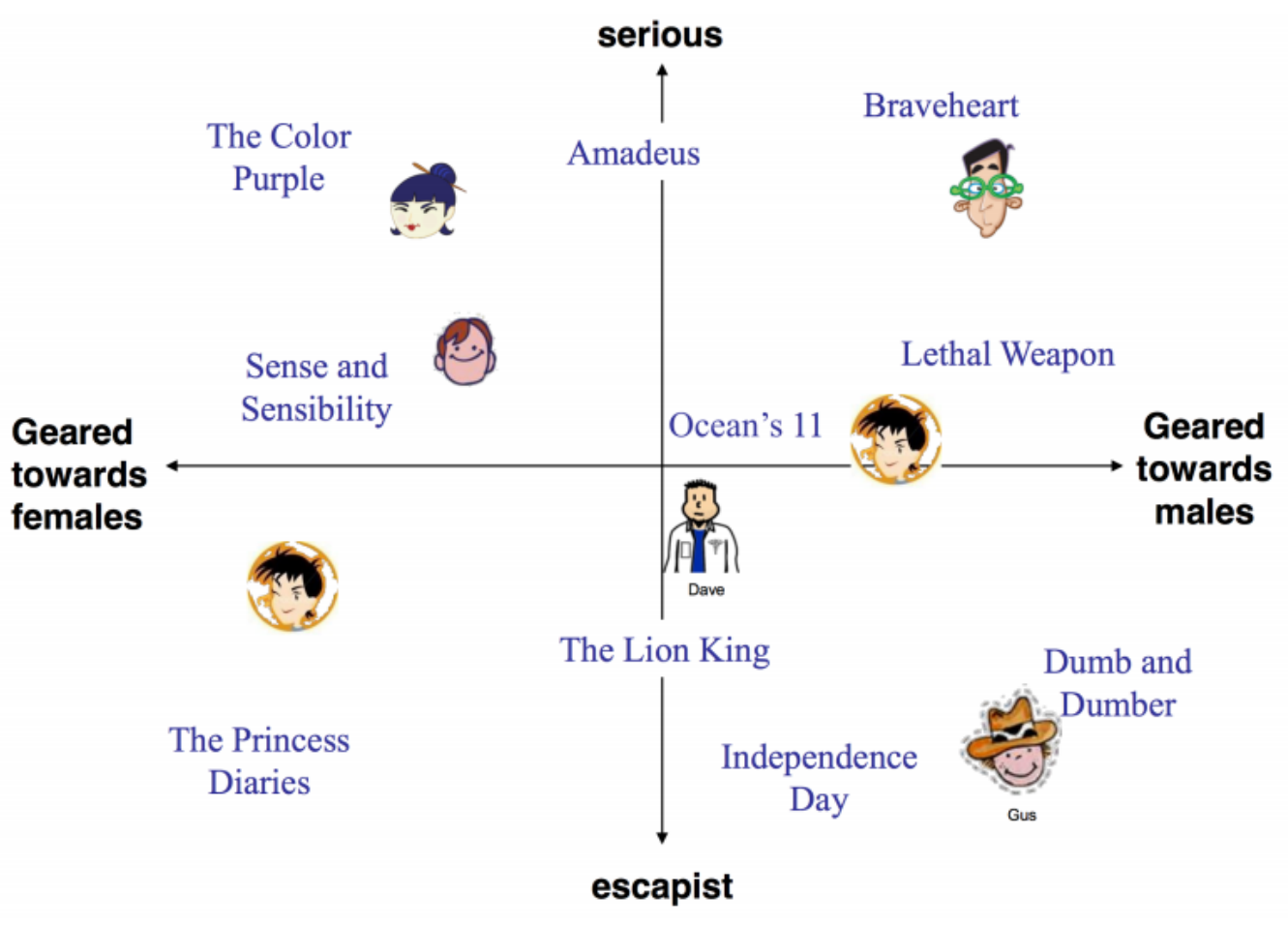

Fonte: Koren et al. (2009)

Figura 4: Transformação das características de usuários e itens num espaço de fator latente para predizer as avaliações dos usuários aos itens

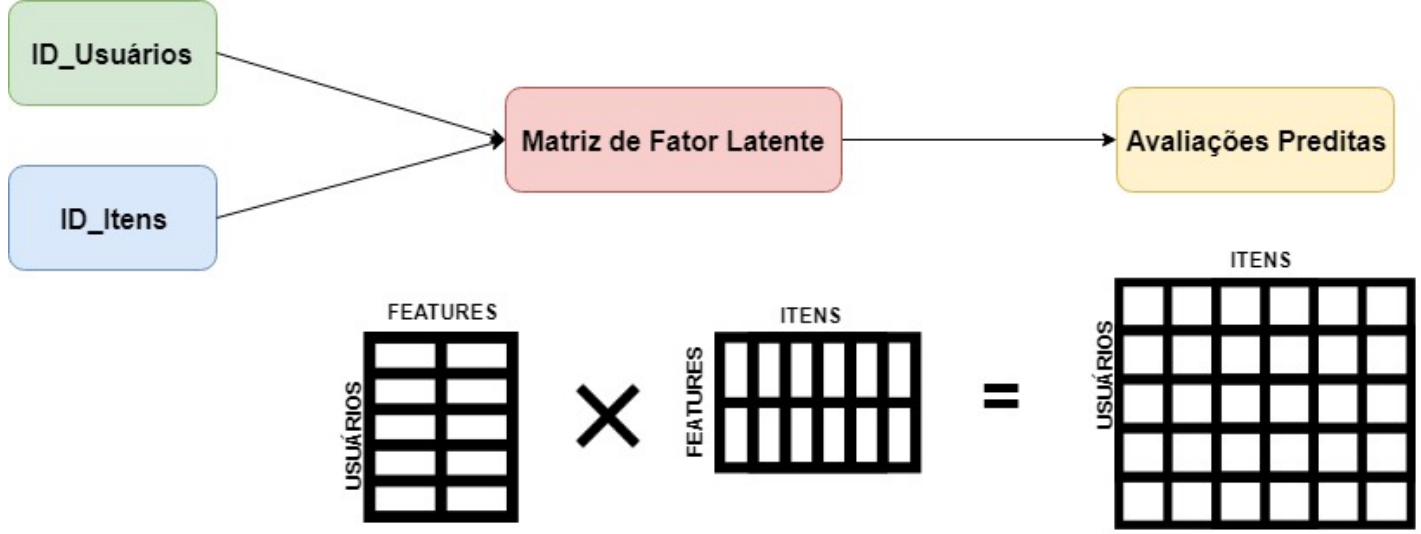

Fonte: elaborado pelo autor

\subsubsection{Especificação de uma Fatoração de Matriz Básica}

Modelos de fatoração matricial mapeiam usuários e itens para um espaço de fatores latentes de dimensionalidade $f$, de modo que as interações item-usuário são modeladas como produtos internos naquele espaço. Assim, cada item $i$ é associado a um vetor 
$q_{i} \in R^{f}$, e cada usuário u é associado a um vetor $p_{u} \in R^{f}$. Dado um item $i$, os elementos de $q_{i}$ medem os fatores positivos ou negativos associados ao elemento $i$. Do mesmo modo, seja um usuário $u$, os elementos de $p_{u}$ medem a extensão do interesse que o usuário tem em itens que se encaixam nos fatores correspondentes, positivos ou negativos. O resultado do produto escalar apresentado na equação 2.1, captura o interesse geral do usuário pelas características do item, ou seja, a interação entre o usuário $u$ e o item $i$, que é denotado por $\hat{r}_{u i}$, Koren and Bell, 2011; Koren et al., 2009):

$$
\hat{r}_{u i}=q_{i}^{T} p_{u}
$$

Com o intuito de reduzir a dispersão que geralmente existe nos modelos de MF por causa da falta de avaliações sobre os itens no sistema, as abordagens mais recentes em MF sugerem modelar diretamente apenas as avaliações observadas, em lugar de fazer a regularização dos dados para evitar problemas de overfitting (predição de futuras observações de forma não confiável) nos RS. Assim, para aprender os vetores fatoriais $\left(p_{u}\right.$ e $\left.q_{i}\right)$, o sistema minimiza o erro quadrático regularizado no conjunto de classificações conhecidas, como mostrado na equação 2.2 :

$$
\min _{q^{*}, p^{*}} \sum_{u, i \in k}\left(r_{u i}^{\prime}-q_{i}^{T} p_{u}\right)^{2}+\lambda\left(\left\|q_{i}\right\|^{2}+\left\|p_{u}\right\|^{2}\right)
$$

Na equação 2.2, $k$ é o conjunto de pares $(u, i)$, para o qual $r_{u i}^{\prime}$ é conhecido (dados de treinamento). O sistema aprende o modelo ajustando as avaliações anteriormente observadas. No entanto, o objetivo é generalizar as avaliações anteriores de forma a prever avaliações futuras e desconhecidas. Assim, o sistema deve evitar sobrecarregar os dados observados, regularizando os parâmetros aprendidos, cujas magnitudes são penalizadas. A constante $\lambda$ controla a extensão da regularização e geralmente é determinada pela validação cruzada (cross-validation). Para minimizar a função da equação 2.2. na literatura são propostas várias abordagens entre elas Stochastic Gradient Descent e Alternating Least Squares (ALS) (Koren et al., 2009).

\subsection{Avaliações de itens em RS}

Em RS, as avaliações dos itens podem ser do tipo explícito ou implícito. As avaliações são explicitas quando os usuários relatam diretamente seu interesse em itens. Por exemplo, a Netflix coleta avaliação de estrelas para filmes e no Youtube o usuário pode indicar 
se gostou ou não de algum vídeo com um ícone de polegar para cima ou para baixo. Esses tipos de dados geralmente são convenientes dentro dos RS porque garante um grau de qualidade na hora de fazer a recomendação. Quando a avaliação explícita não está disponível, os RS podem inferir as preferências do usuário usando avaliação implícita, que indiretamente mostra o interesse do usuário por determinados tipos de produtos/itens. Uma avaliação implícita pode ser feita a partir da observação do comportamento do usuário, como seu histórico de compras, de navegação, padrões de pesquisa, etc., ( $\mathrm{Hu}$ et al., 2008; Koren and Bell, 2011).

A Figura 5 apresenta como a avaliação de um item pode ter significados totalmente diferentes dependendo do tipo de avaliação, se é implícita ou explicita. Por exemplo, na avaliação explicita uma marcação de cinco estrelas mostra que o usuário gosta de determinado item. No entanto, para o caso de avaliação implícita, a avaliação é mais subjetiva, se o usuário procurou por um item menos de cinco vezes (ex. deu cinco cliques no item, ou, escutou uma música 5 vezes) pode significar que tem pouco interesse pelo item, não entanto pode significar também que o usuário não tem muita costume de procurar itens, e 5 seria o valor máximo de interesse que representaria a esse usuário.

Figura 5: Esquema para avaliação explicita e avaliação implícita

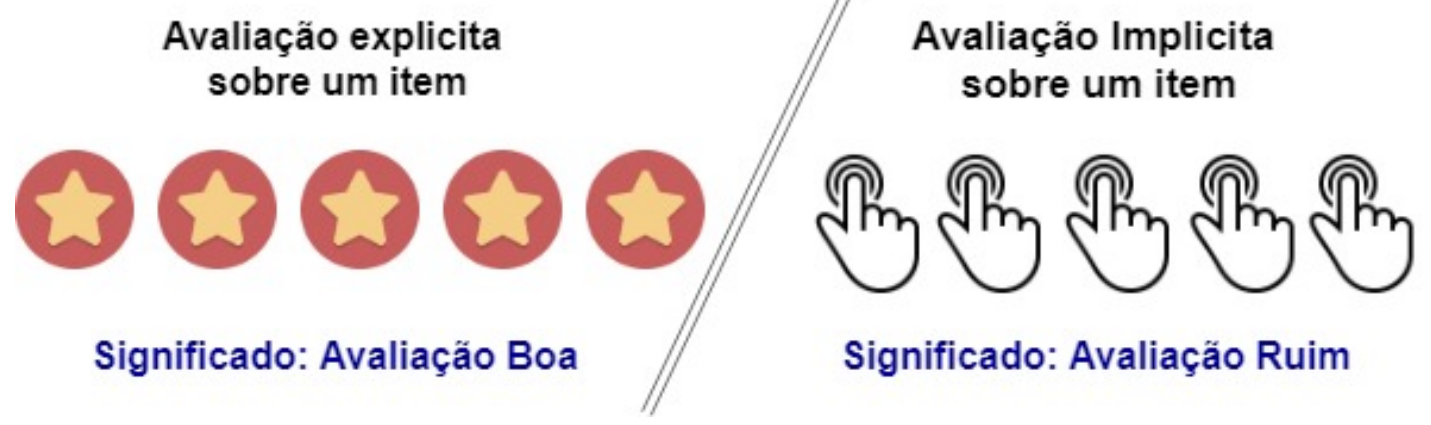

Fonte: Elaborado pelo autor

A avaliação implícita geralmente denota a presença ou ausência de um evento, que normalmente é representada por uma matriz densamente preenchida ( $\mathrm{Hu}$ et al., 2008; Koren et al. 2009). É por isso que uma das vantagens da MF é permite incorporar ditas informações nos casos em que a avaliação explicita não é suficiente, ou não existe, e não é possível inferir as preferências dos usuários. 


\subsection{Desafios dos Sistemas de Recomendação}

Em RS, os dados mais convenientes são as avaliações explícitas, que contém informações dos usuários sobre seus interesses em produtos. Uma avaliação explicita do usuário refere-se à avaliação que o usuário dá sobre algum item. Por exemplo, a Netflix coleta avaliações a partir de estrelas para filmes. Geralmente, a avaliação explicita corresponde a uma matriz esparsa, uma vez que qualquer usuário individual provavelmente avaliou apenas uma pequena porcentagem de itens possíveis (Koren et al., 2009).

Quando um usuário novo é adicionado ao sistema, a previsão da recomendação é muito difícil porque o sistema não possui informação sobre itens que o usuário gosta para conseguir gerar uma recomendação útil para ele. O mesmo ocorre quando um novo item é adicionado ao sistema, pois o item não terá nenhuma avaliação de usuário associada a ele. Portanto, é difícil a recomendação de itens recém introduzidos. Esses problemas são conhecidos nos RS como cold-start (Mohammadi and Andalib, 2017; Thilagam, 2016).

Estudos recentes tem mostrado que métodos de MF podem ser aplicados para melhorar a acurácia das recomendações, especialmente nos casos de cold-start.

\subsection{Redes sociais}

Com o uso exponencial das redes sociais, cada vez mais populares, os dados sociais de pessoas comuns estão se tornando facilmente disponíveis na internet (Thilagam, 2016). Muitos usuários intercambiam seus conhecimentos, ideias, opiniões e experiências sobre determinados produtos, conteúdos e serviços dentro das redes sociais como Facebook, Twitter e outras. Embora existam os motores de busca tradicionais como Google e Yahoo, que facilitam usuários a encontrarem o que precisam, usuários geralmente preferem confiar nas informações obtidas dos seus amigos, incluindo os das redes sociais para a obtenção de informação importante ou exata. Em outras palavras, os usuários buscam opiniões dos amigos próximos, incluindo os das redes sociais, quando desejam adquirir itens como: livros, músicas, filmes, viagens, etc. (Ha et al., 2013; Jiang et al., 2015; Xiushan and Dongfeng, 2017; Zhang, Jia Dong et al., 2017).

Para Ha et al. (2013) a informação e o tipo de relacionamento social das pessoas nas redes sociais dão a oportunidade de se identificar a influência dos relacionamentos sociais para melhorar recomendações de itens aos usuários.

Para Thilagam (2016) ter acesso aos dados sociais dos usuários permite aos sites de e- 
commerce um melhor uso de seus produtos porque conseguem entender o comportamento e os interesses do usuário através das informações das redes sociais.

Wang et al. (2016) acredita que o uso de informação das redes sociais pode combater o problema de cold-start e, portanto, pode melhorar muito a precisão da recomendação. A principal intuição é que, através da confiança e da influência, usuários são mais propensos a desenvolver afinidades com itens que foram consumidos no passado pelos seus amigos (laços sociais).

Prando et al. (2017) e Contratres et al. (2018) propuseram um RS que extraiu dados textuais das redes sociais Facebook (ex.: "posts" da rede social Facebook) e Twitter, (ex.: "tweets" da rede social Twitter) para mitigar o problema de cold-start. No processo de recomendação proposto, o RS compara a similaridade entre os dados de postagens do usuário e os produtos do e-commerce. Nessa proposta somente foram utilizados os dados postados pelo usuário alvo da recomendação e que era novo no e-commerce. Os resultados mostraram melhor na assertividade da recomendação.

Assim, o uso de informação de redes sociais pode ser usada para aprimorar a qualidade das recomendações e já são várias as iniciativas usando tais dados dentro do processo de recomendação (CHEN et al., 2016; Diaz-Agudo et al., 2018).

\subsubsection{Influência social}

Pesquisas na literatura (Ha et al., 2013; Jiang et al., 2015; Thilagam, 2016; Wang et al., 2016) mostraram que identificar padrões de usuários influentes dentro das redes sociais a partir do número de postagens, curtidas e comentários, é um dos tópicos mais populares na análise de dados em mídias sociais. Por meio de aplicações que usam a influência social é possível estabelecer as preferências de um usuário em relação a produtos e serviços, como por exemplo, o marketing viral que usa campanhas de marketing para atingir um grupo de usuários influentes que ajudem a maximizar suas vendas. Outras aplicações interessantes incluem a recomendação de produtos, propagação de informações baseadas no conjunto de amigos mais confiáveis ou influentes do usuário (Ha et al., 2013; Hendry et al., 2017; Jianqiang et al., 2017; Wang et al., 2016).

Embora todas as pessoas tenham a liberdade de divulgar por meio das redes sociais suas opiniões, conhecimento, descobrimentos, entre outros, para Jiang et al. (2015) a influência social é mais perceptível entre amigos que compartilham características semelhantes, pois a chance de terem laços mais forte é maior, além de relações sociais mais 
confiáveis e consequentemente, de maior influência. De forma similar para Zhang et al. (2017), a influência social ocorre com mais frequência quando as pessoas compartilham conhecimentos, ou opiniões semelhantes, ou têm conhecimento, ou opinião, ou capacidades e criatividade discrepantes.

Assim, pode-se considerar que indivíduos são mais suscetíveis a influência daqueles com quem se tem maior similaridade.

Para Guo et al. (2016) o grau de influência de um usuário dentro de um grupo de pessoas pode ser cálculado pela influência social estimada com base em 5 fatores descritos a seguir:

- Expertise Factor: considera o conhecimento de um usuário sobre um dado assunto. Geralmente, a opinião de especialistas tem maior credibilidade e valor que a de outros.

- Susceptibility Factor: considera o quanto um usuário é suscetível a opiniões e emoções de outros usuários.

- Personality Factor: definido pelo padrão de comportamento do indivíduo, determinado realizando um teste de identificação de tendências comportamentais (TKIThomas Kilmann Instrument) com cada integrante do grupo.

- Intimacy Factor: mensura quanto um grupo está conectado. Quanto mais os integrantes de um grupo são íntimos, maior a probabilidade de aceitarem as opiniões de outros.

- Similarity Factor: avalia grau de similaridade entre os integrantes do grupo. Obtido através de atividades e informações em comum.

Na abordagem proposta por Guo et al. (2016), os fatores de influência são de difícil automatização. Por exemplo, para definir o Personality Factor o autor aplica um teste TKI com cada integrante do grupo. Esse procedimento num processo de recomendação de uma aplicação on-line não é viável, pois o tempo necessário para fazer o teste desestimularia o indivíduo na espera pela recomendação.

Assim nesta dissertação, estende-se a proposta de Guo et al. (2016) propondo-se novos fatores e/ou outras formas de medição para o cálculo da influência social considerando principalmente o cenário de usuários cold-start. 


\subsection{Medidas de similaridade}

Em CF-RS, as preferências dos usuários por itens, ou as preferências de todos os usuários por um item, são representados como um vetor para se conseguir aplicar alguma medida de similaridade (Sun et al., 2015).

As medidas de similaridade são usadas para calcular a similaridade entre dois usuários ou dois itens e encontrar os usuários ou itens mais similares. Uma variedade de diferentes técnicas é encontrada na literatura para computar a similaridade entre usuários e itens (Sun et al., 2015). As mais comuns entre essas técnicas incluem: Similaridade de Cosseno, Correlação de Pearson, Similaridade de Jaccard e Similaridade de Confiança (Trust Similarity) Amatriain et al., 2011; Rehman et al., 2017; Ricci et al., 2011).

- Similaridade de Cosseno: A similaridade de Cosseno é o método de medição mais utilizado e representa a similaridade entre as características dos itens ou preferências dos usuários, que são representados como vetores de um espaço dimensional. A similaridade é computada pelo cosseno do ângulo formado entre os vetores de características dos itens, ou de preferências dos usuários; quanto menor o ângulo, maior é a similaridade entre esses itens ou entre usuários.

Similaridade de Cosseno é dada por 2.3, em que • representa o produto escalar (Amatriain et al., 2011).

$$
\cos (x, y)=\frac{(x \bullet y)}{|x||y|}
$$

- Correlação de Pearson: A correlação de Pearson calcula a relação linear entre duas variáveis e é calculada com base na covariância entre essas variáveis e seu desvio padrão. Em RS, a correlação de Pearson é usada para encontrar correlações entre itens, ou preferências dos usuários (Amatriain et al., 2011).

A correlação de Pearson, ou similaridade de Pearson, de dois usuários para um item é dado por 2.4, em que $x_{k}, y_{k}$ representa a avaliação (rating) do usuário $x$ e do usuário $y$ para o item $k$ e $\bar{x} \bar{y}$ são as principais avaliações para os itens $x$ e $y$ respetivamente. A correlação de pearson é semelhante a uma versão modificada da similaridade de cosseno, porque são equivalentes quando, na correlação de Pearson, $\bar{x} \bar{y}$ são 0 (Amatriain et al. 2011).

$$
\rho(x, y)=\frac{\sum(x, y)}{\sigma_{x} \times \sigma_{y}}=\frac{\frac{1}{n} \sum\left(x_{k}-\bar{x}\right)\left(y_{k}-\bar{y}\right)}{\sqrt{\frac{1}{n} \sum\left(x_{k}-\bar{x}\right)^{2}} \sqrt{\frac{1}{n} \sum\left(y_{k}-\bar{y}\right)^{2}}}
$$


- Similaridade de Jaccard: A similaridade de Jaccard calcula a semelhança entre itens tomando a intersecção entre a ocorrência de duas variáveis (classificações de usuários para um item) divididas pelo total de itens (Amatriain et al., 2011).A similaridade de Jaccard é amplamente usada nos casos que os itens possuem apenas atributos binários.

A similaridade de Jaccard é dada por 2.5. Primeiro, são calculadas as quantidades A01, A10, A11, em que $\mathrm{A} 01=$ o número de valor binário em que $x$ era 0 e $y$ era $1, \mathrm{~A} 10=\mathrm{o}$ número de valor binário em que $x$ era 1 e $y$ era 0 e assim por diante Amatriain et al., 2011)

$$
\text { Jaccard }=\frac{A_{11}}{A_{01}+A_{10}+A_{11}}
$$

- Similaridade de Confiança: Na literatura também encontram-se extensões de medidas de similaridade, geralmente conhecidas como Trust Similarity, para medir o grau de confiança (trust degree) entre usuários. Algumas pesquisas (Mohammadi and Andalib, 2017; Rosli et al., 2015; Xiushan and Dongfeng, 2017; Zhang et al., 2014; Zhang, Jia Dong et al., 2017) propõem medidas empíricas de similaridade de confiança que associam os dados da rede social e o grau de amizade entre os usuários a fim de melhorar o algoritmo de recomendação. Essas pesquisas defendem que entre os amigos do usuário há um subconjunto no qual a amizade é mais forte e as semelhanças e/ou influência desse subconjunto de amigos sobre o usuário alvo é maior que com os demais amigos. Além disso, para a abordagem da confiança, alguns trabalhos se concentraram em descobrir o amigo mais influente, uma vez que consideram que suas classificações têm um peso maior no processo de recomendação.

\subsection{Medidas de avaliação}

Para medir a acurácia dos RS, muitas medidas são propostas na literatura. Mean Average Error (MAE), Root Mean Squared Error (RMSE), Coverage, Precision, medida F1 e Recall são as medidas mais populares encontradas nas diferentes pesquisas, que tem como objetivo avaliar a precisão de um método de recomendação (Gonzalez-Camacho and Alves-Souza, 2018).

Coverage é uma medida que avalia a importância da recomendação através do número do conjunto de itens disponíveis que são abrangidos na recomendação e o número de recomendações que podem ser geradas para todos os usuários em potencial. Se a cobertura 
for baixa, isso indica que a previsão é menos valiosa para os usuários devido a limitação dos dados disponíveis para fazer uma previsão (Rosli et al., 2015).

Precision e Recall são duas medidas usadas em conjunto. Precision mede os itens recomendados que foram efetivamente relevantes para um usuário. Recall é a parte dos itens relevantes que foram recomendados.

As equações 2.6 e 2.7 mostram a definição matemática para Precision e Recall.

$$
\begin{aligned}
\text { precision } & =\frac{\text { numero }- \text { respostas }- \text { corretas }- \text { satisfatórias }}{\text { numero }- \text { total }- \text { itens }- \text { retornados }- \text { pelo }- \text { rank }} \\
\text { recall } & =\frac{\text { numero }- \text { respostas }- \text { corretas }- \text { satisfatórias }}{\text { numero }- \text { total }- \text { itens }- \text { relevantes }}
\end{aligned}
$$

F1 refere-se à média harmônica de Precision e Recall, usada para avaliar a eficácia geral de um classificador. Ao contrário da média aritmética, a média harmônica tende para o menor dos dois elementos. Por tanto, o valor de F1 será pequeno se Precision ou Recall for pequena (Chen et al., 2013). A equação 2.8 exibe a definição para F1.

$$
F 1=2 \frac{\text { precision } * \text { recall }}{\text { precision }+ \text { recall }}
$$

O MAE e o RMSE calculam o erro entre uma classificação real do item e a classificação prevista feita por um método de recomendação através das distâncias médias entre eles. Quanto menor o valor, melhor é o desempenho do método (Chen et al., 2013; Jiang et al. 2015).

Matematicamente RMSE e MAE são definidas pelas equações 2.9 e 2.10.

$$
\begin{gathered}
R M S E=\sqrt{\frac{1}{R_{\text {test }}} \sum_{i \in R_{\text {test }}}\left(r_{i}-\hat{r}_{i}\right)^{2}} \\
M A E=\frac{1}{R_{\text {test }}} \sum_{i \in R_{\text {test }}}\left|r_{i}-\hat{r}_{i}\right|
\end{gathered}
$$

Devido que nesse trabalho o objetivo é implementar uma aplicação para prever a nota que um determinado usuário dará para um item recomendado, a métrica mais indicada 
para medir a acurácia das notas previstas é o RMSE ou o MAE (Shani and Gunawardana, 2011). Foi decidido usar o RMSE, pois a principal diferencia entre essas duas métricas, é que o RMSE penaliza fortemente as notas que são discrepantes, já que as diferenças são elevadas ao quadrado, enquanto o MAE penaliza as diferenças de forma uniforme. 


\section{RESULTADOS DA REVISÃO SISTEMÁTICA DA LITERATURA SOBRE USO DE DADOS DE REDES SOCIAIS PARA MELHORIA DA RECOMENDAÇÃO EM CENÁRIOS DE COLD-START}

\subsection{Introdução}

Uma revisão sistemática da literatura (RSL) foi inicialmente produzida para identificar trabalhos de relevância no tema pesquisado, de forma a conseguir apresentar o panorama atual e o estado da arte.

Como resultado da RSL realizada, um artigo foi publicado Gonzalez-Camacho and Alves-Souza, 2018). Neste detalha-se o procedimento seguido, incluindo o método proposto, formas de seleção de artigos, dentre outros.

Assim, nesta seção apresenta-se apenas uma síntese da RSL realizada, maiores detalhes podem ser vistos em Gonzalez-Camacho and Alves-Souza (2018). Aqui apresenta-se apenas o método que foi definido para a execução da RSL e os principais resultados obtidos com a mesma, destacando as técnicas mais empregadas no processo de recomendação e também as utilizadas para a avaliação da recomendação em si.

Para fazer uma revisão bibliográfica mais objetiva, uma RSL foi elaborada. Para a realização de uma RSL um método deve ser definido e seguido para identificação, seleção, avaliação e síntese dos trabalhos prévios relacionados ao tema da pesquisa.

A Figura 6 apresenta o diagrama de fluxo que resume os passos seguidos no método empregado para a realização da RSL. Cada um desses passos é detalhado a seguir:

1. Definição das questões de pesquisa e keywords: nesta etapa as questões de pesquisa e as keywords foram definidas.

2. Elaboração das strings de busca e escolha das bases de pesquisa a ser utilizadas: 
nesta etapa foram definidas as strings de busca de acordo com as bases de pesquisa selecionadas. Foram realizadas buscas nas bases de dados da Scopus, IEEE, ACM e Web of Science, que foram selecionadas tendo em vista sua credibilidade, adequação à área de computação e por serem bases já pagas pela universidade, permitindo o acesso completo ao conteúdo dos artigos.

3. Elaboração dos critérios de inclusão e exclusão: foram elaborados critérios para a seleção dos artigos que seriam então selecionados para leitura completa.

4. Busca dos artigos: nesta etapa procedeu-se a busca dos artigos utilizando as strings de busca elaboradas com base nas questões de pesquisa e nas keywords.

5. Pré-seleção: nesta etapa foram lidos apenas o título e o abstract. Seguindo os critérios de inclusão e exclusão, os artigos foram selecionados para leitura completa ou descartados. Uma filtragem com o intuito de determinar a relevância do artigo também foi utilizada.

6. Artigos selecionados: foram definidos critérios para avaliar a relevância dos artigos. Assim, os artigos selecionados para leitura completa foram posteriormente classificados de acordo com sua relevância.

7. Leitura completa dos artigos selecionados: os artigos selecionados na etapa 6 foram completamente lidos e avaliados segundo sua importância dentro do escopo da pesquisa. Para essa avaliação, definiu-se métricas com base nas questões de pesquisa, o que permitiu classificar os artigos.

8. Classificação: Finalmente os artigos foram avaliados e ranqueados como altamente, parcialmente, ou não relevantes para as questões de pesquisa estabelecidas.

Maiores detalhes da RSL realizada são apresentados em Gonzalez-Camacho and AlvesSouza (2018). 
Figura 6: Diagrama de Fluxo da RSL

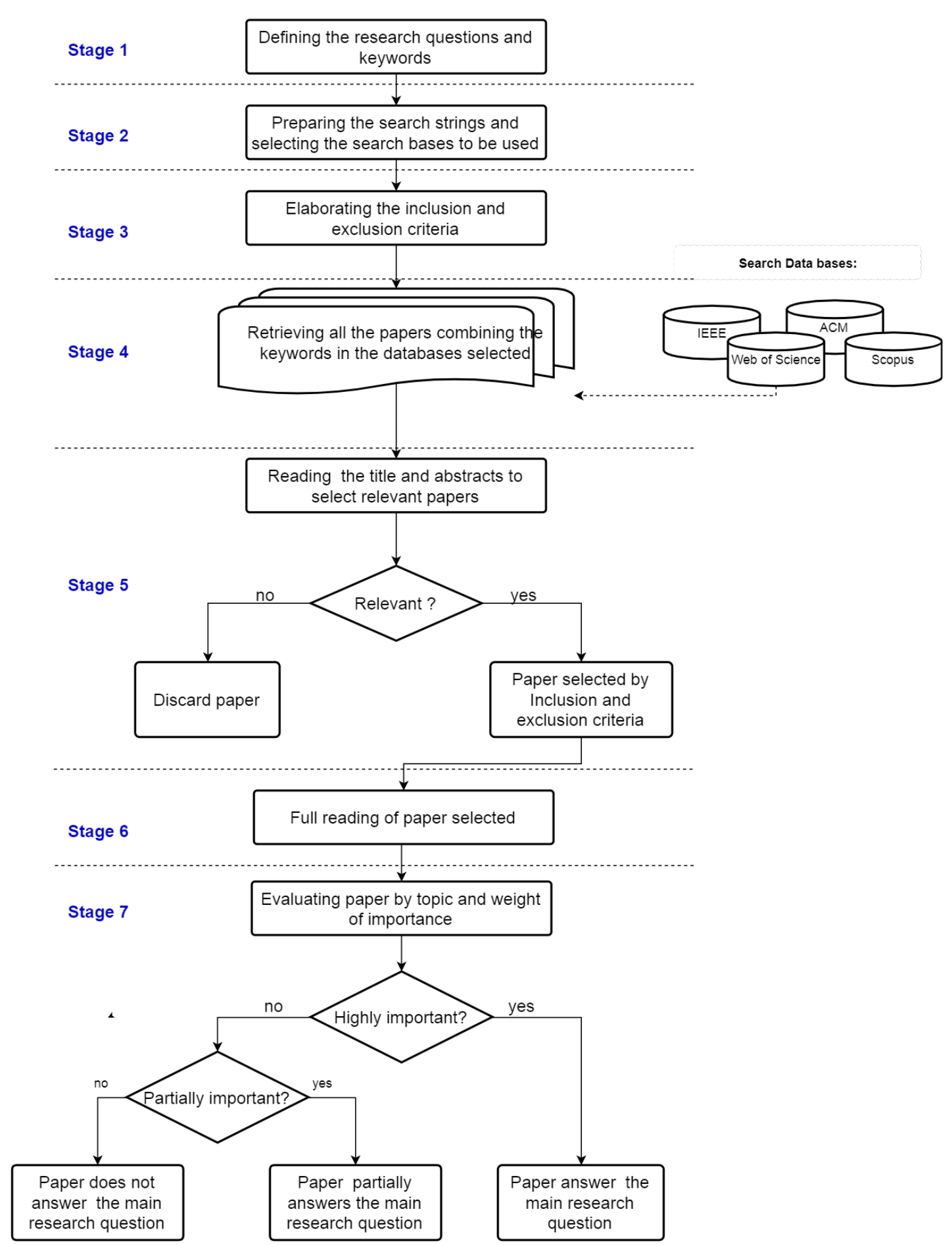

Fonte: Gonzalez-Camacho and Alves-Souza (2018)

\subsection{Principais aspectos dos artigos selecionados}

A principal questão de pesquisa que se tentou responder foi: 
- O uso de dados de amigos em redes sociais como a única ou principal fonte de dados melhora a recomendação em situações de cold-start?

Esta questão corresponde a Q3 na Tabela 1. Por outro lado, usar informações de redes sociais da rede de amigos implica fazer uso de técnicas de filtragem colaborativa. Assim, esta foi a técnica escolhida para a busca de artigos e duas outras questões (Q1 e Q2) associadas à questão principal foram formuladas, como pode ser observado na Tabela 1.

Tabela 1: Questões de pesquisa para RSL

Pergunta de pesquisa

\begin{tabular}{ll}
\hline Q1 & $\begin{array}{l}\text { Is Existe alguma melhoria para o problema de cold-start com o uso } \\
\text { de técnicas de CF? }\end{array}$ \\
Q2 & $\begin{array}{l}\text { Há melhora na recomendação quando é usado dados extraídos de } \\
\text { redes sociais, considerando a extração de dados da rede de amigos? }\end{array}$ \\
Q3 & $\begin{array}{l}\text { O uso de dados de amigos em redes sociais como a única ou principal } \\
\text { fonte de dados melhora a recomendação em situações de cold-start? }\end{array}$ \\
\hline
\end{tabular}

Os critérios de inclusão e exclusão que foram usados nessa RSL são apresentados na tabela 2 .

Tabela 2: Critérios de inclusão e exclusão para a RSL

\begin{tabular}{ll}
\hline Critérios de inclusão & Critérios de exclusão \\
\hline O artigo foi publicado em um jornal en- & Artigo foi publicado em um jornal com \\
tre $01 / 01 / 2011$ and $07 / 12 / 2017$ & JCR inferior a 1. \\
O artigo foi publicado em conferência & O artigo não foi escrito em inglês. \\
entre 01/01/2013 - 07/12/2017 & \\
O artigo apresenta uma proposta para & \\
mitigar o problema de cold-start em & \\
RS. & \\
O artigo incorpora dados de rede social & \\
em RS baseados em CF. \\
O artigo propõe um RS para resolver o \\
cold-start usando informações de redes \\
sociais e RS baseadas em CF.
\end{tabular}

\subsection{Principais técnicas empregadas no processo de recomendação}

Dentre os resultados alcançados com a RSL estão as técnicas empregadas pelos artigos avaliados, de acordo com o método seguido, como mais relevantes para a RSL. Estes artigos, 20 no total, são os que respondem à questão principal da pesquisa. 
A Tabela 3, resume o conjunto de técnicas mais usadas no processo de recomendação dentre os artigos selecionados como mais relevantes na RSL. A Tabela 4 , apresenta as medidas de similaridade usadas nas diferentes pesquisas selecionadas. Finalmente, a Tabela 3 mostra as medidas de avaliação da acurácia do RS mais usadas dentre os artigos selecionados.

Tabela 3: Techniques employed in recommendation process for the selected papers

\begin{tabular}{|c|c|c|c|}
\hline Technique & $\begin{array}{l}\text { Number } \\
\text { of Papers }\end{array}$ & $\%$ & References \\
\hline \multirow{6}{*}{$\begin{array}{l}\text { MF and extensi- } \\
\text { ons }\end{array}$} & \multirow{6}{*}{10} & \multirow{6}{*}{50} & (CHEN et al., 2016; Deng et al. 2014; Jiang \\
\hline & & & et al., 2015; Lian et al., 2016; Liu et al., 2013 ; \\
\hline & & & Senthilkumar and Ponnusamy, 2016; Wang \\
\hline & & & et al. 2016; Xiushan and Dongfeng, 2017; \\
\hline & & & Zhang et al., 2013; Zhang, Jia Dong et al. \\
\hline & & & 2017 \\
\hline hybrid & 4 & 20 & 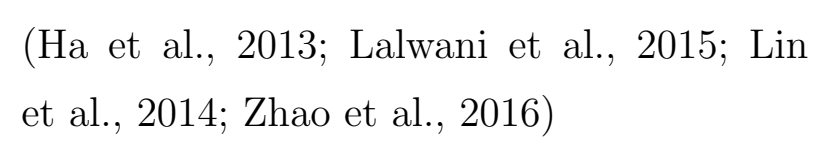 \\
\hline $\begin{array}{l}\text { k-means and ex- } \\
\text { tensions }\end{array}$ & 4 & 20 & $\begin{array}{l}\text { Chen et al., 2013; Rosli et al. 2015: Wu } \\
\text { et al., 2013; Zhang et al., 2014) }\end{array}$ \\
\hline $\begin{array}{l}\text { Fuzzy Geo- } \\
\text { graphic cluste- } \\
\text { ring }\end{array}$ & 1 & 5 & Mohammadi and Andalib, 2017) \\
\hline Social network & & & \\
\hline $\begin{array}{l}\text { ontological } \\
\text { representation }\end{array}$ & 1 & 5 & (Hannech et al. 2016$)$ \\
\hline
\end{tabular}


Tabela 4: Similarity measures employed in the main papers

\begin{tabular}{|c|c|c|c|c|}
\hline \multirow{2}{*}{ Reference } & \multicolumn{4}{|c|}{ similarity measures } \\
\hline & $\begin{array}{l}\text { Cosine si- } \\
\text { milarity }\end{array}$ & $\begin{array}{l}\text { Pearson } \\
\text { correlation }\end{array}$ & $\begin{array}{l}\text { jaccard } \\
\text { similarity }\end{array}$ & $\begin{array}{l}\text { Trust simi- } \\
\text { larity }\end{array}$ \\
\hline Mohammadi and Andalib, 2017) & & $\checkmark$ & & $\checkmark$ \\
\hline Xiushan and Dongfeng, 2017) & & & & $\checkmark$ \\
\hline (Zhang, Jia Dong et al., 2017) & & & & $\checkmark$ \\
\hline CHEN et al. 2016) & $\checkmark$ & & & $\checkmark$ \\
\hline Hannech et al., 2016) & & & $\checkmark$ & $\checkmark$ \\
\hline Lian et al. 2016) & $\checkmark$ & & & \\
\hline Senthilkumar and Ponnusamy, & & & & $\mathcal{J}$ \\
\hline 2016) & & & & $\checkmark$ \\
\hline (Wang et al., 2016) & & & & $\checkmark$ \\
\hline Zhao et al. 2016) & & $\checkmark$ & & \\
\hline Jiang et al. 2015) & $\checkmark$ & & $\checkmark$ & $\checkmark$ \\
\hline Lalwani et al. 2015) & $\checkmark$ & & & \\
\hline Rosli et al. 2015) & $\checkmark$ & $\checkmark$ & $\checkmark$ & $\checkmark$ \\
\hline Deng et al. 2014) & $\checkmark$ & & & $\checkmark$ \\
\hline Lin et al. 2014) & $\checkmark$ & & & \\
\hline Zhang et al., 2014) & $\checkmark$ & $\checkmark$ & & \\
\hline Chen et al., 2013) & & & & $\checkmark$ \\
\hline Ha et al. 2013) & & $\checkmark$ & & \\
\hline Liu et al. 2013) & & $\checkmark$ & & \\
\hline Wu et al. 2013) & & $\checkmark$ & & \\
\hline (Zhang et al., 2013) & $\checkmark$ & & & $\checkmark$ \\
\hline Number of Papers & 9 & 7 & 3 & 12 \\
\hline
\end{tabular}


Tabela 5: Evaluation measures used in the main papers

\begin{tabular}{|c|c|c|c|c|c|c|c|}
\hline \multirow{2}{*}{ Reference } & \multicolumn{7}{|c|}{ Evaluation measure } \\
\hline & \multirow{3}{*}{$\begin{array}{l}\text { MAE } \\
\qquad \checkmark\end{array}$} & \multirow[t]{3}{*}{ RMSE } & \multicolumn{3}{|c|}{ PrecisionCoverageRecall } & \multirow[t]{2}{*}{$\begin{array}{l}\text { F1- } \\
\text { measure }\end{array}$} & \multirow[t]{2}{*}{ Other } \\
\hline Mohammadi and Andalib & & & & & & & \\
\hline 2017) & & & & & & & \\
\hline Xiushan and Dongfeng, & $d$ & 1 & & & & & \\
\hline 2017) & $\checkmark$ & 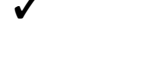 & & & & & \\
\hline (Zhang, Jia Dong et al. & $d$ & 1 & & & & & \\
\hline 2017 & 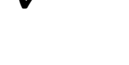 & 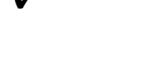 & & & & & \\
\hline (CHEN et al. 2016) & & & $\checkmark$ & $\checkmark$ & & $\checkmark$ & \\
\hline Lian et al. 2016) & & & $\checkmark$ & & $\checkmark$ & & \\
\hline Hannech et al., 2016) & & & & & & & $\checkmark$ \\
\hline Senthilkumar and Ponnu- & 1 & 1 & & & & & \\
\hline samy, 2016) & $\checkmark$ & $\checkmark$ & & & & & \\
\hline (Wang et al. 2016) & & & $\checkmark$ & & $\checkmark$ & & $\checkmark$ \\
\hline (Zhao et al. 2016) & & & $\checkmark$ & & $\checkmark$ & & \\
\hline$($ Jiang et al. 2015$)$ & $\checkmark$ & $\checkmark$ & $\checkmark$ & & $\checkmark$ & & \\
\hline (Lalwani et al. 2015 ) & & & & $\checkmark$ & & & $\checkmark$ \\
\hline Rosli et al. 2015) & $\checkmark$ & & & $\checkmark$ & & & \\
\hline (Deng et al. 2014) & & $\checkmark$ & $\checkmark$ & $\checkmark$ & & $\checkmark$ & \\
\hline (Lin et al., 2014) & & & & & & $\checkmark$ & \\
\hline (Zhang et al., 2014) & $\checkmark$ & $\checkmark$ & & & & & \\
\hline Chen et al. 2013) & $\checkmark$ & & $\checkmark$ & $\checkmark$ & $\checkmark$ & $\checkmark$ & \\
\hline (Wu et al., 2013) & & & & & & & $\checkmark$ \\
\hline (Ha et al. 2013) & $\checkmark$ & & & & & & \\
\hline Liu et al. 2013) & $\checkmark$ & $\checkmark$ & & & & & \\
\hline (Zhang et al., 2013) & & $\checkmark$ & & $\checkmark$ & & & $\checkmark$ \\
\hline Number of Papers & 10 & 8 & 7 & 6 & 5 & 4 & 5 \\
\hline
\end{tabular}




\subsection{Conclusão da RSL}

O resultado da RSL mostrou que a técnica mais empregada no processo de recomendação é a baseada em fatoração de matrizes (MF). Para o cálculo da similaridade se percebeu que similaridade de Cossenos e Pearson eram as mais populares, não entanto muitas pesquisas propuseram medidas empíricas para medir o grau de confiança (trust similarity). Em relação a medidas de acurácia do sistema, MAE e RMSE foram as mais populares. Tais resultados guiaram as escolhas feitas neste trabalho, as quais são detalhadas na próxima seção. 


\section{RESULTADOS DA RSL SOBRE INFLUÊNCIA SOCIAL EM REDES SOCIAIS}

\subsection{Introdução}

A influência social tem um papel predominante no modelo de recomendação proposto. Assim, considerou-se relevante a busca na literatura por trabalhos sobre influência social. Essa busca revelou que o tópico tem sido muito estudado em redes sociais. Nesta seção apresenta-se, como na seção anterior, apenas uma síntese da RSL realizada. Como resultado da RSL realizada, um artigo foi submetido e aceito para a 9th International Conference on Data Science, Technology and Applications (DATA). Neste detalha-se o procedimento seguido, incluindo o método proposto, formas de seleção de artigos, dentre outros.

Assim, nesta seção apresenta-se apenas uma síntese da RSL realizada, maiores detalhes poderão ser vistos em Gonzalez-Camacho and Alves-Souza (2020).

\subsection{Principais aspectos dos artigos mais relevantes}

As questões de pesquisa que guiaram a a busca dos artigos foram:

- existem técnicas para identificar em redes sociais o usuário, e/ou conjunto de usuários, mais influentes;

- tais informações foram usadas para melhoraria da recomendação?

Com base nela foram definidas strings de busca aplicados as bases de pesquisa selecionadas. Para essa revisão foram selecionadas as bases Scopus, IEEE, ACM e Web of Science, e o período estabelecido para a busca de artigos foi entre 2017 e 2019. Essa RSL não foi tão abrangente como a apresentada na seção 3, pois ela não era parte do objetivo inicial e a intensão foi levantar os trabalhos bem recentes que permitissem ter uma visão da pesquisa sobre influência social. 
A tabela 6 mostra os criterios de inclusão e exclusão usados nessa RSL.

\begin{tabular}{l} 
Tabela 6: Criterios de inclusão e exclusão \\
\hline Inclusão \\
\hline A pesquisa usa informações de A pesquisa não está escrita em \\
redes sociais para determinar o inglês \\
amigo mais influente \\
A pesquisa está relacionada a sis- \\
temas de recomendação \\
A pesquisa identifica o tipo de \\
relação social do usuário nas re- \\
des sociais \\
A pesquisa foi publicada em \\
periódico ou conferência entre \\
2017 e 2019
\end{tabular}

A Tabela 7 mostra o número de artigos resultantes na passagem de cada etapa do método empregado. Ao final, 14 artigos foram classificados como os mais relevantes para a questão elencada. As Tabelas 8 e 9 sumarizam as técnicas e o conjunto de informações usadas nos 14 artigos selecionados ao final desta RSL.

Tabela 7: Número de artigos encontrados e selecionados

\begin{tabular}{ll}
\hline Resumo & Numero de artigos \\
\hline Total encontrados & 80 \\
Duplicados & 2 \\
Pre-selecionados & 31 \\
Selecionados para leitura completa & 23 \\
Extração final & 14 \\
\hline
\end{tabular}

A Tabela 8 mostra, para cada artigo, quais foram as técnicas empregadas para determinar a influência social na rede social. Do conjunto de artigos selecionados percebeuse que, no geral, as técnicas podiam ser classificadas em duas abordagens: Grafos e Heurísticas/Grafos. Grafos abrange o uso de medidas de centralidade para determinar a influência social, enquanto que heurísticas/grafos envolve o uso de medidas de centralidade associado a heurísticas propostas pelos autores, ou outras técnicas diferentes das comumente empregadas. A abordagem em grafos foi dividida em medidas de centralidade: Eigenvector (Eigen), Degree (Deg), Closeness (Close), Betweenness (Betw). Enquanto que a abordagem por Heurísticas/Grafos foi dividida em: Baseado em grafo (Gp-B), Baseado em Page Rank (Pr-B) e Outro.

A Tabela 9 mostra, para cada artigo, o conjunto de dados usados para determinar a influência social. Esta tabela destaca principalmente sete diferentes categorias de dados: follower $(\mathrm{Fw})$, followee (Fwe), postagem (Ps), re-postagem (R-ps), curtidas (Lk), 
Tabela 8: Técnicas usadas para calcular a influência social

\begin{tabular}{|c|c|c|c|c|c|c|c|}
\hline \multirow{2}{*}{ Referência } & \multicolumn{4}{|c|}{ Grafos } & \multicolumn{3}{|c|}{ Heurísticas/Grafos } \\
\hline & Eigen & Deg & Close & Betw & Gp-B & Pr-B & Outro \\
\hline Bhowmick et al. & & & & & & & $\checkmark$ \\
\hline & & & & & & & \\
\hline Diaz-Agudo et al. & & & & & $\checkmark$ & & \\
\hline$(2018)$ & & & & & & & \\
\hline Liu et al. (2018) & $\checkmark$ & & & & & & \\
\hline Ma et al. (2018) & $\checkmark$ & $\checkmark$ & $\checkmark$ & $\checkmark$ & & & \\
\hline Wu et al. $(\overline{2018})$ & & & & & & $\checkmark$ & \\
\hline Yang et al. (2018) & & & & & $\checkmark$ & & \\
\hline Hendry et al. (2017) & & & & & $\checkmark$ & & \\
\hline Jianqiang et al. (2017) & & & & & & & $\checkmark$ \\
\hline Li and Xiong $(2017)$ & & & & & & & $\sqrt{ }$ \\
\hline Xing et al. (2017) & & & & & & & $\checkmark$ \\
\hline Sumith et al. (2017) & & & & & $\checkmark$ & & \\
\hline Zhang et al. (2017) & & & & & & $\checkmark$ & \\
\hline Zhou, J et al. (2017) & & & & & & & $\checkmark$ \\
\hline Zhou et al. (2017) & & $\checkmark$ & $\checkmark$ & $\checkmark$ & & & \\
\hline Total de artigos & 2 & 2 & 2 & 2 & 3 & 2 & 5 \\
\hline
\end{tabular}

comentários $(\mathrm{Cm})$ e menções (Mt). Outras categorias, aqui não explicitadas, que apareceram com menor frequência, foram classificados como "outros". Exemplos destas são: tempo em que uma informação é propagada na rede social, estatísticas sobre a relevância do conteúdo publicado.

Para avaliar o desempenho dos algoritmos propostos para determinar a influência social, alguns artigos empregaram medidas de avaliação amplamente conhecidas e empregadas para a avaliação de sistemas de recomendação como: MAE, RMSE, R2, F1, Precision e Recall. No entanto, a maioria dos artigos utilizou um método de avaliação empírica (Hendry et al., 2017; Liu et al., 2018; Ma et al., 2018; Sumith et al., 2017; Wu et al., 2018; Yang et al., 2018; Zhang et al., 2017; Zhou et al., 2017). Contudo, não há uma medida amplamente aceita na literatura, pelo menos até onde esta pesquisa chegou, que sirva para verificar o desempenho de tais algoritmos.

\subsection{Conclusões}

Das diferentes abordagens propostas para realizar o cálculo da influência social, as técnicas por grafos foram destaque nessa RSL, pois muitos dos artigos fizeram uso dessas técnicas para modelar a interação social. Alguns desses trabalhos fizeram uso de medidas 
Tabela 9: Tipos de dados de redes sociais usados para calcular a influência social

\begin{tabular}{|c|c|c|c|c|c|c|c|c|}
\hline \multirow{2}{*}{ Referência } & \multicolumn{8}{|c|}{ Dados sociais } \\
\hline & $\mathrm{Fw}$ & Fwe & Ps & R-ps & Lk & $\mathrm{Cm}$ & $\mathrm{Mt}$ & Outro \\
\hline $\begin{array}{llll}\text { Bhowmick } & \text { et } & \text { al. } \\
(2018) & & \end{array}$ & & & & $\checkmark$ & & & & $\checkmark$ \\
\hline $\begin{array}{l}\text { Diaz-Agudo et al. } \\
(2018)\end{array}$ & $\checkmark$ & & & & $\checkmark$ & $\checkmark$ & & $\checkmark$ \\
\hline Liu et al. (2018) & $\checkmark$ & $\checkmark$ & & & & & & \\
\hline Ma et al. (2018) & & & & $\checkmark$ & & $\checkmark$ & $\checkmark$ & \\
\hline Wu et al. (2018) & & $\checkmark$ & & $\checkmark$ & & & & \\
\hline Yang et al. (2018) & $\checkmark$ & $\checkmark$ & & & & & & $\checkmark$ \\
\hline Hendry et al. (2017) & & & $\checkmark$ & & $\checkmark$ & $\checkmark$ & & $\checkmark$ \\
\hline Jianqiang et al. (2017) & & & & $\checkmark$ & & $\checkmark$ & & $\checkmark$ \\
\hline Li and Xiong (2017) & $\checkmark$ & & & $\checkmark$ & & $\checkmark$ & $\checkmark$ & \\
\hline Xing et al. (2017) & & $\checkmark$ & $\checkmark$ & $\checkmark$ & $\checkmark$ & $\checkmark$ & & $\checkmark$ \\
\hline Sumith et al. (2017) & & & $\checkmark$ & $\checkmark$ & $\checkmark$ & & & \\
\hline Zhang et al. (2017) & & & $\checkmark$ & $\checkmark$ & $\checkmark$ & $\checkmark$ & & \\
\hline Zhou, J et al. (2017) & $\checkmark$ & $\checkmark$ & $\checkmark$ & $\checkmark$ & $\checkmark$ & $\checkmark$ & $\checkmark$ & $\checkmark$ \\
\hline Zhou et al. $(2017)$ & $\checkmark$ & $\checkmark$ & & & & $\checkmark$ & & \\
\hline Total de artigos & 5 & 6 & 5 & 9 & 5 & 8 & 3 & 6 \\
\hline
\end{tabular}

Fonte: Elaborado pelo autor

de centralidade para estimar a influência social, no entanto muitos outros propuseram novas formas para realizar esse cálculo.

A RSL destacou as categorias de dados sociais mais utilizadas para estimar a influência social e, como mostrado, os mais utilizados foram: número de re-postagem de publicações, número de comentários e número de followees que os usuários tiveram em suas redes sociais. Esses três categorias podem ter um peso maior em um modelo para o cálculo da influência social.

Finalmente, dos artigos selecionados concluiu-se que não existe um consenso na literatura, de uma medida que consiga verificar a assertividade dos algoritmos propostos para o cálculo da influência social. Como exposto, muitas das pesquisas prévias fizeram avaliações empíricas para a validação de sua proposta. 


\section{SISTEMA DE RECOMENDAÇÃO PROPOSTO}

\subsection{Introdução}

Nesta seção detalha-se a proposta deste trabalho. Nela se mostra o processo da recomendação por CF de uma plataforma de streaming voltada para música, fazendo uso de MF como algoritmo e de informações de redes sociais para melhorar as recomendações dos usuários cold-start. Este sistema faz uso de dados implícitos como base para o treinamento do modelo preditivo, modela as interações sociais do usuário com seu grupo de amigos para caracterizar a força da amizade e calcular a influência social e relaciona o conjunto de preferências observadas das informações da rede social, para dar um peso maior a abordagem da recomendação baseada em CF e diminuir os problemas de cold-start.

\subsection{Características do Sistema de Recomendação}

A Figura 7, exemplifica a relação existente entre as informações da rede social, as informações da plataforma de streaming de música e a interação com o sistema de recomendação. Esta figura mostra que as recomendações não somente são influenciadas pela base extraída da plataforma de streaming, mas também pelas informações extraídas da rede social. Assim, nos casos de cold-start, o sistema utiliza informações das preferências observadas do grupo de amigos, identificados pela rede social, para recomendar algum produto/item ao usuário cold-start.

Neste trabalho, simula-se a plataforma de streaming de música com uma base de produtos já existente. Assim, não há atualização constante dos produtos, nem sincronização, refletindo novas aquisições/avaliações de produtos entre a plataforma de streaming e o RS.

Similarmente a Prando et al. (2017) e Contratres et al. (2018), utiliza-se uma aplicação para simular a interação do usuário com a plataforma de streaming. O usuário acessa a aplicação fornecendo sua identificação da rede social e suas credenciais de uma plataforma 
Figura 7: Relação geral entre o serviço de música, a rede social e o Sistema de Recomendação

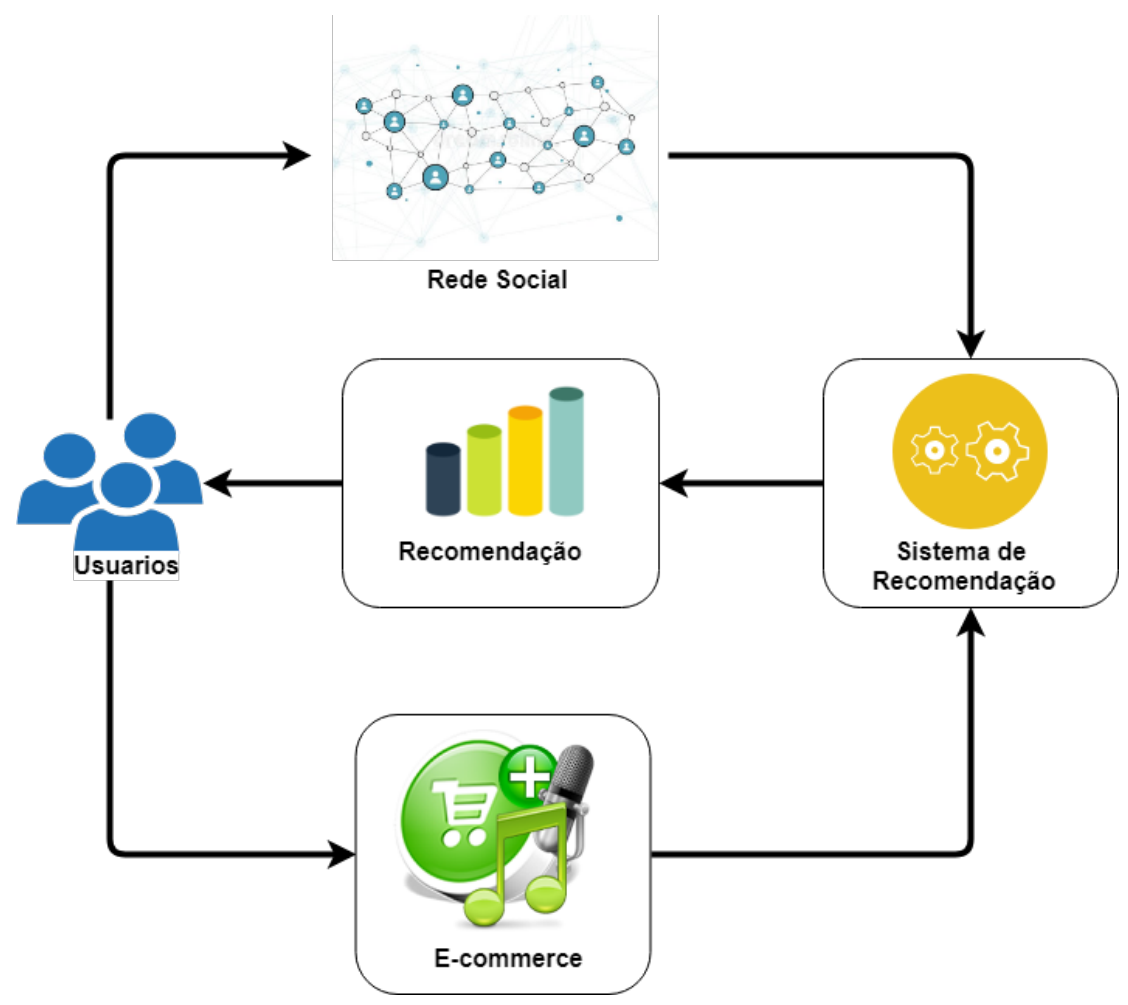

Fonte: Elaborado pelo autor

de música, recebe a recomendação e, em seguida, dá uma nota para a recomendação recebida. As credencias da plataforma de música são necessárias para capturar as preferências musicais do usuário quando não exerce o papel de usuário cold-start no sistema. Nos testes, preferências musicas dos usuários assumidos como cold-start, foram ignoradas, ou seja descartadas no cálculo da recomendação.

As credenciais da rede social permitem que o sistema colete informações sobre aspectos sociais relevantes para identificar o conjunto de amigos de maior influência sobre o usuário cold-start. Essa influência é baseado em determinados fatores descritos nas seções 5.2.2 e 5.2 .3 .

Outras diferenças em relação a Prando et al. (2017) está no tipo de rede social utilizada. Enquanto este extraiu dados do Facebook e Twitter, neste trabalho utiliza-se uma rede social especialmente criada para os testes. Isto permitiu ter um ambiente controlado, no qual se garantisse a existência de usuários com interação na rede social e que também fizessem uso da plataforma de música para que a hipótese desta dissertação pudesse ser testada. A rede criada para o experimento foi denominada "SocialTracks Mastodon".

É importante ressaltar que para a recomendação (Figura 7) utiliza-se tanto os dados da rede social quanto os do streaming. Além disso, poderia ter sido empregado qualquer 
outro produto na recomendação, ou seja, o ambiente proposto é adequado não apenas para a recomendação de músicas.

No processo da recomendação a seguinte hipótese é considerada: os amigos são clientes do e-commerce ou plataforma de streaming; Com base nessa hipótese, neste trabalho, optou-se por recomendar itens já adquiridos pelos amigos.

\subsubsection{Friendly Group Factor}

Considera-se que calcular a influência social a partir de informações extraídas das redes sociais para uso no cálculo da recomendação pode conduzir a recomendações de produtos/serviços mais precisas, principalmente quando se tem pouco, ou nenhum, conhecimento sobre preferências do usuário. A ideia parte do intuito que quando um usuário deseja adquirir produtos como: livros, músicas, filmes, viagens, dentre outros, geralmente prefere considerar a opinião dos amigos mais confiáveis, incluindo os das redes sociais. Ou seja, os usuários procuram opiniões dos amigos próximos, em vez de realizar pesquisas tradicionais, pois se sentem mais confiáveis em adquirir os produtos que seus amigos adquiriram no passado (Ha et al., 2013; Jiang et al., 2015; Xiushan and Dongfeng, 2017).

Neste trabalho, propõe-se uma função de preferência baseada na influência social. Tal função é calculada com base nas preferências do grupo de amigos mais próximos ao usuário alvo da recomendação. No caso deste trabalho, o usuário alvo é um cold-start.

Para estabelecer o grupo de usuários mais próximos ao usuário alvo definiu-se o Friendly Group Factor, que calcula o número de menções e comentários que o usuário alvo fez de outros usuários. O Friendly Group Factor é definido pela equação 5.1 apresentada a seguir.

$$
F G_{i j}=\frac{\sum_{1}^{m} \frac{m_{i, j}}{t m_{i}}+\sum_{1}^{c} \frac{c_{i, j}}{t c_{i}}}{2}
$$

Em que:

- $F G_{i j}$ corresponde ao número total de menções e comentários que o usuário alvo $i$ fez do cada um dos outros usuários $j$ da rede social,

- $m$ é o número total de postagens que o usuário $i$ faz menções na rede social,

- $c$ é o número total de postagens em que o usuário $i$ comenta outro usuário,

- $m_{i, j}$ é o número de postagens em que o usuário $i$ mencionou o usuário $j$, 
- $\quad c_{i, j}$ é o número de postagens em que o usuário $i$ comentou do usuário $j$.

Cada usuário da rede social tem um valor de Friendly Group Factor que depende das interações do usuário alvo com o mesmo.

Para identificar o grupo mais próximo do usuário alvo escolheu-se, dentre as categorias de informações de redes sociais, as postagens e os comentários porque considera-se que este tipo de interação acontece quando há maior grau de intimidade ou amizade entre os usuários.

A equação 5.2 é usada para definir um indicador para formar o grupo de amigos mais próximos.

$$
\text { friendlyThreshold }_{i}=\frac{\sum_{j=1}^{n u} F G_{i j}}{n u}
$$

Em que:

- friendlyThreshold $i$ é o valor medio do Friendly Group Factor do usuário alvo $i$ e

- $n u$ é número de usuários da rede social.

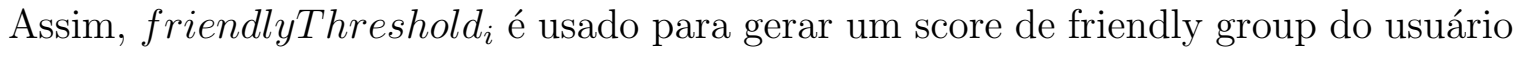
alvo em relação aos demais amigos. Os 5 usuários com maior valor para Friendly Group Factor, que sejam iguais ou superiores ao valor do indicador (eq. 5.2), são selecionados para compor o grupo de amigos realmente mais próximos do usuário alvo. A função de preferência de usuário é posteriormente calculada com base nas informações sociais desse grupo de amigos mais próximos. A seleção de 5 indivíduos para compor o grupo foi devido as limitações computacionais do sistema, pois na medida que o número de usuários aumentava, também aumentava significativamente o tempo para gerar a recomendação.

\subsubsection{Representação da função de preferência de usuário}

Wang and Lu (2014) comentam sobre o conceito de influência, em que um usuário pode ter maior poder de contágio e conformidade em um grupo. A conformidade exprime que a opinião de um usuário pode influenciar a opinião de outro. Assim, descobrir o usuário com maior influência em um grupo passa a ser relevante, pois satisfazendo este usuário, aumenta-se as chances de satisfazer todo o grupo. Considerando essas ideias e o proposto por Guo et al. (2016) (detalhado na seção 2.6.1), propõe-se a influência social (SI) definida pela equação 5.3 apresentada a seguir. 


$$
S I\left(F a_{j}, G s_{j}\right)_{f_{g}}=\frac{F \exp _{j}+2\left(F a_{j}+G s_{j}\right)}{5}
$$

Em que::

- $S I$ : corresponde a influência social do usuário $j$ dentro do grupo de amizade $f_{g}$ do usuário alvo.

- Fexp : fornece o quanto o usuário $j$ do grupo de amizade $f_{g}$ conhece sobre um determinado tópico.

- $F a_{j}$ : força da amizade do usuário $j$ em relação a cada membro do grupo de amizade $f_{g}$.

- $G s_{j}$ : grau de semelhança do usuário $j$ em relação a cada membro do grupo de amizade $f_{g}$.

Os termos Força de amizade $(F a)$ e Grau de semelhança $(G s)$ são definidos pelos 4 fatores: Expect Factor, Leader Factor, Similar Factor e Friendly Factor.

Expect, Similar e Friendly factors são baseados respectivamente nos fatores expertise, similarity e intimacy propostos por Guo et al. (2016). A diferença em relação ao proposto por Guo et al. (2016) está na forma de cálculo dos fatores mencionados, que neste trabalho é feito por meio dos dados extraídos das redes sociais, tornando viável seu emprego em aplicações nas quais é preciso determiná-los em alguns segundos, caso dos sistemas de recomendação. Também, diferentemente de Guo et al. (2016), propõe-se o emprego do Leader factor (Wang and Lu, 2014), cuja definição é apresentada mais adiante.

Expect Factor, Leader Factor, Friendly Factor e Similar Factor são definidos, respectivamente, pelas equações 5.5, 5.7, 5.11 e 5.9. Os cálculos são feitos construindo-se uma matriz para cada um desses fatores, na qual a média dos valores das colunas de uma linha i corresponde ao fator para o usuário i.

Nas equações 5.5, 5.7, 5.11 e 5.9 a seguir, i e j se referem a dois usuários pertencentes a um grupo.

- Expert Factor (Fexp): avalia quanto um usuário tem conhecimento sobre um determinado assunto. Por exemplo, no caso de músicas, Fexp (equação 5.5) avalia o quanto um usuário ouve e conhece artistas em relação aos demais do grupo. 


$$
E_{i j}=\sum_{i=1}^{n u} \sum_{i \neq j, j=1}^{n u} \frac{\frac{n f_{i}}{n f_{i}+n f_{j}}+\frac{n a_{i}}{n a_{i}+n a_{j}}+\frac{n m_{i}}{n m_{i}+n m_{j}}}{3}
$$

Em que:

- $E_{i j}$ é o elemento da matriz $E$ que mede a expertise dos usuários,

- nu é o número de usuários no grupo,

- $n f$ é o número de seguidores (followers) que o usuário tem na plataforma de música,

- na é o numero de artistas (músicos) que o usuário segue (followee), e

- $n m$ é o numero de músicas que o usuário tem na sua biblioteca.

$$
F \exp _{i}=\frac{\sum_{j=1}^{n u} E_{i j}}{n u}
$$

Em que:

- Fexp $i$ é o Expert Factor para o usuário $i$,

- nu é o numero de usuários no grupo.

- Leader Factor (Flead): determina o quanto um usuário representa a figura de um líder para o grupo. Flead (equação 5.7) é medido pelo quanto a suas postagens geram repercussão em relação as dos demais integrantes do grupo.

$$
L_{i j}=\sum_{i=1}^{n u} \sum_{i \neq j, j=1}^{n u} \frac{\frac{t l_{i}}{t l_{i}+t l_{j}}+\frac{t m_{i}}{t m_{i}+t m_{j}}}{2}
$$

Em que:

- $L_{i j}$ é o elemento da matriz L para avaliar a repercussão das postagens dos usuários,

- nu é o numero de usuários no grupo,

- $t l_{i}$ é o total de Likes que o usuário $i$ recebeu por suas postagens, análago para $t l_{j}$

- $t m_{i}$ é o total de menções que o usuário $i$ recebeu, análago $t m_{j}$.

$$
\text { Flead }_{i}=\frac{\sum_{j=1}^{n u} L_{i j}}{n u}
$$


Em que:

- Fleadi representa o Leader Factor para o usuário $i$ e

- nu é o numero de usuários no grupo.

- Similarity Factor (Fsim): mensura quão similar é cada par de usuários em um grupo. Fsim (equação 5.8) é calculado pelo número de postagens que um usuário gostou e compartilhou com os demais do grupo.

$$
S_{i j}=\sum_{i=1}^{n u} \sum_{i \neq j, j=1}^{n u} \frac{\frac{l_{j, i}+l_{i, j}}{t l_{j}+t l_{i}}+\frac{s_{j, i}+s_{i, j}}{t s_{j}+t s_{i}}}{2}
$$

Em que:

- $S_{i j}$, calculado entre cada par de usuários no grupo, é o elemento da matriz $\mathrm{S}$ que associa tanto as postagens de interesse como as postagens compartilhadas por cada usuário.

- nu é o número de usuários no grupo,

- $l_{j, i}$ é o número de postagens que o usuário $j$ gostou do usuário $i$, analogamente $\left.\operatorname{para} l_{(} i, j\right)$,

- $s_{j, i}$ é o número de postagens que o usuário $j$ compartilhou do usuário $i$, analogamente para $s_{i, j}$.

$$
F \operatorname{sim}_{i}=\frac{\sum_{j=1}^{n u} S_{i j}}{n u}
$$

Em que:

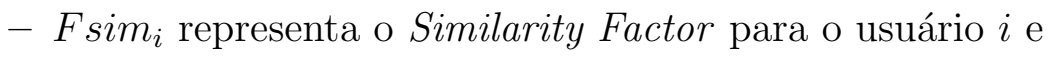

- nu é o número do usuários do grupo.

- Friendly Factor (Ffri): avalia o quanto cada par de usuário de um grupo está conectado. F fri (equação 5.11) calcula o quanto um usuário comentou ou mencionou outros usuários em suas postagens.

$$
F_{i j}=\sum_{i=1}^{n u} \sum_{i \neq j, j=1}^{n u} \frac{\frac{m_{j, i}}{t m_{j}}+\frac{c_{j, i}}{t c_{j}}}{2}
$$

Em que: 
- $F_{i j}$ é a matriz que associa o número total de menções e comentários das postagens feitas por cada usuário do grupo,

- nu é o número de usuários do grupo,

- $m_{j, i}$ é o número de postagens em que o usuário $j$ mencionou o usuário $i$,

- $c_{j, i}$ é o número de postagens em que o usuário $j$ comentou do usuário $i$.

$$
F f r i_{i}=\frac{\sum_{j=1}^{n u} F_{i j}}{n u}
$$

Em que:

- Ffri $i_{i}$ é o Friendly Factor para o usuário $i$ e

- nu é número de usuários no grupo.

Os fatores apresentados pelas equações 5.5, 5.7, 5.11 e 5.9 já estão normalizados numa escala de 0 a 1, ou seja, o valor máximo que um usuário receberá em qualquer dos fatores será 1 e o mínimo, 0.

A Força de amizade $(F a)$ é definida pela equação 5.12 , na qual $F$ fri tem um peso maior, pois considera-se que este fator representa (em função das informações utilizadas no cálculo) as pessoas que são mais fortemente conectadas, ou seja com maior nível de amizade.

$$
F a_{i}=\frac{\text { Flead }_{i}+2 * F f r i_{i}}{3}
$$

O Grau de semelhança $(G s)$ é definido pela equação 5.13 , em que: Fsim determina o grau de semelhança entre dois usuários baseado nas informações extraídas das redes sociais.

$$
G s_{i}=F \operatorname{sim}_{i}
$$

Assim, a influência social ( $S I)$ é definida como segue:

$$
S I\left(F a_{i}, G s_{i}\right)_{f_{g}}=\frac{F \exp _{i}+2\left(\frac{\text { Flead }_{i}+2 * F f r i_{i}}{3}+G s_{i}\right)}{5}
$$

Que corresponde a equação 5.3 . 
Assim, a função de preferência $P_{u, j}(r, S I)$ de um usuário por um item é definida pela equação 5.15 .

$$
P_{u, j}=\sum_{i=1}^{n u} r_{i, j} *\left(1+S I_{i}\right)
$$

Em que:

- $P_{u, j}$ representa a preferência do usuário alvo $u$ por um item $j$,

- $r_{i, j}$ corresponde as recomendações de cada usuário $i$ pertencente ao grupo de amigos $f_{g}$ para o item $j$

- $S I_{i}$ é função de influência social calculada no grupo $f_{g}$ sobre o usuário $i$ dada pela equação 5.3 .

Desta forma, a recomendação ao usuário alvo é feita considerando as recomendações dos integrantes do grupo de amigos como também a influência social de cada integrante sobre o usuário alvo, que no caso desta dissertação, é um cold-start.

\subsubsection{Processo da recomendação}

No processo de recomendação adotado nesta dissertação os usuários logam no RS por meio de uma aplicação web que simula ser uma plataforma de streaming de música e que permite ter acesso aos dados da rede social e às preferências musicais. Quando um usuário cold-start acessa a aplicação e solicita uma recomendação, suas informações sociais juntamente com as de seus amigos e as preferências musicais desses amigos que fazem parte da plataforma de streaming de música são enviadas ao RS. O RS é composto pelos seguintes módulos:

- Calculador do grupo de amigos: define o grupo de amigos mais próximos do usuário cold-start e é calculada pelo friendly group factor $F G$ (equação 5.1).

- Calculador da influência social: calcula a influência de cada individuo pertencente ao grupo de amigos do usuário cold-start, ou seja, corresponde a $S I_{i}$ (equação 5.3).

- Calculador de recomendações individuais: calcula a recomendação para cada membro do grupo de amigos do usuário cold-start usando os dados coletado da plataforma de música, ou seja, corresponde ao primeiro termo da equação 5.15. As 
recomendações individuais são determinadas usando $\mathrm{CF}$, implementando $\mathrm{MF}$, mais especificamente ALS. ALS é usado para inferir as preferências do usuário por um conjunto de itens, usando a avaliação implícita feita por outros usuários. Esta técnica foi escolhida porque, segundo a literatura, é a mais adequada quando se empregam dados implícitos (Koren and Bell, 2011; Koren et al., 2009).

- Recomendador de músicas: são agregadas às recomendações individuais a influência social de cada integrante do grupo de amigos do usuário cold-start, ou seja, é calculado pela função de preferência (equação 5.15). Como resultado tem-se o subconjunto de músicas recomendado para o usuário cold-start.

\subsection{Arquitetura e implementação}

A Figura 8 mostra a arquitetura de implantação para o RS proposto, que é dividida em três partes principais:

1. API de Gerenciamento: faz a conexão entre a aplicação web e a API de recomendação. Tem a função de receber, organizar e formatar os dados que serão enviados à API de recomendação. Posteriormente o resultado da recomendação também é organizada e enviada ao cliente web para ser mostrado ao usuário.

2. API de Recomendação: parte da aplicação na qual a função de preferência é efetivamente calculada. Assim, é composta pelos componentes (i) que identifica o grupo de amigos do usuário cold-start, (ii) gera as recomendações deste grupo e (iii) calcula a influência social para o usuário cold-start.

3. Cliente Web: Permite a interação dos usuários com o RS. É por esse meio, que o usuário consegue entrar no sistema fornecendo suas credencias da rede social (SocialTracks Mastodon) e da plataforma de música (Spotify), além também de receber as recomendações, escutar as música recomendadas e avaliá-las. 
Figura 8: Arquitetura do RS proposto

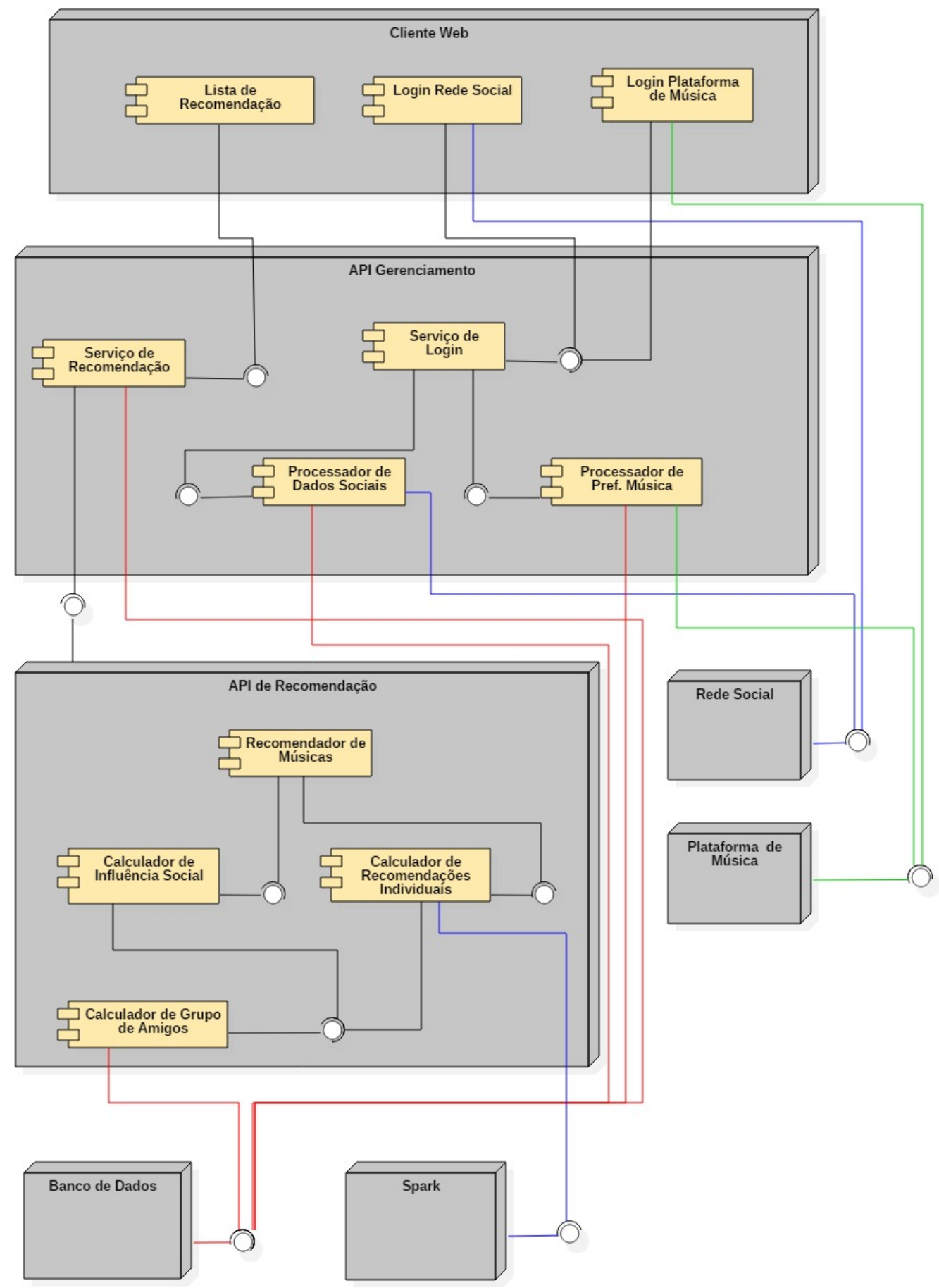

Fonte: Elaborado pelo autor

Na Tabela 10 descreve-se O ambiente computacional usado nas camadas da arquitetura apresentada na Figura 8. Na API de Recomendação a biblioteca Pyspark foi utilizada para que fosse possível usar o algoritmo de filtragem colaborativa ALS do Spark. 
Tabela 10: Tecnologias de cada camada da arquitetura

\begin{tabular}{|c|c|}
\hline Elementos & Tecnologias \\
\hline Cliente Web & React Versão 16.11 .0 \\
\hline API de Gerenciamento & $\begin{array}{l}\text { Express Versão } 4.17 .1 \\
\text { Node.js Versão } 10.17 .0\end{array}$ \\
\hline API de Recomendação & $\begin{array}{l}\text { Falcon Versão 2.0.0 } \\
\text { Gunicorn Versão 19.9.0 } \\
\text { Python Versão 3.5.2 } \\
\text { PySpark Versão 2.4.4 }\end{array}$ \\
\hline Banco de dados & MongoDB Versão 4.0.16 \\
\hline Spark & Spark Versão 2.3.2 \\
\hline
\end{tabular}

\subsubsection{Fluxo dos dados da recomendação}

A Figura 9 apresenta o processo de recomendação e o tipo de informação gerada em cada fase. O fluxo da recomendação inicia com o cadastro do usuário na plataforma web por meio das suas credencias da rede social.

Figura 9: processo de recomendação do RS proposto

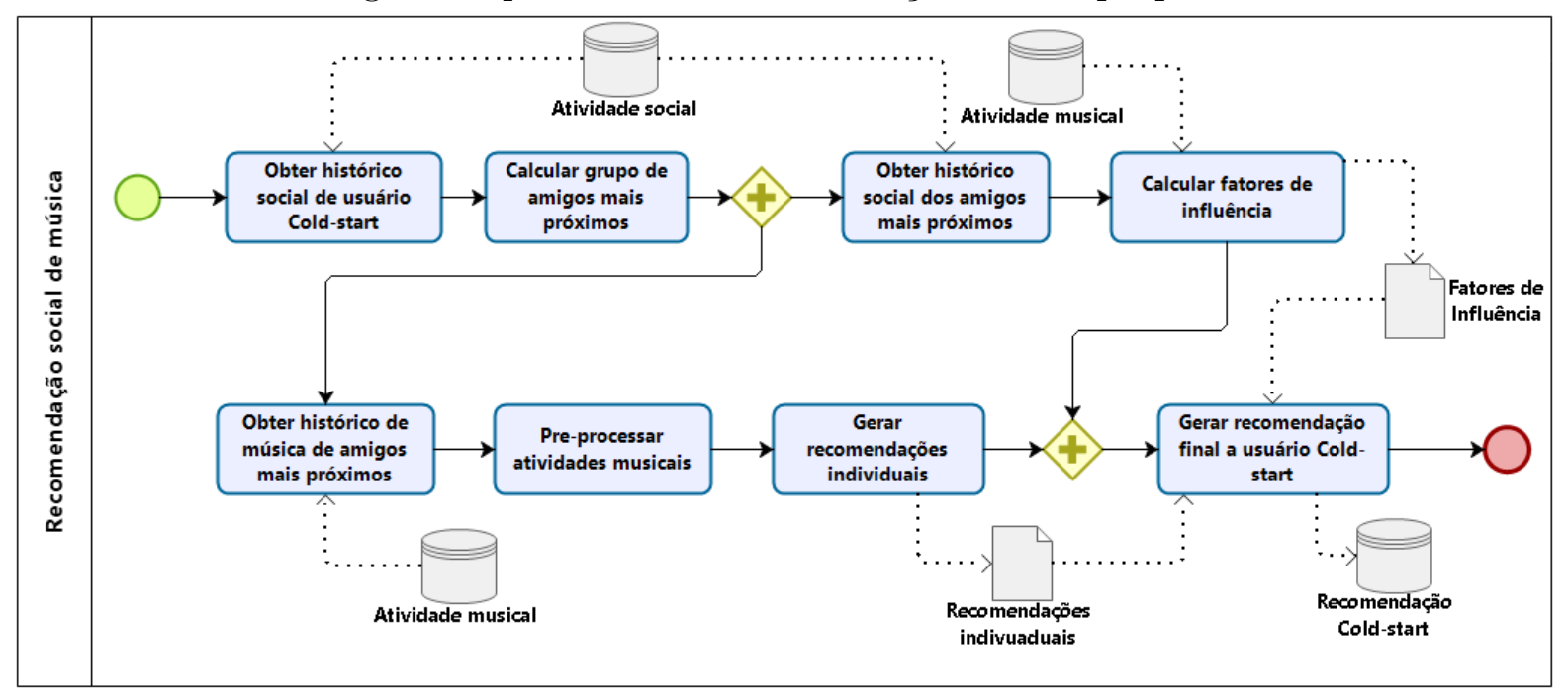

Fonte: Elaborado pelo autor

Após o cadastro, o sistema obtém o histórico social do usuário cold-start e com essa informação calcula o friendly group factor, para determinar o grupo de amigos mais próximos ao cold-start. O sistema então, recupera o histórico social desse grupo de amigos, incluindo o do usuário alvo (cold-start), como curtidas, menções, comentários e informações compartilhadas (re-postadas). Além disso, o sistema recupera da plata- 
forma de músicas o histórico de músicas do grupo dos amigos mais próximos. Exemplos de informações musicais recuperadas são: nome do cantor ou banda, nome da música e o número total de vezes que o usuário escutou a música.

A informação musical é importante para simular a hipótese de que os amigos já são clientes do e-commerce, que neste caso é a plataforma de streaming de músicas, e assim, já adquiriram produtos (escutaram músicas). Logo, as preferências desses amigos são conhecidas por esta plataforma.

Assim, as informações musicais são usados para gerar as recomendações e uma lista de recomendações é gerada para cada membro do grupo dos amigos mais próximos ao usuário cold-start.

Os dados sociais são usados para calcular os fatores de Similarity, Friendly e Leader. O Expert factor, é calculado a partir das informações musicais de cada membro do grupo, como apresentado na seção 5.2.2. Assim, que todos esses fatores são calculados, a influência de cada individuo em relação ao grupo é calculada e a recomendação individual para cada membro do grupo é gerada. Em seguida, as recomendações individuais são agregadas ao sistema considerando a influência, gerando finalmente uma lista de recomendações gerais para o usuário cold-start.

No processo de recomendação, o usuário cold-start, recebe por meio da aplicação web, o conjunto de músicas recomendadas, as quais podem ser ouvidas e avaliadas por ele. A avaliação das músicas permite estimar se o resultado da recomendação foi assertiva ou não para o usuário cold-start.

A etapa em que são geradas as recomendações individuais é a mais dispendiosa do fluxo da recomendação, devido a enorme quantidade de dados sobre usuários e músicas para a determinação os fatores latentes utilizados no ALS.

O cálculo dos fatores de influência é muito rápido. Porém, como o processo de geração de recomendações individuais é muito dispendioso, o número de pessoas consideradas para formar o grupo dos amigos mais próximos usuário alvo da recomendação foi no máximo de 5 , como já mencionado. 


\section{TESTES E RESULTADOS NO AMBIENTE CONTROLADO}

\subsection{Introdução}

Nesse capitulo detalha-se sobre a etapa de treinamento do algoritmo de recomendação e sobre os procedimentos seguidos para a criação do experimento controlado e obtenção dos resultados das recomendações.

\subsection{Dados para o treinamento do RS}

\subsubsection{Dataset da Plataforma de serviço de música}

Para coletar os dados que serviram como base de treino para o algoritmo ALS, foi usado a API do Last.fm, plataforma online que funciona como uma comunidade virtual com foco em música. Nela é possível encontrar um perfil detalhado de preferências musicais de indivíduos, como músicas e artistas favoritos. Essas informações são extraídas diretamente de aplicativos de streaming como Spotify, Deezer, Youtube, entre outros(https://www.last.fm). Com Last.fm é possível extrair diferentes tipos de informações, como comentários, social tags, gênero das músicas, número de vezes um indivíduo escutou determinada música ("play count"), dentre outras.

A API do Last.fm permitiu o crawling de 105.655 músicas, avaliadas por 41.242 indivíduos, para um total de 309.986 avaliações implícitas. Nesta API, todos os dados dos indivíduos são publicamente disponíveis. Este dataset foi usado para simular uma plataforma de streaming de música com um número de usuários e músicas suficientes para gerar recomendações por meio do algoritmo de ALS. A Tabela 11 detalha a estrutura deste dataset. O valor "Usuário-Música"no campo Tipo do Dado, é um exemplo de avaliação implícita porque não fornece as avaliação diretas das músicas, mas sim o número de vezes que um indivíduo ouviu uma música específica. 
Tabela 11: Detalhamento de informações do dataset Last.fm

\begin{tabular}{|c|c|c|}
\hline Tipo do Dado & Quantidade & Detalhe \\
\hline Música & 105.655 & $\begin{array}{l}\text { Nome, duração e artista (nome do } \\
\text { cantor, banda ou grupo) }\end{array}$ \\
\hline Usuário & 41.262 & $\begin{array}{l}\text { Nome, país, idade, e playcount } \\
\text { (número total de vezes que um in- } \\
\text { divíduo ouviu músicas) }\end{array}$ \\
\hline $\begin{array}{l}\text { Usuário- } \\
\text { Música }\end{array}$ & 309.986 & $\begin{array}{l}\text { Indivíduo, música e playcount } \\
\text { (número de vezes que um in- } \\
\text { divíduo escutou uma música es- } \\
\text { pecífica) }\end{array}$ \\
\hline
\end{tabular}

\subsubsection{Dataset das preferências individuais musicais}

Spotify foi a plataforma de música usada para obter as preferências musicais dos participantes do experimento. Esta plataforma foi escolhida por ser amplamente conhecida no Brasil e por dispor de uma API Rest simples de usar, que permite fácil integração com aplicações web/mobile. A API do Spotify retorna um metadado do tipo JSON, com informações sobre artistas, álbuns e músicas que um indivíduo ouviu no Spotify.

As preferências musicais de cada participante foram coletadas quando este acessou a aplicação web com suas credencias do Spotify. Para o processo da recomendação, as preferências musicais dos participantes do experimento são usadas quando o sistema obtém o histórico musical do conjunto de amigos do usuário cold-start (Figura 9). Então, parte desses dados são pré-processados e adicionados ao dataset do Last.fm para realizar o treinamento do algoritmo ALS. Nesta etapa foram incluídas aquelas músicas que corresponderam ao conjunto de músicas disponíveis no dataset do Last.fm.

O algoritmo avalia o conjunto de itens a serem recomendados aos usuários com base nos fatores latentes. Uma lista com as 30 músicas melhor avaliadas é gerada para cada usuário pertencente ao conjunto de amigos do usuário cold-start.

\subsection{Avaliação do Comitê de Ética}

Para execução do experimento, esta pesquisa precisou da autorização de um comité de ética por causa da retenção da identificação e outras informações sociais dos participantes. Assim, um projeto específico foi elaborado e submetido à plataforma Brasil, tendo sido designado o comitê da EACH.

Primeiramente foi necessário ter a concordância de cada individuo na sua participação 
no experimento para que, então, esse pudesse ser executado. Para tal, um Termo de Consentimento Livre e Esclarecido (TCLE) teve que ser assinado por cada participante.

O TCLE detalha o experimento, informando sobre o objetivo, o que precisa ter para participar, explica como se será todo o processo de interação no experimento, o que é a SocialTracks Mastodon, que dados serão solicitados do participante, e que será necessário a interação com os amigos usando a rede social. No TCLE incui-se ainda informações sobre riscos e benefícios da participação na pesquisa.

O modelo do TCLE elaborado para essa pesquisa encontra-se no Apêndice A. O experimento foi iniciado somente após a obtenção de todos os termos assinados, tendo tido acesso ao experimento somente aqueles que assinaram o respectivo termo.

\subsection{Rede social SocialTracks Mastodon}

Para o experimento controlado foi usada a rede social SocialTracks Mastodon, criada para garantir que houvesse troca de informações entre os participantes do experimento na rede social, de forma a poder avaliar as hipóteses assumidas nesta pesquisa que pressupunha que identificando as preferências dos amigos mais influentes seria possível melhorar os resultados de recomendações de itens/produtos para usuários que são novos (usuário cold-start) dentro de uma plataforma de e-commerce ou de serviço de streaming.

Mastodon (https://mastodon.social) é uma plataforma de rede social open source e desentralizada, que permite a criação de instâncias de redes sociais. Foi escolhida por ser fácil de usar e por ter caraterísticas similares ao Twitter.

A instância de Mastodon foi criada para suportar até 100 usuários. Todas as limitações foram ditadas pelos recursos existentes.

\subsubsection{O experimento controlado}

Para a realização do experimento um grupo de pessoas foi convidada para interagir na SocialTracks Mastodon, mediante o compartilhamento de informações (curtidas, comentários, posts) referentes a um tema específico. Além disso, informações sobre as preferências musicais dos participantes foram acessados através de processos de autenticação simplificados que permitiram o acesso às funcionalidades de plataformas de música como Spotify.

O experimento foi dividido em três etapas: 
- Etapa 1: Interação na rede social

- Etapa 2: Acesso ao Sistema de recomendação

- Etapa 3: Avaliação da recomendação

O experimento iniciou com a distribuição e coleta do TCLE entre pessoas maiores de 18 anos. No total 40 pessoas assinaram o TCLE. Posteriormente, os participantes foram informados, recebendo o endereço web (URL), sobre a rede social, tendo sido também passado instruções explicativas do funcionamento dessa rede social, criada especialmente para os fins do experimento. Como uma prova de conceito havia sido feita anteriormente (Faria, 2018; Gonzalez-Camacho et al., 2019), algumas lições já haviam sido aprendidas. Assim, para facilitar a interação das pessoas, um vídeo explicativo foi preparado e distribuído aos participantes. Esse vídeo mostrava como o usuário podia usar as opções da rede para fazer postagens, encontrar amigos, dentre outros recursos.

Na rede social os participantes tiveram a liberdade de compartilhar qualquer tipo de informação e interagir com amigos e amigas. No total, somente 20 pessoas efetivamente interagiram na rede social. Assim, foi com esse grupo que foi possível realizar as demais etapas do experimento.

Os cálculos dos fatores de influência foram feitos a partir das informações coletadas da SocialTracks.

Após a etapa da interação na rede social, cada participante teve que acessar a aplicação web com suas credenciais da rede social e a conta do Spotify. Em seguida o sistema recomendava um conjunto de 10 músicas para a avaliação pelo participante.

Para a avaliação o participante atribuiu uma nota entre 1 e 5 (Não Gostou - Gostou Muito), indicada por estrelinhas, para cada música recomendada.

Algumas telas da aplicação criada para o experimento estão apresentadas no Apêndice B.

\subsection{Fatores de influência}

Os valores calculados para os fatores empregados para o cálculo da influência social estão apresentados no Apêndice C. Os dados de identificação real de cada participante foram omitidos por razões de privacidade, tendo sido atribuídos códigos numéricos. Para ilustrar mostra-se parte desses valores na Tabela 12. Nesta amostra, apresenta-se apenas 
os dados referentes aos usuários alvo (cold-start) 2, 7 e 10. Os campos na Tabela 12 correspondem a:

- coldstart-id: identificador do usuário cold-start;

- user-id: identificador dos usuários do grupo de amigos mais próximos ao usuário cold-start;

- $F_{\text {exp }}$ : Expert factor do user_id;

- $F_{f r i}$ : Friendly Factor do user_id;

- $F_{\text {lead }}$ : Leader Factor do user_id;

- $F_{\text {sim }}$ : Similarity Factor do user_id;

- SI: influência social do user_id no grupo de amigos.

Tabela 12: Exemplo de cálculo de fatores de influência

\begin{tabular}{rrrrrrr}
\hline Coldstart_id & User_id & $F_{\text {exp }}$ & $F_{\text {fri }}$ & $F_{\text {lead }}$ & $F_{\text {sim }}$ & $S I$ \\
\hline & 1 & 0.588198 & 0.142678 & 0.291798 & 0.0963585 & 0.233137 \\
& 2 & 0 & 0.187722 & 0.393407 & 0.134336 & 0.156248 \\
& 6 & 0.212229 & 0.0829682 & 0.328291 & 0.052549 & 0.129362 \\
& 3 & 0.596618 & 0.186865 & 0.407225 & 0.0846154 & 0.257297 \\
& 7 & 0.831416 & 0.163873 & 0.400791 & 0.0977058 & 0.302504 \\
& 11 & 0.271539 & 0.0457113 & 0.178487 & 0.0384615 & 0.10568 \\
\hline & 2 & 0.438547 & 0.116901 & 0.365196 & 0.101003 & 0.207977 \\
& 16 & 0.199383 & 0.0107955 & 0.184938 & 0.06 & 0.0914138 \\
& 19 & 0.518636 & 0.102757 & 0.246743 & 0.129167 & 0.215695 \\
& 7 & 0 & 0.231588 & 0.481652 & 0.168145 & 0.193235 \\
& 3 & 0.674155 & 0.279709 & 0.480933 & 0.141548 & 0.330163 \\
& 1 & 0.669279 & 0.0411742 & 0.240538 & 0.100476 & 0.217098 \\
\hline & 1 & 0.751454 & 0.190064 & 0.191599 & 0 & 0.226521 \\
& 5 & 0.173607 & 0.13179 & 0.167901 & 0 & 0.0922522 \\
& 19 & 0.574939 & 0.0811728 & 0.0965608 & 0 & 0.149509 \\
& 10 & 0 & 0.05882 & 0.210606 & 0 & 0.0437662 \\
\hline
\end{tabular}

Os diferentes fatores que determinam a SI, são influenciados pelas interações dos 
usuários dentro da rede social. Por exemplo, $F_{\text {sim }}$ pode ser diferente para dois usuários (User_id), mesmo que os mesmos sejam muito similares, se a atividade dentro da rede social tiver sido diferente para cada um deles. Como exemplo, considere os usuários i e $\mathrm{j}$, os quais deram muitas curtidas em postagens feitas por cada um deles. No entanto, o usuário i compartilhou mais postagens do usuário j do que o vice-versa. Logo, o valor de $F_{\text {sim }}$ para o usuário i será maior do que o para o usuário j. Além disso, o fator $F_{\text {sim }}$ pode ser zero, se o usuário somente postou informação nas redes sociais, mas não curtiu ou compartilhou as publicações de outros usuários que formam o grupo de amigos do usuário cold-start. De forma similar os fatores $F_{f r i}$ e $F_{\text {lead }}$ podem ser zero, se o usuário não recebeu curtidas, menções ou comentários.

É importante destacar que alguns dos usuários cold-start tiveram pouca interação na rede social o que refletiu no baixo número de amigos identificados como mais próximos. Por exemplo, para o usuário com id 12 (coldstar-id), identificou-se apenas 1 amigo próximo para realização dos cálculos de fatores de influência.

\subsection{Recomendações}

Dado que o número de participantes que conseguiram passar por todas as etapas do experimento foi baixo, somente 20, dos 40 que assinaram o TCLE, a estratégia seguida foi fazer com que todos exercessem o papel de cold-start. Assim, quando o usuário i está no papel de cold-start, seus dados do streaming de música não são utilizados, somente suas informações na rede social são recuperadas para o cálculo da influência social e recuperação das preferências musicais do seu grupo de amigos mais próximos, como explicado no capítulo 5 .

A Tabela 13 mostra a lista das músicas que foram recomendadas ao usuário cold-start considerando ou não a influência social. Nela mostra-se também o grau da predição do sistema e a nota (avaliação) que aquele usuário cold-start deu para a música recomendada. Nesta amostra, são apresentados os resultados para os usuários cold-start 2, 7 e 10. Os demais resultados podem ser consultados no Apêndice D. Os campos da Tabela 13 correspondem a:

- Coldstart id: identificador do usuário cold-start;

- Música: nome da música recomendada;

- Predição sem SI: valor da predição quando o RS não é considerada a Influencia 
Social (SI, Social Influence)

- Predição com SI: valor da predição quando o RS considera a SI

- R_system: valor da predição com SI normalizada

- R_user: avaliação (nota) dada pelo usuário cold-start para a música recomendada

A faixa de valores gerada na predição foi $[0,2,5]$, enquanto que os valores da avaliação feita pelo usuário foram inteiros entre $[1,5]$. Assim, para ser possível a comparação, os valores da predição foram normalizado para a faixa $[1,5]$, conforme a equação 6.1 .

$$
R_{\text {System }}(i, j)=\left\lfloor\frac{\text { Prediction }_{i, j}}{\max \left(\text { Prediction }_{i, j}\right)} * 4\right\rfloor+1
$$

No qual $R_{\text {System }}(i, j)$ é a normalização dos $j$ itens avaliados pelo usuário $i$.

Tabela 13: Exemplo recomendação considerando influência social e avaliação das músicas

\begin{tabular}{|c|c|c|c|c|c|}
\hline $\begin{array}{l}\text { Coldstart } \\
\text { Id }\end{array}$ & Música & $\begin{array}{l}\text { Predição } \\
\text { sem SI }\end{array}$ & $\begin{array}{l}\text { Predição } \\
\text { com SI }\end{array}$ & R_system & R_user \\
\hline 2 & The Scientist & 1.85105 & 2.20013 & 5 & 3 \\
\hline 2 & $\begin{array}{l}\text { Somebody That I } \\
\text { Used To Know }\end{array}$ & 1.92139 & 2.1675 & 5 & 5 \\
\hline 2 & Mr. Brightside & 1.94921 & 2.15296 & 5 & 3 \\
\hline 2 & Do I Wanna Know? & 1.84418 & 2.11113 & 5 & 4 \\
\hline 2 & Sex on Fire & 1.87884 & 2.08468 & 5 & 4 \\
\hline 2 & Radioactive & 1.84577 & 2.06627 & 4 & 5 \\
\hline 2 & Pumped Up Kicks & 1.84429 & 2.03114 & 4 & 5 \\
\hline 2 & $\begin{array}{l}\text { Nirvana smells like } \\
\text { teen spirit - remix }\end{array}$ & 1.78984 & 2.00881 & 4 & 5 \\
\hline 2 & Use Somebody & 1.85372 & 2.00284 & 4 & 2 \\
\hline 7 & Losing My Religion & 1.8517 & 2.27127 & 5 & 5 \\
\hline 7 & Paradise & 1.74279 & 2.14798 & 5 & 3 \\
\hline 7 & $\begin{array}{l}\text { Coldplay - Fix You } \\
\text { (Remix) }\end{array}$ & 1.76151 & 2.16209 & 5 & 2 \\
\hline 7 & Use Somebody & 1.90501 & 2.20177 & 5 & 3 \\
\hline 7 & Somebody Told Me & 1.79069 & 2.25811 & 5 & 4 \\
\hline
\end{tabular}


Tabela 13: Exemplo recomendação considerando influência social e avaliação das músicas

\begin{tabular}{|c|c|c|c|c|c|}
\hline $\begin{array}{l}\text { Coldstart } \\
\text { Id }\end{array}$ & Música & $\begin{array}{l}\text { Predição } \\
\text { sem SI }\end{array}$ & $\begin{array}{l}\text { Predição } \\
\text { com SI }\end{array}$ & R_system & R_user \\
\hline 7 & Viva La Vida & 1.93776 & 2.32483 & 5 & 4 \\
\hline 7 & $\begin{array}{l}\text { Wonderwall - Remas- } \\
\text { tered }\end{array}$ & 1.94982 & 2.3226 & 5 & 4 \\
\hline 7 & The Scientist & 1.93033 & 2.31468 & 5 & 5 \\
\hline 7 & Mr. Brightside & 2.00053 & 2.31187 & 5 & 4 \\
\hline 7 & $\begin{array}{l}\text { Somebody That I } \\
\text { Used To Know }\end{array}$ & 1.85606 & 2.28996 & 5 & 4 \\
\hline 10 & Mr. Brightside & 1.22619 & 1.33735 & 3 & 2 \\
\hline 10 & The Pretender & 1.19016 & 1.32464 & 3 & 1 \\
\hline 10 & In the End & 1.25082 & 1.32566 & 3 & 2 \\
\hline 10 & Numb & 1.25718 & 1.34704 & 3 & 2 \\
\hline 10 & Viva La Vida & 1.18858 & 1.3903 & 3 & 4 \\
\hline 10 & My Hero & 1.16358 & 1.47449 & 3 & 1 \\
\hline 10 & Use Somebody & 1.16769 & 1.48938 & 4 & 1 \\
\hline 10 & Everlong & 1.25079 & 1.53904 & 4 & 1 \\
\hline
\end{tabular}


A Figura 10 exibe a distribuição das avaliações das músicas feitas pelo RS proposto (R_system) e pelos usuários (R_user) em forma de boxplot. Nesse gráfico pode se observar que a concentração das avaliações feitas pelo RS está entre os valores 2 a 4, com valor médio em 3, sendo os valores mínimo e máximo são iguais a 1 e 5 respectivamente. R_user diferentemente de R_system, concentra a suas avaliações entre os valores 3 e 5, com valor médio em 4. Considerando que $R_{-}$user reflete o grau de satisfação dos usuários com o resultado das recomendações feitas pelo RS proposto, pode-se dizer que o usuário aprovou o resultado.

Figura 10: Distribuição das avaliações com influência social

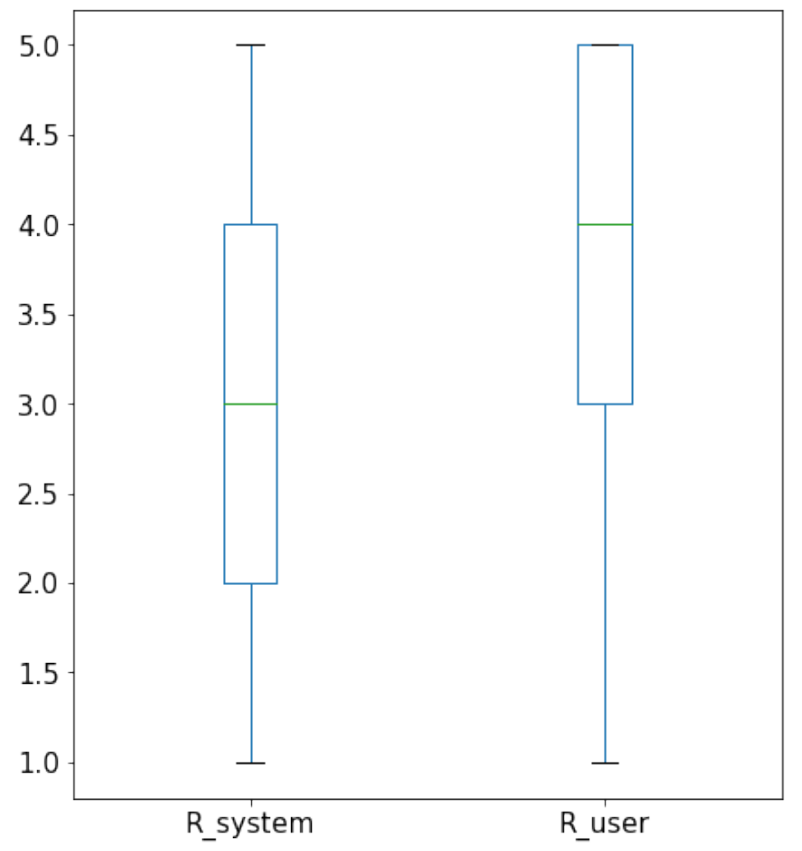

Para mensurar a diferença entre as avaliações feitas pelos usuários ( $R_{-}$user) e as predições calculadas pelo sistema( R_system) foi usada a métrica RMSE.

O RMSE é dada por:

$$
\begin{gathered}
R M S E=\sqrt{\frac{1}{K} \sum_{i=1}^{N} \sum_{j=1}^{M_{i}}\left(\hat{R}_{i, j}-R_{i, j}\right)^{2}} \\
K=\sum_{i=1}^{N} \sum_{j=1}^{M_{i}} 1
\end{gathered}
$$

Em que:

- $\hat{R}_{i, j}=R_{\text {system }}(i, j)$ é a predição que o sistema fez para a música $j$, que é recomendada ao usuário $i$, 
- $R_{i, j}$ é a avaliação que o usuário fez para a música recomendada $j$,

- $N$ é o número total de usuários cold-start do sistema, e

- $M_{i}$ é o número de recomendações feitas para o usuário $i$.

O valor do RMSE varia entre 0 e 4 Contratres et al. 2018), pois $\left|\hat{R}_{i, j}-R_{i, j}\right| \leq 4$, então $0 \leq\left(\hat{R}_{i, j}-R_{i, j}\right)^{2} \leq 4^{2}$, logo:

$$
0 \leq \sqrt{\frac{1}{K} \sum_{i=1}^{N} \sum_{j=1}^{M_{i}}\left(\hat{R}_{i, j}-R_{i, j}\right)^{2}} \leq 4
$$

Então, quanto mais próximos forem os valores da predição feita pelo sistema de recomendação e o da avaliação do usuário, melhor será a predição. Assim, quanto menor for o RMSE melhor é a predição.

Para o cenário em que a recomendação das músicas considera a influência social, o resultado da métrica de avaliação do modelo foi (eq: 6.2):

$$
\operatorname{RMSE}=1.8392
$$

Segundo o resultado do RMSE, a variação entre as avaliações dadas pelo RS proposto e as dos usuários cold-start foi de 1.84 pontos aproximadamente. 
Observou-se que alguns usuários tiveram resultados de fatores de influência muito baixos, causados pela baixa interação na rede social. Isso significa que as informações coletadas não são suficientes para avaliar a influência. Assim, decidiu-se analisar os resultados das recomendações, desconsiderando esses usuários com baixa, ou nenhuma interação na rede social, que foram aqueles que tiveram apenas 1 amigo mais próximo (Coldstart_id 9, 12, 14, 16 e 17). Em outras palavras, para tais usuários a função de influência social não seria significativa para melhorar as recomendações daquele usuário cold-start. A Figura 11 mostra a distribuição das avaliações R_system e R_user desconsiderando aqueles usuários que não tiveram interação social na rede social, ou esta foi muita pequena. Na Figura 11 observa-se que as predições das músicas, R_system, se concentram entre 3 e 4, com valor médio em 3,5, sendo os valores mínimos e máximos entre 2 e 5 . Tal resultado ficou mais próximo das avaliações feitas pelo usuário (R_user), diferentemente do observado na Figura 10. Assim, para os casos em que houve maior interação social, foi possível gerar melhor recomendação.

Figura 11: Distribuição das avaliações com influência social dos usuários mais ativos na rede social

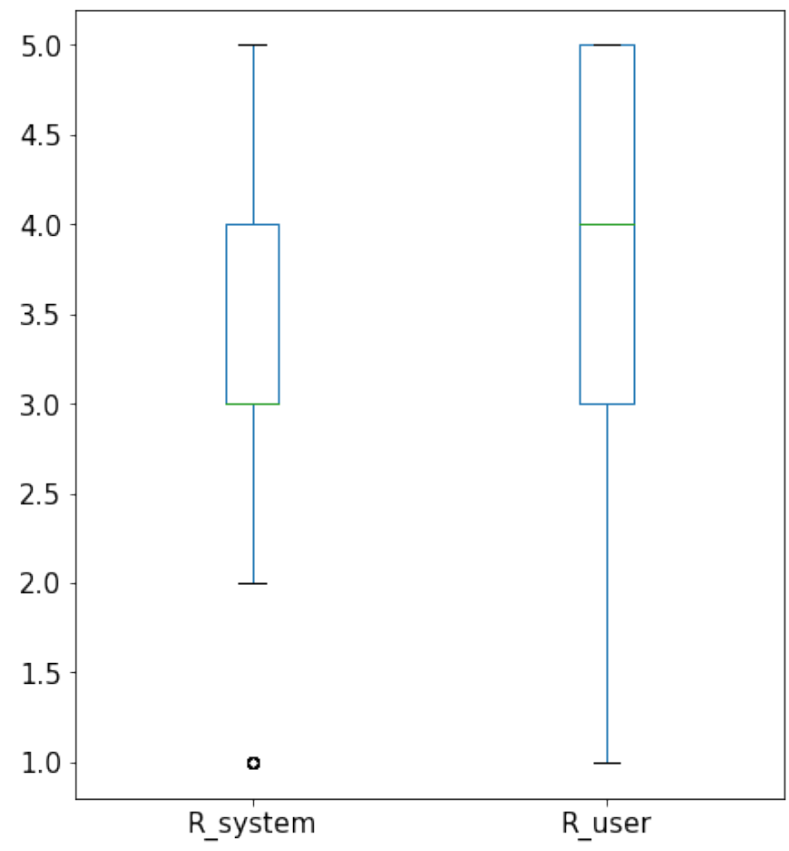

Para esse último cenário, o resultado da métrica de avaliação do modelo foi (eq: 6.2):

$$
\mathrm{RMSE}=1.5651
$$

O resultado do RMSE de 1,57 é menor que o anterior $(1,84)$, o que mostra que as recomendações feitas pelo sistema foram mais próximas das avaliações feitas pelo usuário quando houve efetivamente uma interação social na rede. 


\section{CONCLUSÕES}

Nesta dissertação foi proposto um RS que utiliza a influência social para melhorar a recomendação de itens para usuários cold-start. A influência social é calculada com base na função de preferência de usuário, computada por 4 fatores: expert factor, leader factor, similarity factor e friendly factor. Todos esses factores foram calculados por meio de informações vindas de uma rede social. Utilizou-se um ambiente controlado para realização dos testes do experimento. Foi necessário a aprovação por um comitê de ética, pois os dados de identificação dos participantes foram retidos no experimento. Assim, o experimento foi aprovado pelo Comitê de Ética da EACH (CAAE:08465018.0.0000.5390), tendo os testes iniciado somente após esta aprovação. O experimento controlado foi conduzido com 20 pessoas, as quais participaram de forma voluntaria após terem assinado o TCLE.

Durante a execução do experimento controlado vivenciou-se alguns problemas que dificultaram a coleta de maior quantidade de informação que auxiliaria em uma melhor avaliação dos resultados. Inicialmente o processo de aprovação do comitê de ética foi demorado, o que adiou bastante o início do experimento. Por outro lado, apesar de termos tido um número considerado razoável de aceitação na participação no experimento, 40 assinaram o TCLE, apenas 50\% deste valor participaram de todas as 3 etapas do experimento. Também foi necessário entrar em contato repetidamente com os participantes para solicitar que interagissem na rede social, pois sem dados suficientes não seria possível validar a proposta da proposta. Outro ponto que vale ressaltar foi que, em função de ter sido feito um experimento preliminar como prova de conceito, observou-se que algumas pessoas tiveram dificuldade de interagir com a rede social SocialTracks. Então, para facilitar a interação e participação no experimento, produziu-se um vídeo explicando sobre o uso da SocialTracks. Considerou-se, que foi positivo, pois algumas pessoas, que participaram tanto da fase de prova de conceito quanto da do experimento, relataram que foi mais fácil com a explicação por vídeo. Na prova de conceito havia explicações, mas em forma textual. Contudo, foi um vídeo amador, caso houvesse uma preparação mais profissional, possivelmente pudesse haver maior interação na rede. 
As principais contribuições desta dissertação foram: (i) a proposta de uma função de influência social baseada em 4 fatores: expert factor, leader factor, similarity factor e friendly factor, os quais são calculados usando unicamente dados coletados das redes sociais; (ii) o uso de dados de redes sociais para melhorar a recomendações de itens a usuários cold-start; (iii) apresentar de forma detalhada o procedimento de um experimento em ambiente controlado.

O foco do sistema de recomendação proposto foi em usuário cold-start, mas seria plenamente aplicável, com pequenos ajustes a usuários não cold-start.

Como resultado deste trabalho foram publicados 3 artigos: Gonzalez-Camacho and Alves-Souza (2018), Gonzalez-Camacho et al. (2019) e Gonzalez-Camacho and AlvesSouza (2020).

Um quarto artigo já está sendo produzido com os resultados finais desta dissertação.

Como trabalho futuro, esta pesquisa pode ser estendida para analisar e modelar a influência social por técnicas de grafos. Isto possibilitará comparar os valores dos fatores de influência com a técnica proposta nesta dissertação. Também pode ser considerado como trabalho futuro a inclusão dos fatores de influência à técnica ALS para o cálculo dos fatores latentes, permitindo avaliar se há melhora nas recomendações de itens a usuários cold-start.

É importante destacar que embora os RS tem como objetivo melhorar a experiencia do usuário dentro das plataformas de streaming e e-commerce, diminuindo a carga de informações com que este tem de lidar, as limitações impostas pela Ley Geral de Proteção de Dados (LGPD) em relação a privacidade dos dados, implicam em revisões sobre o que e até que ponto RS podem usar dados de usuários no processo de recomendação. 


\section{REFERÊNCIAS BIBLIOGRÁFICAS}

Al-Hassan, M., Lu, H., Lu, J., 2015. A semantic enhanced hybrid recommendation approach: A case study of e-Government tourism service recommendation system. Decis. Support Syst. 72, 97-109. doi:10.1016/j.dss.2015.02.001.

Almohsen, K.A., Al-Jobori, H., 2015. Recommender systems in light of big data. Int. J. Electr. Comput. Eng. 5, 1553-1563.

Amatriain, X., Jaimes, A., Oliver, N., M. Pujo, J., 2011. Data mining methods for recommender systems, in: Recommender Systems Handbook. Springer US. chapter 2.

Barjasteh, I., Forsati, R., Masrour, F., Esfahanian, A.H., Radha, H., 2015. Cold-Start Item and User Recommendation with Decoupled Completion and Transduction. Proc. 9th ACM Conf. Recomm. Syst. - RecSys '15 , 91-98.

Bhowmick, A.K., Sai Bharath Chandra, G., Singh, Y., Mitra, B., 2018. Constructing Influence Trees from Temporal Sequence of Retweets: An Analytical Approach, in: 2018 IEEE International Conference on Big Data (Big Data), pp. 624-633. doi:10. 1109/BigData.2018.8622315.

Bobadilla, J., Ortega, F., Hernando, A., 2012. A collaborative filtering similarity measure based on singularities. Inf. Process. Manag. 48, 204-217.

Bobadilla, J., Ortega, F., Hernando, A., Gutiérrez, A., 2013. "Recommender systems survey. Knowledge-Based Syst 46, 109-132.

Chen, C.C., Wan, Y.H., Chung, M.C., Sun, Y.C., 2013. An effective recommendation method for cold start new users using trust and distrust networks. Inf. Sci. (Ny). 224, 19-36. doi:10.1016/j.ins.2012.10.037.

CHEN, L., Shao, C., Zhu, P., Zhu, H., 2016. Using Trust of Social Ties for Recommendation. IEICE Trans. Inf. Syst. E99.D, 397-405. doi:10.1587/transinf.2015EDP7199.

Christou, I.T., Amolochitis, E., Tan, Z.H.H., 2016. AMORE: design and implementation of a commercial-strength parallel hybrid movie recommendation engine. Knowl. Inf. Syst. 47, 671-696. doi:10.1007/s10115-015-0866-z. 
Contratres, F.G., Alves-Souza, S.N., Filgueiras, L.V.L., DeSouza, L.S., 2018. Sentiment analysis of social network data for cold-start relief in recommender systems, in: Advances in Intelligent Systems and Computing, Springer Verlag. pp. 122-132. doi:10.1007/978-3-319-77712-2_12.

De-Campos, L.M., Fernández-Luna, J.M., Huete, J.F., Rueda-Morales, M.A., 2010. Combining content-based and collaborative recommendations: A hybrid approach based on Bayesian networks. Int. J. Approx. Reason. 51, 785-799.

Deng, S., Huang, L., Xu, G., 2014. Social network-based service recommendation with trust enhancement. Expert Systems with Applications 41, 8075-8084. doi:10.1016/j. eswa.2014.07.012.

Desrosiers, C., Karypis, G., 2011. A comprehensive survey of neighborhood-based recommendation methods, in: Recommender Systems Handbook. Springer US. chapter 4.

Diaz-Agudo, B., Jimenez-Diaz, G., Recio-Garcia, J.A., 2018. SocialFan: Integrating social networks into recommender systems. Proceedings - International Conference on Tools with Artificial Intelligence, ICTAI 2018-November, 171-176. doi:10.1109/ICTAI . 2018. 00035 .

Douglas Rodrigues Oliveira, A., Bessa, L., Rodrigues Andrade, T., Filgueiras, L., Sichman, J., 2012. Trust-based recommendation for the social web 10, 1661-1666.

Faria, J.H.K., 2018. Social Tracks - Sistema de Recomendação para Múltiplos Indivíduos Utilizando Dados Sociais. Trabalho de Conclusão de Curso, (Engenharia de Computação) - Escola Politécnica, Universidade de São Paulo, São Paulo, Brasil.

Gonzalez-Camacho, L.A., Alves-Souza, S.N., 2018. Social network data to alleviate coldstart in recommender system: A systematic review. Information Processing \& Management 54, 529-544. doi:10.1016/J. IPM.2018.03.004.

Gonzalez-Camacho, L.A., Alves-Souza, S.N., 2020. Identification of social influence on social networks and its use in recommender systems: A systematic review, in: Proceedings of 9th International Conference on Data Science, Technology and Applications (DATA), INSTICC. SciTePress. pp. 234-241. doi:10.5220/0009829702340241.

Gonzalez-Camacho, L.A., Faria, J.H.K., Alves-Souza, S.N., Filgueiras, L.V.L., 2019. Social tracks: Recommender system for multiple individuals using social influence, in: 
Proceedings of the 11th International Joint Conference on Knowledge Discovery, Knowledge Engineering and Knowledge Management - Volume 1: KDIR,, INSTICC. SciTePress. pp. 363-371. doi:10.5220/0008166503630371.

Guo, J., Zhu, Y., Li, A., Wang, Q., Han, W., 2016. A Social Influence Approach for Group User Modeling in Group Recommendation Systems. IEEE Intelligent Systems 31, 40-48. doi:10.1109/MIS.2016.28.

Ha, I., Oh, K.J., Jo, G.S., 2013. Personalized advertisement system using social relationship based user modeling. Multimed. Tools Appl. 74, 1-19. doi:10.1007/ s11042-013-1691-6.

Hannech, A., Adda, M., Mcheick, H., Science, C., 2016. Cold-start recommendation strategy based on social graphs 1, in: 2016 IEEE 7th Annu. Inf. Technol. Electron. Mob. Commun. Conf.

Hendry, Su, Y.J., Chen, R.C., 2017. A New Method for Identifying Users Interest for Personalized Recommendations, in: Tsai P.-W. Watada J., K.N. (Ed.), Proceedings - 2016 3rd International Conference on Computing Measurement Control and Sensor Network, CMCSN 2016, Institute of Electrical and Electronics Engineers Inc.. pp. 8487. doi:10.1109/CMCSN. 2016.15.

Hu, Y., Volinsky, C., Koren, Y., 2008. Collaborative filtering for implicit feedback datasets. Proceedings - IEEE International Conference on Data Mining, ICDM doi:10.1109/ICDM.2008.22.

Huang, T.C.K., Chen, Y.L., Chen, M.C., 2016. A novel recommendation model with Google similarity. Decis. Support Syst. 89, 17-27.

Jain, S., Grover, A., Thakur, P., Choudhary, S., 2015. Trends, problems and solutions of recommender system, in: International Conference on Computing, Communication \& Automation, pp. 955-958.

Jiang, M., Cui, P., Chen, X., Wang, F., Zhu, W., Yang, S., 2015. Social Recommendation with Cross-Domain Transferable Knowledge. IEEE Trans. Knowl. Data Eng. 27, 30843097. doi:10.1109/TKDE.2015.2432811.

Jianqiang, Z., Xiaolin, G., Feng, T., 2017. A New Method of Identifying Influential Users in the Micro-Blog Networks. IEEE Access 5, 3008-3015. doi:10.1109/ACCESS. 2017. 2672680 . 
Khalid, O., Khan, M.U.S., Khan, S.U., Zomaya, A.Y., 2014. OmniSuggest: A Ubiquitous Cloud based Context Aware Recommendation System for Mobile Social Networks. IEEE Trans. Serv. Comput., 1doi:10.1109/TSC.2013.53.

Kitchenham, B., Charters, S., 2007. Guidelines for performing Systematic Literature reviews in Software Engineering Version 2.3. Engineering 45, 1051. doi:10.1145/1134285. 1134500 .

Koren, Y., Bell, R., 2011. Advances in collaborative filtering, in: Recommender Systems Handbook. Springer US. chapter 5.

Koren, Y., Bell, R., Volinsky, C., 2009. Matrix factorization techniques for recommender systems. Computer 42, 30-37. doi:10.1109/MC.2009.263.

Lalwani, D., Somayajulu, D.V.L.N., Krishna, P.R., 2015. A community driven social recommendation system. Proc. - 2015 IEEE Int. Conf. Big Data, IEEE Big Data 2015 , 821-826doi:10.1109/BigData.2015.7363828.

Li, C., Xiong, F., 2017. Social recommendation with multiple influence from direct user interactions. IEEE Access 5, 16288-16296. doi:10.1109/ACCESS.2017.2739752.

Lian, D., Ge, Y., Zhang, F., Yuan, N.J., Xie, X., Zhou, T., Rui, Y., 2016. Contentaware collaborative filtering for location recommendation based on human mobility data. Proc. - IEEE Int. Conf. Data Mining, ICDM 2016-Janua, 261-270. doi:10.1109/ ICDM. 2015.69.

Lin, C., Xie, R., Guan, X., Li, L., Li, T., 2014. Personalized news recommendation via implicit social experts. Inf. Sci. (Ny). 254, 1-18. doi:10.1016/j .ins.2013.08.034.

Liu, J., Hao, F., Wang, Y., 2018. Discovering Influential Areas According to CheckIn Records and User Influence in Social Networks, in: 2018 IEEE 20th International Conference on High Performance Computing and Communications; IEEE 16th International Conference on Smart City; IEEE 4th International Conference on Data Science and Systems (HPCC/SmartCity/DSS), pp. 1151-1155. doi:10.1109/HPCC/SmartCity/ DSS.2018.00193.

Liu, J., Wu, C., Liu, W., 2013. Bayesian probabilistic matrix factorization with social relations and item contents for recommendation. Decis. Support Syst. 55, 838-850. doi $10.1016 /$ j.dss.2013.04.002. 
Ma, Q., Luo, X., Zhao, M., 2018. User Behaviour Network Based User Role Mining of Web Event, in: 2018 14th International Conference on Semantics, Knowledge and Grids (SKG), pp. 211-217. doi:10.1109/SKG.2018.00038.

Maniktala, M., Sachdev, S., Bansal, N., Susan, S., 2016. Finding the most informational friends in a Social Network based Recommender System. 12th IEEE Int. Conf. Electron. Energy, Environ. Commun. Comput. Control (E3-C3), INDICON 2015 , 1-6doi:10. 1109/INDICON . 2015.7443226.

Mohammadi, S.A., Andalib, A., 2017. Using the opinion leaders in social networks to improve the cold start challenge in recommender systems, in: 2017 3th Int. Conf. Web Res., pp. 62-66. doi:10.1109/ICWR.2017.7959306.

Moreno, M.N., Segrera, S., López, V.F., Muñoz, M.D., Sánchez, Á.L., 2016. Web mining based framework for solving usual problems in recommender systems. A case study for movies' recommendation. Neurocomputing 176, 72-80. doi:10.1016/j.neucom. 2014 . 10.097.

Prando, A., 2016. Um Sistema de Recomendação para E-commerce Utilizando Redes Sociais em ambiente Big Data. Dissertação (Mestrado em )-Instituto de Pesquisas Tecnológicas do Estado de São Paulo - IPT, São Paulo, Brasil.

Prando, A.V., Contratres, F.G., Souza, S.N.A., De Souza, L.S., 2017. Content-based recommender system using social networks for cold-start users, in: 9th International Joint Conference on Knowledge Discovery, Knowledge Engineering and Knowledge Management (KDIR 2017), pp. 181-189. doi:10.5220/0006496301810189.

Rehman, F., Khalid, O., Madani, S.A., 2017. A comparative study of location-based recommendation systems. Knowl. Eng. Rev. 32, e7.

Ricci, F., Rokach, L., Shapira, B., 2011. Recommender Systems Handbook. Springer US.

Rosli, A.N., You, T., Ha, I., Chung, K.Y.Y., Jo, G.S.S., 2015. Alleviating the coldstart problem by incorporating movies facebook pages. Cluster Comput. 18, 187-197. doi:10.1007/s10586-014-0355-2.

Salehi, M., Nakhai Kamalabadi, I., Ghaznavi Ghoushchi, M.B., 2013. An effective recommendation framework for personal learning environments using a learner preference tree and a GA. IEEE Trans. Learn. Technol. 6, 350-363. 
Senthilkumar, K.T., Ponnusamy, R., 2016. Diffusing Multi-Aspects of Local and Global Social Trust for Personalizing Trust Enhanced Recommender System, in: ICACCS 2016 - 3rd Int. Conf. Adv. Comput. Commun. Syst. Bringing to Table, Futur. Technol. from Arround Globe. doi:10.1109/ICACCS.2016.7586387.

Shani, G., Gunawardana, A., 2011. Evaluating recommendation systems, in: Recommender Systems Handbook. Springer US. chapter 8.

Sumith, N., Annappa, B., Bhattacharya, S., 2017. A holistic approach to influence maximization. Springer International Publishing. doi:10.1007/978-3-319-65139-2_6.

Sun, J., Wang, G., Cheng, X., Fu, Y., 2015. Mining affective text to improve social media item recommendation. Inf. Process. Manage. 51, 444-457. doi:10.1016/j.ipm. 2014. 09.002 .

Thilagam, P.S., 2016. Alleviating Data Sparsity and Cold Start in Recommender Systems using Social Behaviour, in: 2016 FIFTH Int. Conf. Recent TRENDS Inf. Technol. doi:10.1109/ICRTIT. 2016.7569532.

Wang, X., Lu, W., Ester, M., Wang, C., Chen, C., 2016. Social Recommendation with Strong and Weak Ties, in: Conf. Inf. Knowl. Manag., ACM Press. pp. 5-14. doi:10. 1145/2983323.2983701.

Wang, Z., Lu, H., 2014. Online recommender system based on social network regularization 8834, 487-494.

Wu, H., Wang, X., Peng, Z., Li, Q., 2013. Div-clustering: Exploring active users for social collaborative recommendation. J. Netw. Comput. Appl. 36, 1642-1650. doi:10.1016/ j.jnca.2013.02.016.

Wu, L., Yang, B., Jian, M., Sang, J., Zhang, D., Zhang, L., 2018. MPPR: Multi Perspective Page Rank for User Influence Estimation, in: 2018 IEEE International Conference on Big Data and Smart Computing (BigComp), pp. 25-29. doi:10.1109/BigComp. 2018.00013 .

Xing, L., Ma, Q., Jiang, L., 2017. Microblog user recommendation based on particle swarm optimization. China Communications 14, 134-144. doi:10.1109/CC.2017.7942321.

Xiushan, X., Dongfeng, Y., 2017. A novel matrix factorization recommendation algorithm fusing social Trust and Behaviors in micro-blogs, in: 2017 IEEE 2nd Int. Conf. Cloud Comput. Big Data Anal., IEEE. pp. 283-287. doi 10.1109/ICCCBDA.2017.7951925. 
Yang, S., Shi, L., Liu, L., 2018. Community Detection Method Based on User Influence Probability and Similarity, in: 2018 Sixth International Conference on Advanced Cloud and Big Data (CBD), pp. 183-190. doi 10.1109/CBD.2018.00041.

Yin, H., Cui, B., Chen, L., Hu, Z., Zhang, C., 2015. Modeling Location-Based User Rating Profiles for Personalized Recommendation. ACM Trans. Knowl. Discov. Data 9, 1-41. doi:10.1145/2663356.

Zhang, C., Lu, T., Chen, S., Zhang, C., 2017. Integrating Ego, Homophily, and Structural Factors to Measure User Influence in Online Community. IEEE Transactions on Professional Communication 60, 292-305. doi:10.1109/TPC.2017.2703038.

Zhang, D., Hsu, C.H.H., Chen, M., Chen, Q., Xiong, N., Lloret, J., 2014. Cold-start recommendation using Bi-clustering and fusion for large-scale social recommender systems. IEEE Trans. Emerg. Top. Comput. 2, 239-250. doi:10.1109/TETC.2013. 2283233 .

Zhang, Y., Chen, W., Yin, Z., 2013. Collaborative filtering with social regularization for TV program recommendation. Knowledge-Based Syst. 54, 310-317. doi:10.1016/j. knosys.2013.09.018.

Zhang, Jia Dong, Chow, C.Y., Xu, J., 2017. Enabling kernel-based attribute-aware matrix factorization for rating prediction. IEEE Trans. Knowl. Data Eng. 29, 798-812. doi:10. 1109/TKDE. 2016.2641439.

Zhao, W.X., Li, S., He, Y., Chang, E.Y., Wen, J.R., Li, X., 2016. Connecting Social Media to E-Commerce: Cold-Start Product Recommendation Using Microblogging Information. IEEE Trans. Knowl. Data Eng. 28, 1147-1159. doi:10.1109/TKDE. 2015.2508816.

Zhou, Y., Li, Y., Wang, Z., Luo, Y., Yang, X., 2017. Identification of influential spreaders in geo-social network, in: 2017 25th International Conference on Geoinformatics, pp. 1-4. doi:10.1109/GEOINFORMATICS . 2017.8090941.

Zhou, J, Wu, G., Tu, M., Wang, B., Zhang, Y., Yan, Y., 2017. Predicting user influence under the environment of big data, in: 2017 2nd IEEE International Conference on Cloud Computing and Big Data Analysis, ICCCBDA 2017, Institute of Electrical and Electronics Engineers Inc.. pp. 133-138. doi:10.1109/ICCCBDA .2017.7951898. 


\title{
APÊNDICE A - TERMO DE CONSENTIMENTO LIVRE E ESCLARECIDO (TCLE)
}

Neste seção apresenta-se o TCLE que foi elaborado e aprovado pelo comitê de ética da EACH, inclui-se também o modelo do termo que foi preenchido e assinado por cada participante, antes que este tivesse acesso ao experimento. Assim, reproduz-se a seguir o TCLE que foi elaborado.

\section{TERMO DE CONSENTIMENTO LIVRE E ESCLARECIDO (TCLE)}

\author{
Escola Politécnica - Universidade de São Paulo \\ Departamento de Computação e Sistemas Digitais
}

Convidamos o(a) Sr(a). para participar do experimento "Big Data e Business Intelligenceuso de dados de redes sociais como solução para cenário de cold-start em sistemas de recomendação", que tem como objetivo avaliar se fazer uso de informação de redes sociais dentro de um e-commerce ou site de serviço é possível melhorar a experiência e satisfação dos usuários, na recomendação de itens baseado nas informações coletadas de sua rede social.

Com o grande volume de dados que são gerados diariamente, é cada vez mais difícil que usuários encontrem itens que realmente sejam de seu interesse. Estamos estudando uma nova forma de recomendar itens/produtos para as pessoas com base nas informações coletadas das redes sociais. 
Pedimos a sua participação no experimento porque há a necessidade da utilização do sistema por pessoas, com informações reais, para que possamos verificar a eficiência do nosso sistema de recomendação e compará-lo com outros. Três algoritmos serão testados dentro do experimento afim de comparar diferentes abordagens.

Como participante, você deve ter um telefone com sistema operacional android, ter uma conta no Spotify e saber fazer uso de redes sociais, como Facebook ou Twitter.

O experimento iniciará com um cadastro dentro de uma rede social chamada Social Tracks Mastodon, criada especialmente para a execução dos testes. Nela você precisará preencher informações básicas como nome, idade e sexo. Caso não seja da sua vontade exibir seu nome, qualquer outro nome ou apelido poderá ser utilizado. Além disso, durante o cadastro você poderá criar o seu login e senha para acesso. Você será incluído em um grupo contendo amigos que também participarão do experimento. Você deverá interagir com seus amigos dentro da rede social fazendo posts, curtidas e compartilhando informação relacionadas ao que desejar.

Posteriormente será solicitado que instale no seu celular uma aplicação chamada "SocialTracks" que foi criada com o intuito de simular o sistema de recomendação no experimento. Dentro da aplicação você deverá fornecer suas credenciais da rede social Social Tracks Mastodon e as credenciais da sua conta do Spotify. O sistema recomendará um conjunto de itens baseado nas informações extraídas e processadas da rede social e do Spotify.

Finalmente, após receber a recomendação, você precisará avaliar a recomendação. Para tal, você deverá, para cada recomendação exibida, atribuir uma nota de 1 a 5 , de tal modo que 1 represente pouca afinidade com a recomendação feita e 5 represente muita afinidade. Caso não atribua nenhuma nota, a recomendação será descartada.

\section{Riscos e Benefícios da participação na Pesquisa:}

\section{Benefícios:}

- Permitir uma discussão sobre Sistemas de Recomendação e a importância do uso de dados das redes sociais como estratégia para mitigar o problema de cold-start.

\section{Riscos:}

- Dependendo do perfil do participante é provável que durante a execução dos testes possa experimentar constrangimento emocional como: medo, insegurança ou frus- 
tração, em casos que a aplicação apresente problemas de funcionalidade impedindo ao usuário executar todo o processo do teste.

- Todas as informações obtidas nos testes, com excessão da identificação, serão armazenadas em banco de dados.

- O sistema em nenhum momento salvará ou terá acesso ao seu login e senha da rede social, ou plataforma de serviço de música. Garantimos a privacidade das suas credenciais e acesso apenas aos dados que você concordar liberar, como por exemplo: número de curtidas, número de compartilhamentos de postagens, menções, comentários, entre outros.

- Os dados serão anonimizados, o que significa que os dados coletados da rede social e da plataforma musical não poderão ser relacionados com você. Esta pesquisa não avalia a pessoa que participa dos testes e sim o sistema de recomendação. Todos os dados inseridos no sistema serão analisados apenas estatisticamente.

- Os dados coletados das redes sociais, com excessão de login, senha e identificação, serão guardados por dois anos. Após esse tempo, os dados serão descartados.

Todos os dados coletados nesta pesquisa serão usados como fundamentação dos trabalhos de dissertação de mestrado e trabalhos de conclusão de curso. Esses trabalhos estão dentro do projeto da pesquisa principal "Big Data e Business Intelligence - uso de dados de redes sociais como solução para cenário de cold-start em sistema de recomendação", e são de grande relevância porque permitirão uma discussão mais abrangente sobre Sistemas de Recomendação e seus problemas associados.

Você poderá pedir informações sobre a pesquisa a qualquer momento, durante e após sua participação. As informações de contato dos pesquisadores da Escola Politécnica estão no fim desta carta.

Você tem a liberdade de desistir ou interromper a colaboração nesse estudo no momento em que desejar, sem necessidade de qualquer explicação.

Finalmente ressaltamos que sua participação é voluntária e que você não irá receber nenhuma remuneração ou prêmio pela sua participação.

Se você concordar em participar, solicitamos que assine o termo em anexo. O qual será emitido em duas vias, sendo que uma delas fica com o participante. Todos os riscos e benefícios desta pesquisa estão também destacados no termo anexo que você deverá assinar. 
Agradecemos pela sua atenção.

Atenciosamente,

Solange Nice Alves de Souza.

Coordenadora da pesquisa.

Para esclarecimento de duvidas:

- Lesly Alejandra Gonzalez Camacho.

E-mail: alejandragc@usp.br

- João Henrique Kersul Faria.

E-mail: joao.henrique.faria@usp.br

- Felipe Gusmão Contratres.

E-mail: felipe.contratres@gmail.com

- Solange Nice Alves de Souza.

Escola Politécnica da Universidade de São Paulo.

Avenida Professor Luciano Gualberto, travessa 3, n.158.

055080-900- São Paulo - SP.

Tel: (11)3091-0693.

E-mail: ssouza@usp.br

- Comitê de Ética em Pesquisa em Seres Humanos - CEP da Escola de Artes, Ciências e Humanidades (EACH) da Universidade de São Paulo (USP)

Telefone: (11) 3091-1046

Email CEP: cep-each@usp.br

Atendimento: Segunda à sexta-feira das $10 \mathrm{~h}$ às $12 \mathrm{~h}$ e das $14 \mathrm{~h}$ às $16 \mathrm{~h}$

Localização: Prédio I1 — Sala T14 


\section{TERMO DE CONSENTIMENTO LIVRE E ESCLARECIDO}

(maiores de 18 anos)

Big Data e Business Intelligence - uso de dados de redes sociais como solução para cenário de cold-start em sistemas de recomendação

Você está sendo convidado (a) a participar do projeto de pesquisa acima citado. $O$ documento abaixo contém todas as informações necessárias sobre a pesquisa que estamos fazendo. Sua colaboração neste estudo será muito importnte para nós. Este Termo de Consentimento Livre e Esclarecido (TCLE) está de acordo com as resoluções CNS 0466/12 e 0510/16, que dispõem sobre a pesquisa envolvendo seres humanos.

$\mathrm{Eu}$ .(inserir nome), residente e domiciliado(a) na portador(a) da Cédula de Identidade, RG inscrito(a) no $\mathrm{CPF} / \mathrm{MF}$ nascido(a) em ..../.../...., abaixo assinado, concordo de livre e espontânea vontade em participar do estudo "Big Data e Business Intelligence- uso de dados de redes sociais como solução para cenário de cold-start em sistemas de recomendação", e esclareço que obtive todas as informações.

Estou ciente que:

- O estudo tem como objetivo avaliar uma nova forma de recomendar produtos/itens através de informações extraídas das redes sociais.

- Após dois anos os dados coletados serão completamente descartados, sem nenhuma referencia a minha pessoa.

\section{- Benefícios da pesquisa:}

- Avaliar o uso de redes sociais em Sistemas de Recomendação para que novos usuários de um e-commerce, ou de site de músicas, ou de aplicativos de viagens, dentre outros, possam ter recomendações apropriadas aos seus interesses.

- Permitir uma discussão sobre Sistemas de Recomendação e a importância do uso de dados das redes sociais como estratégia para mitigar o problema de cold-start (usuário novo no e-commerce).

\section{- Riscos:}


- O experimento não apresenta nenhum risco de constrangimento físico para minha pessoa.

- Tenho consciência de que sendo um experimento computacional e que depende dos recursos de internet, pode haver demora na execução e apresentação das informações e resultados, bem como perda da conexão.

- Não existem riscos de meus dados e informações pessoais serem divulgados a outras pessoas.

- Meus dados de identificação não serão armazenados no sistema.

- Não existe a obrigação de minha participação até o final do experimento. Posso desistir ou interromper minha colaboração na pesquisa a qualquer momento que desejar, sem a necessidade de dar qualquer explicação para isso.

- Posso demorar o tempo que precisar para realizar o teste.

- Somente os pesquisadores responsaveis farão uso dos dados coletados no experimento.

- Não sou obrigrado a participar da pesquisa mesmo que eu trabalhe/estude/ pesquise na instituição.

- Os dados que eu inserir no sistema estarão disponíveis ao término do experimento. Porém sem nenhuma referência ao meu nome ou fotografia.

- As credenciais que eu fornecer da minha conta da rede social e do meu serviço de música não serão salvos no sistema.

Concordo que:

- Os resultados obtidos durante essa pesquisa sejam divulgados em publicações científicas e que os dados pessoais que possam permitir minha identificação, não serão divulgados, pois nem serão armazenados.

- Não terei nenhum tipo de remuneração por participar desta pesquisa.

- Caso deseje, poderei tomar conhecimento dos resultados, ao final dessa pesquisa:

- ( )Desejo conhecer os resultados dessa pesquisa. E-mail:

- ( )Não desejo conhecer os resultados dessa pesquisa 
São Paulo, de de 2019

Nome do Pesquisador Assinatura do Pesquisador

Assinatura do Participante 


\section{APÊNDICE B - EXPERIMENTO}

Nesta seção apresenta-se alguns prints das telas da aplicação usada no experimento.

Figura 12: inicio

Faça login com o Spotify e com Mastodon.

Figura 13: Acesso com Spotify

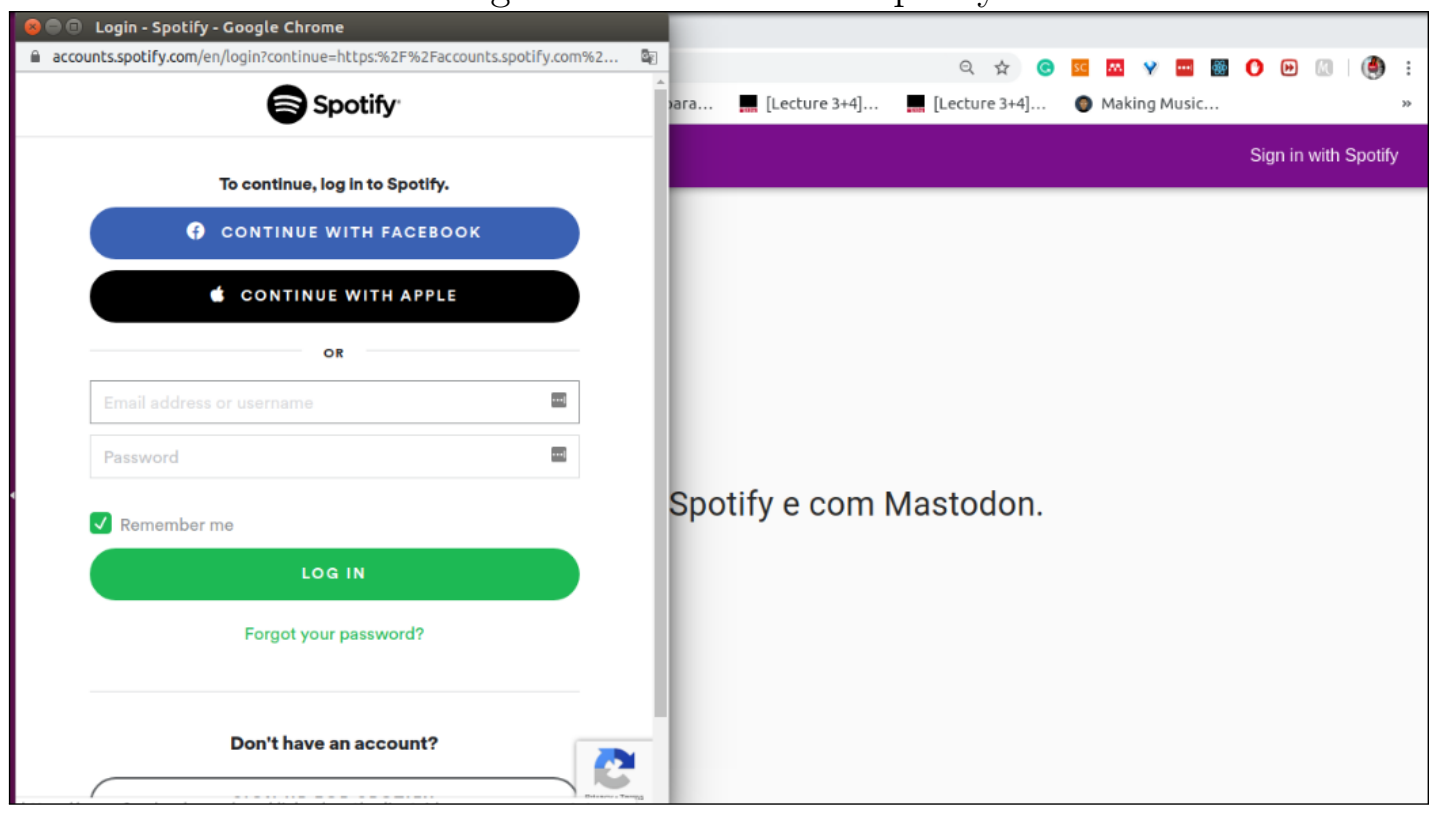


Figura 14: Acesso com Mastodon

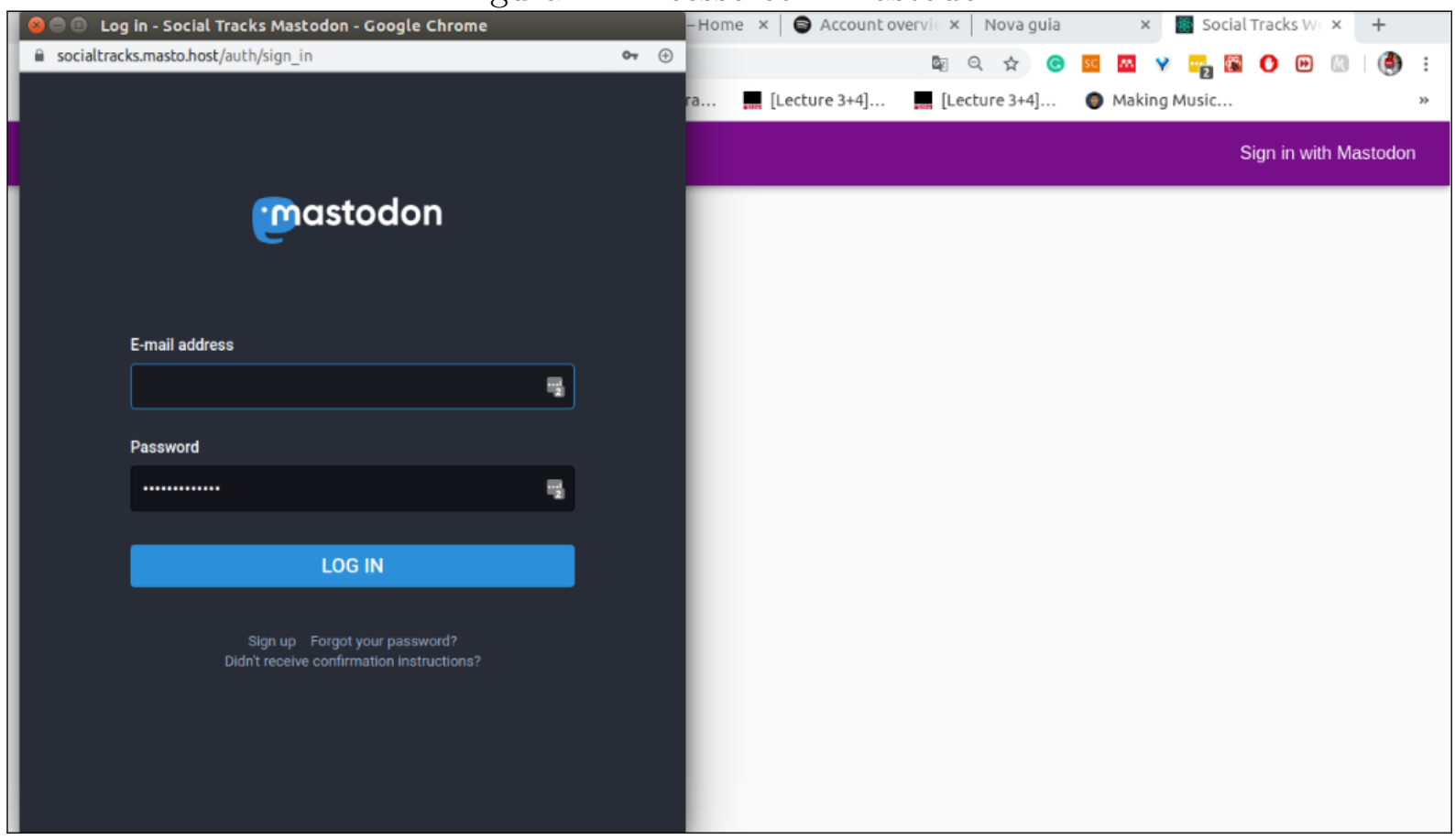

Figura 15: Geração de Recomendação

Espere até todos os usuários estarem cadastrados e gere sua recomendação :) 
Figura 16: Recomendação das músicas

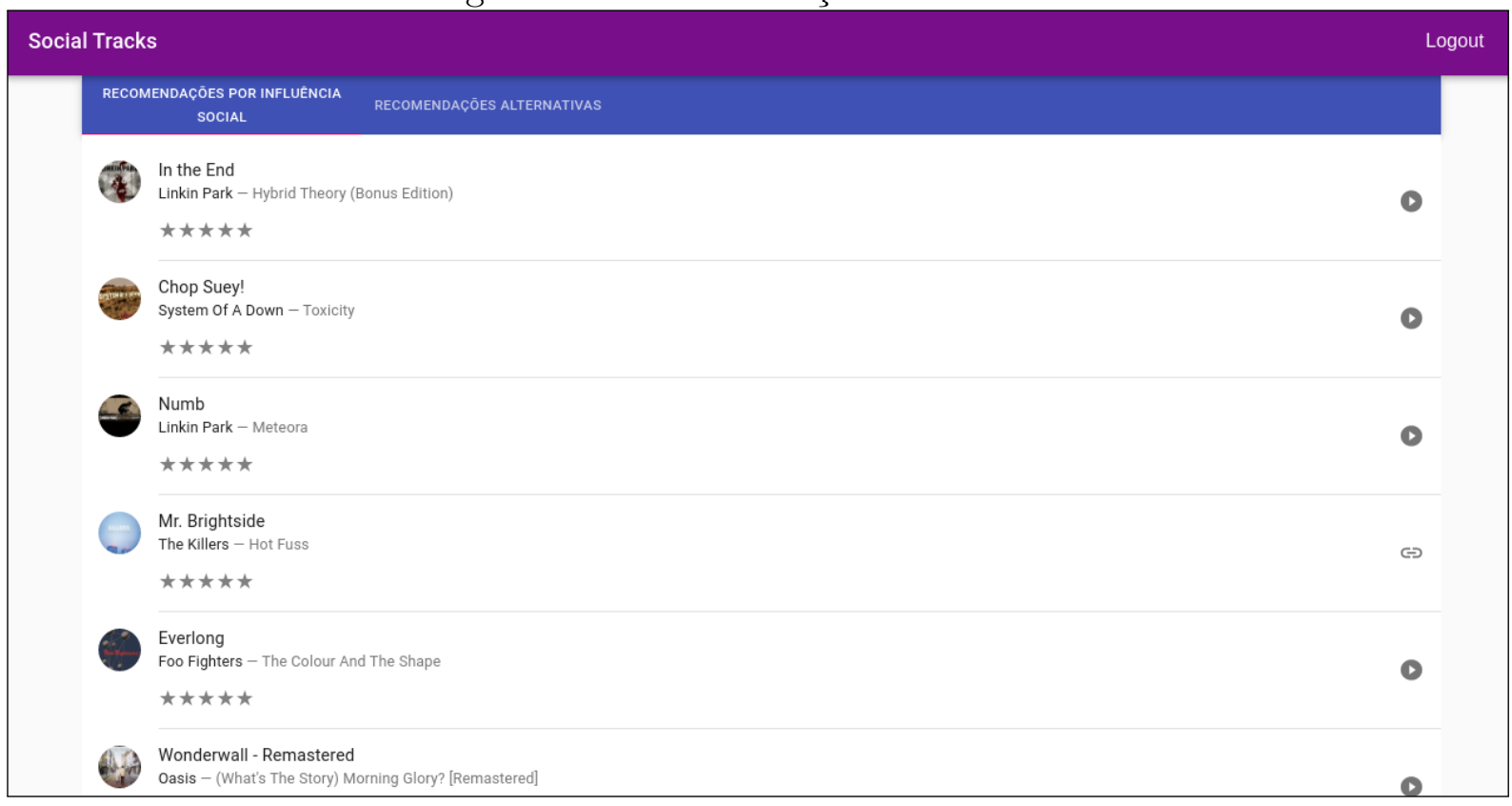

Figura 17: Avaliação das músicas pelo usuário

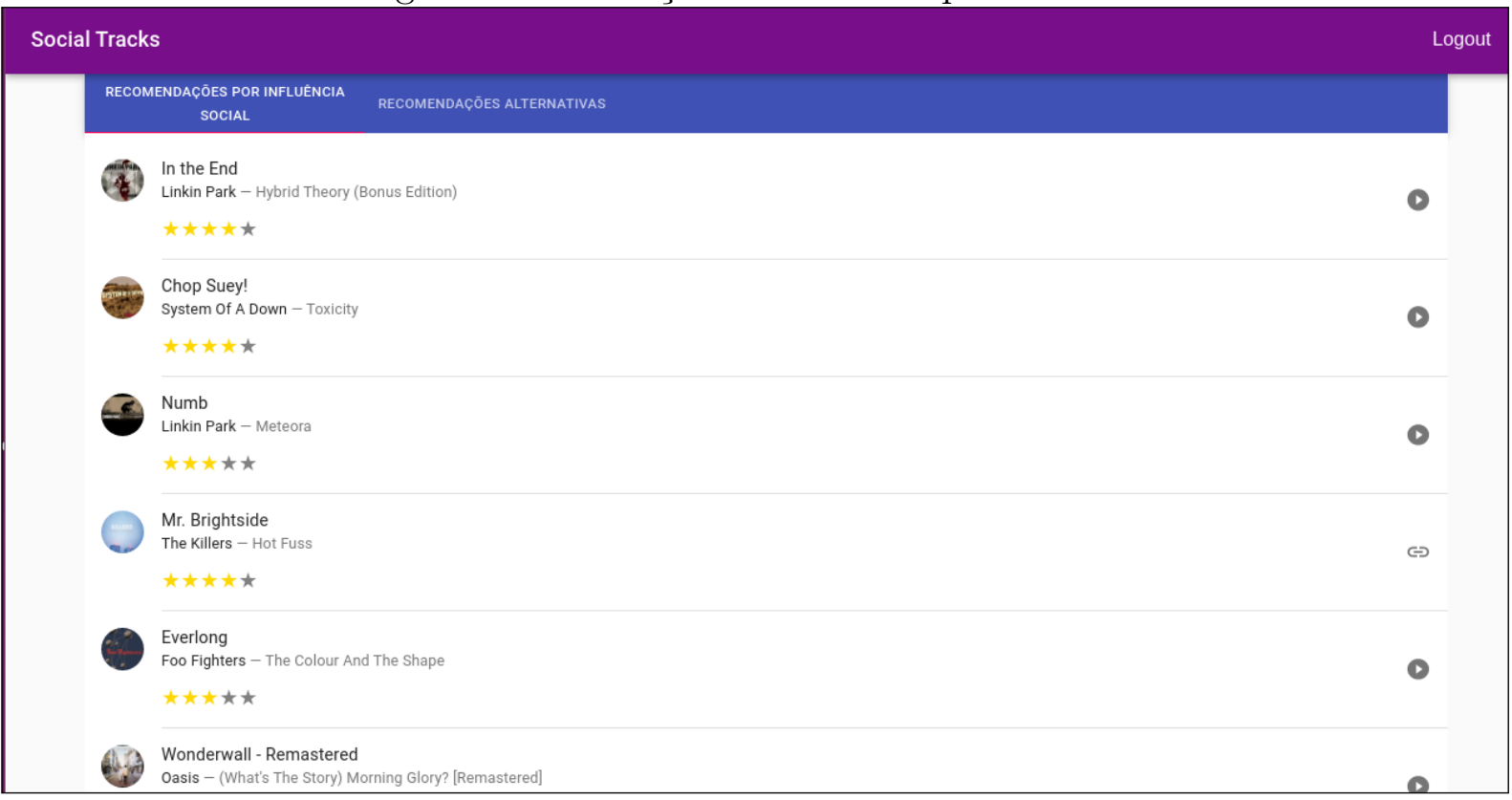




\section{APÊNDICE C - CÁLCULO DE FATORES DE INFLUÊNCIA}

Nesta seção apresenta-se (Tabela 14) todos os valores calculados para os fatores empregados no cálculo da influência social. As identificações reais de cada participante foram omitidas por razões de privacidade, tendo sido atribuídos códigos numéricos para identificar cada participante. Os campos na Tabela 14 correspondem a:

- coldstart-id: identificador do usuário cold-start;

- user-id: identificador dos usuários do grupo de amigos mais próximos ao usuário cold-start;

- $F_{\text {exp }}$ : Expert factor do user_id;

- $F_{f r i}$ : Friendly Factor do user_id;

- $F_{\text {lead }}$ : Leader Factor do user_id;

- $F_{\text {sim }}$ : Similarity Factor do user_id;

- SI: influência social do user_id no grupo de amigos.

Tabela 14: Resultado do cálculo dos fatores de influência para cada usuário cold-start

\begin{tabular}{rrrrrrr}
\hline coldstart_id & user_id & $F_{\text {exp }}$ & $F_{\text {fri }}$ & $F_{\text {lead }}$ & $F_{\text {sim }}$ & SI \\
\hline & 1 & 0 & 0.2713 & 0.474972 & 0.12747 & 0.186664 \\
& 2 & 0.753041 & 0.0532275 & 0.377993 & 0.13006 & 0.267225 \\
& 5 & 0.219296 & 0.0140741 & 0.262373 & 0.05 & 0.102595 \\
& 6 & 0.615091 & 0.0719907 & 0.494432 & 0.0392157 & 0.223826 \\
& 9 & 0.700475 & 0.0204665 & 0.309674 & 0.0673611 & 0.213787 \\
& 12 & 0.128763 & 0.0103704 & 0.0805556 & 0.02 & 0.0472587 \\
\hline
\end{tabular}


Tabela 14: Resultado do cálculo dos fatores de influência para cada usuário cold-start

\begin{tabular}{|c|c|c|c|c|c|c|}
\hline coldstart_id & user_id & $F_{\text {exp }}$ & $F_{f r i}$ & $F_{\text {lead }}$ & $F_{\text {sim }}$ & SI \\
\hline \multirow{6}{*}{2} & 1 & 0.588198 & 0.142678 & 0.291798 & 0.0963585 & 0.233137 \\
\hline & 2 & 0 & 0.187722 & 0.393407 & 0.134336 & 0.156248 \\
\hline & 6 & 0.212229 & 0.0829682 & 0.328291 & 0.052549 & 0.129362 \\
\hline & 3 & 0.596618 & 0.186865 & 0.407225 & 0.0846154 & 0.257297 \\
\hline & 7 & 0.831416 & 0.163873 & 0.400791 & 0.0977058 & 0.302504 \\
\hline & 11 & 0.271539 & 0.0457113 & 0.178487 & 0.0384615 & 0.10568 \\
\hline \multirow{5}{*}{3} & 7 & 0.879662 & 0.175395 & 0.396526 & 0.173323 & 0.344904 \\
\hline & 11 & 0.268645 & 0.0856291 & 0.269874 & 0.1006 & 0.152787 \\
\hline & 19 & 0.466922 & 0.175132 & 0.357945 & 0.213982 & 0.273405 \\
\hline & 3 & 0 & 0.379593 & 0.427834 & 0.19937 & 0.238018 \\
\hline & 2 & 0.384771 & 0.191622 & 0.214488 & 0.0131579 & 0.161915 \\
\hline \multirow{5}{*}{4} & 6 & 0.547293 & 0.2 & 0.333333 & 0.01 & 0.211236 \\
\hline & 12 & 0.0331487 & 0 & 0 & 0 & 0.00662975 \\
\hline & 4 & 0 & 0 & 0 & 0 & 0 \\
\hline & 14 & 0.260539 & 0 & 0.333333 & 0.01 & 0.100552 \\
\hline & 17 & 0.721829 & 0 & 0 & 0 & 0.144366 \\
\hline \multirow{5}{*}{5} & 1 & 0.80362 & 0.184215 & 0.199176 & 0.0138889 & 0.24196 \\
\hline & 10 & 0.429491 & 0.0649484 & 0.21339 & 0 & 0.13167 \\
\hline & 5 & 0 & 0.307176 & 0.517063 & 0.0625 & 0.175855 \\
\hline & 9 & 0.524335 & 0.0255832 & 0.389352 & 0.0763889 & 0.194158 \\
\hline & 18 & 0.242554 & 0.0252404 & 0.0976852 & 0 & 0.0682662 \\
\hline \multirow{6}{*}{6} & 1 & 0.606579 & 0.112603 & 0.316321 & 0.106359 & 0.236063 \\
\hline & 2 & 0.39944 & 0.119758 & 0.388185 & 0.134336 & 0.217316 \\
\hline & 6 & 0 & 0.0907942 & 0.388185 & 0.0557023 & 0.0982507 \\
\hline & 7 & 0.847943 & 0.18016 & 0.455453 & 0.114812 & 0.324283 \\
\hline & 19 & 0.45913 & 0.0713282 & 0.221433 & 0.0497467 & 0.16027 \\
\hline & 16 & 0.186908 & 0.0393669 & 0.230423 & 0.0676923 & 0.10568 \\
\hline \multirow{5}{*}{7} & 2 & 0.438547 & 0.116901 & 0.365196 & 0.101003 & 0.207977 \\
\hline & 16 & 0.199383 & 0.0107955 & 0.184938 & 0.06 & 0.0914138 \\
\hline & 19 & 0.518636 & 0.102757 & 0.246743 & 0.129167 & 0.215695 \\
\hline & 7 & 0 & 0.231588 & 0.481652 & 0.168145 & 0.193235 \\
\hline & 3 & 0.674155 & 0.279709 & 0.480933 & 0.141548 & 0.330163 \\
\hline
\end{tabular}


Tabela 14: Resultado do cálculo dos fatores de influência para cada usuário cold-start

\begin{tabular}{|c|c|c|c|c|c|c|}
\hline coldstart_id & user_id & $F_{\text {exp }}$ & $F_{f r i}$ & $F_{\text {lead }}$ & $F_{\text {sim }}$ & SI \\
\hline & 1 & 0.669279 & 0.0411742 & 0.240538 & 0.100476 & 0.217098 \\
\hline \multirow{4}{*}{8} & 4 & 0.468274 & 0.0238095 & 0.0667989 & 0 & 0.108911 \\
\hline & 11 & 0.292859 & 0.0537919 & 0.126543 & 0 & 0.0897887 \\
\hline & 1 & 0.738867 & 0.145363 & 0.243471 & 0 & 0.219 \\
\hline & 8 & 0 & 0.0813422 & 0.229853 & 0 & 0.0523384 \\
\hline \multirow{2}{*}{9} & 9 & 0 & 0.0518519 & 0.5 & 0.0555556 & 0.102716 \\
\hline & 1 & 0 & 0.166667 & 0.166667 & 0.0555556 & 0.0888889 \\
\hline \multirow{4}{*}{10} & 1 & 0.751454 & 0.190064 & 0.191599 & 0 & 0.226521 \\
\hline & 5 & 0.173607 & 0.13179 & 0.167901 & 0 & 0.0922522 \\
\hline & 19 & 0.574939 & 0.0811728 & 0.0965608 & 0 & 0.149509 \\
\hline & 10 & 0 & 0.05882 & 0.210606 & 0 & 0.0437662 \\
\hline \multirow{6}{*}{11} & 7 & 0.799303 & 0.150686 & 0.409992 & 0.138658 & 0.310173 \\
\hline & 3 & 0.521402 & 0.307378 & 0.435587 & 0.159496 & 0.308125 \\
\hline & 1 & 0.521481 & 0.0712494 & 0.187957 & 0.0904762 & 0.184547 \\
\hline & 2 & 0.286428 & 0.163668 & 0.302708 & 0.101003 & 0.181693 \\
\hline & 19 & 0.371385 & 0.143809 & 0.37139 & 0.171185 & 0.230619 \\
\hline & 11 & 0 & 0.072207 & 0.292366 & 0.0804803 & 0.0904294 \\
\hline \multirow{2}{*}{12} & 12 & 0 & 0.0518519 & 0.111111 & 0.1 & 0.068642 \\
\hline & 1 & 0 & 0.583333 & 0.222222 & 0.1 & 0.225185 \\
\hline \multirow{4}{*}{13} & 6 & 0.252605 & 0.286651 & 0.447332 & 0.107026 & 0.229416 \\
\hline & 13 & 0 & 0.017284 & 0.236893 & 0.12037 & 0.0843429 \\
\hline & 1 & 0.752859 & 0.298214 & 0.36498 & 0.197635 & 0.357813 \\
\hline & 2 & 0.494536 & 0.119268 & 0.284129 & 0.248016 & 0.267802 \\
\hline \multirow{2}{*}{14} & 14 & 0 & 0 & 0.333333 & 0.05 & 0.0644444 \\
\hline & 6 & 0 & 1 & 0.333333 & 0.05 & 0.331111 \\
\hline \multirow{6}{*}{15} & 15 & 0 & 0 & 0.262455 & 0.0737361 & 0.0644885 \\
\hline & 13 & 0.138113 & 0.014359 & 0.0956349 & 0 & 0.044203 \\
\hline & 8 & 0.468938 & 0.0530789 & 0.185859 & 0 & 0.132723 \\
\hline & 19 & 0.652248 & 0.172848 & 0.483913 & 0.147891 & 0.30022 \\
\hline & 11 & 0.462379 & 0.0960928 & 0.415873 & 0.0893793 & 0.209302 \\
\hline & 3 & 0.778321 & 0.1769 & 0.489599 & 0.119496 & 0.315916 \\
\hline & 16 & 0 & 0.0539773 & 0.333333 & 0.25 & 0.158838 \\
\hline
\end{tabular}


Tabela 14: Resultado do cálculo dos fatores de influência para cada usuário cold-start

\begin{tabular}{rrrrrrr}
\hline coldstart_id & user_id & $F_{\text {exp }}$ & $F_{\text {fri }}$ & $F_{\text {lead }}$ & $F_{\text {sim }}$ & SI \\
\hline \multirow{2}{*}{17} & 7 & 0 & 0.5 & 0.333333 & 0.25 & 0.277778 \\
\hline \multirow{2}{*}{18} & 17 & 0 & 0 & 0.333333 & 0.213514 & 0.12985 \\
& 11 & 0 & 0.104762 & 0.333333 & 0.213514 & 0.157786 \\
\hline & 18 & 0 & 0.0504808 & 0.0892857 & 0 & 0.0253663 \\
& 10 & 0.900154 & 0.111378 & 0.194805 & 0 & 0.235706 \\
& 5 & 0.0998457 & 0.579167 & 0.215909 & 0 & 0.203201 \\
\hline & 2 & 0.431017 & 0.196155 & 0.270032 & 0.0438596 & 0.192059 \\
& 6 & 0.244458 & 0.0810309 & 0.249754 & 0.0487943 & 0.123318 \\
& 19 & 0 & 0.168677 & 0.370611 & 0.173313 & 0.163721 \\
& 11 & 0.314716 & 0.0685033 & 0.270474 & 0.0804803 & 0.149466 \\
& 3 & 0.646424 & 0.303674 & 0.430537 & 0.166163 & 0.334135 \\
& 7 & 0.863384 & 0.168887 & 0.408593 & 0.145325 & 0.330322 \\
\hline \multirow{2}{*}{20} & 6 & 0.73018 & 0.416667 & 0.534722 & 0.3125 & 0.453443 \\
& 13 & 0.26982 & 0.166667 & 0.465278 & 0.0625 & 0.185445 \\
& 20 & 0 & 0 & 0 & 0.25 & 0.1 \\
\hline
\end{tabular}




\section{APÊNDICE D - RESULTADOS FINAIS}

A Tabela 15 apresenta os resultados das predições das musicas dadas pelo RS considerando ou não a Influencia Social, assim como a avaliação que cada usuário deu para cada música recomendada. Os campos na Tabela 15 correspondem a:

- Coldstart Id: identificador do usuário cold-start

- Música: O nome asociado a cada música recomendada

- Predição sem SI: valor da predição quando o RS não é considerada a Influencia Social (SI, Social Influence)

- Predição com SI: valor da predição quando o RS considera a SI

- R_system: valor da predição com SI normalizada

- R_user: avaliação (nota) dada pelo usuário cold-start para a música recomendada

Tabela 15: Resultados das predições e avaliações das músicas considerando a influência social

\begin{tabular}{|c|c|c|c|c|c|}
\hline $\begin{array}{l}\text { Coldstart } \\
\text { Id }\end{array}$ & Música & $\begin{array}{l}\text { Predição } \\
\text { sem SI }\end{array}$ & $\begin{array}{l}\text { Predição } \\
\text { com SI }\end{array}$ & R_system & R_user \\
\hline 1 & In the End & 1.37515 & 1.32268 & 3 & 4 \\
\hline 1 & Chop Suey! & 1.26387 & 1.28402 & 3 & 4 \\
\hline 1 & Numb & 1.33178 & 1.28367 & 3 & 3 \\
\hline 1 & Mr. Brightside & 1.14339 & 1.27878 & 3 & 4 \\
\hline 1 & Everlong & 1.22074 & 1.27588 & 3 & 3 \\
\hline 1 & $\begin{array}{l}\text { Wonderwall - Remas- } \\
\text { tered }\end{array}$ & 1.17508 & 1.24202 & 3 & 4 \\
\hline 1 & $\begin{array}{l}\text { Nirvana smells like } \\
\text { teen spirit - remix }\end{array}$ & 1.17367 & 1.22896 & 3 & 2 \\
\hline
\end{tabular}


Tabela 15: Resultados das predições e avaliações das músicas considerando a influência social

\begin{tabular}{|c|c|c|c|c|c|}
\hline $\begin{array}{l}\text { Coldstart } \\
\text { Id }\end{array}$ & Música & $\begin{array}{l}\text { Predição } \\
\text { sem SI }\end{array}$ & $\begin{array}{l}\text { Predição } \\
\text { com SI }\end{array}$ & R_system & R_user \\
\hline 1 & Scar Tissue & 1.17695 & 1.22797 & 3 & 4 \\
\hline 2 & The Scientist & 1.85105 & 2.20013 & 5 & 3 \\
\hline 2 & $\begin{array}{l}\text { Somebody That I } \\
\text { Used To Know }\end{array}$ & 1.92139 & 2.1675 & 5 & 5 \\
\hline 2 & Mr. Brightside & 1.94921 & 2.15296 & 5 & 3 \\
\hline 2 & Do I Wanna Know? & 1.84418 & 2.11113 & 5 & 4 \\
\hline 2 & Sex on Fire & 1.87884 & 2.08468 & 5 & 4 \\
\hline 2 & Radioactive & 1.84577 & 2.06627 & 4 & 5 \\
\hline 2 & Pumped Up Kicks & 1.84429 & 2.03114 & 4 & 5 \\
\hline 2 & $\begin{array}{l}\text { Nirvana smells like } \\
\text { teen spirit - remix }\end{array}$ & 1.78984 & 2.00881 & 4 & 5 \\
\hline 2 & Use Somebody & 1.85372 & 2.00284 & 4 & 2 \\
\hline 3 & $\begin{array}{l}\text { Somebody That I } \\
\text { Used To Know }\end{array}$ & 1.07475 & 1.3801 & 3 & 5 \\
\hline 3 & Losing My Religion & 1.1489 & 1.24059 & 3 & 5 \\
\hline 3 & Somebody Told Me & 1.05048 & 1.26269 & 3 & 5 \\
\hline 3 & Mr. Brightside & 1.12844 & 1.26456 & 3 & 5 \\
\hline 3 & $\begin{array}{l}\text { Wonderwall - Remas- } \\
\text { tered }\end{array}$ & 1.16641 & 1.27578 & 3 & 5 \\
\hline 3 & Viva La Vida & 1.18141 & 1.34217 & 3 & 5 \\
\hline 3 & Linger & 1.09995 & 1.42257 & 3 & 5 \\
\hline 4 & Take Me To Church & 1.26509 & 1.00386 & 3 & 5 \\
\hline 4 & Ho Hey & 1.39253 & 0.992528 & 3 & 5 \\
\hline 4 & Do I Wanna Know? & 1.16698 & 0.977596 & 3 & 4 \\
\hline 4 & Sex on Fire & 1.24098 & 0.925011 & 3 & 5 \\
\hline 4 & Use Somebody & 1.47953 & 1.04746 & 3 & 5 \\
\hline 4 & The Scientist & 1.38223 & 1.03931 & 3 & 5 \\
\hline 5 & Pumped Up Kicks & 1.39973 & 1.65605 & 4 & 5 \\
\hline 5 & Use Somebody & 1.34224 & 1.67119 & 4 & 2 \\
\hline 5 & Radioactive & 1.23178 & 1.76677 & 4 & 5 \\
\hline
\end{tabular}


Tabela 15: Resultados das predições e avaliações das músicas considerando a influência social

\begin{tabular}{|c|c|c|c|c|c|}
\hline $\begin{array}{l}\text { Coldstart } \\
\text { Id }\end{array}$ & Música & $\begin{array}{l}\text { Predição } \\
\text { sem SI }\end{array}$ & $\begin{array}{l}\text { Predição } \\
\text { com SI }\end{array}$ & R_system & R_user \\
\hline 5 & $\begin{array}{l}\text { Somebody That I } \\
\text { Used To Know }\end{array}$ & 1.24579 & 1.62382 & 4 & 4 \\
\hline 5 & Counting Stars & 1.25862 & 1.65105 & 4 & 5 \\
\hline 6 & The Scientist & 1.9 & 2.30762 & 5 & 4 \\
\hline 6 & $\begin{array}{l}\text { Wonderwall - Remas- } \\
\text { tered }\end{array}$ & 1.92226 & 2.21286 & 5 & 4 \\
\hline 6 & Poker Face & 1.89715 & 2.24218 & 5 & 2 \\
\hline 6 & Mr. Brightside & 1.83249 & 2.28118 & 5 & 4 \\
\hline 6 & Losing My Religion & 1.99874 & 2.36529 & 5 & 3 \\
\hline 6 & Rolling in the Deep & 1.88286 & 2.3506 & 5 & 4 \\
\hline 6 & Linger & 1.89193 & 2.31417 & 5 & 4 \\
\hline 6 & Viva La Vida & 1.92524 & 2.31431 & 5 & 3 \\
\hline 7 & Losing My Religion & 1.8517 & 2.27127 & 5 & 5 \\
\hline 7 & Paradise & 1.74279 & 2.14798 & 5 & 3 \\
\hline 7 & $\begin{array}{l}\text { Coldplay - Fix You } \\
\text { (Remix) }\end{array}$ & 1.76151 & 2.16209 & 5 & 2 \\
\hline 7 & Use Somebody & 1.90501 & 2.20177 & 5 & 3 \\
\hline 7 & Somebody Told Me & 1.79069 & 2.25811 & 5 & 4 \\
\hline 7 & Viva La Vida & 1.93776 & 2.32483 & 5 & 4 \\
\hline 7 & $\begin{array}{l}\text { Wonderwall - Remas- } \\
\text { tered }\end{array}$ & 1.94982 & 2.3226 & 5 & 4 \\
\hline 7 & The Scientist & 1.93033 & 2.31468 & 5 & 5 \\
\hline 7 & Mr. Brightside & 2.00053 & 2.31187 & 5 & 4 \\
\hline 7 & $\begin{array}{l}\text { Somebody That I } \\
\text { Used To Know }\end{array}$ & 1.85606 & 2.28996 & 5 & 4 \\
\hline 8 & The Scientist & 1.42148 & 1.6246 & 4 & 4 \\
\hline 8 & Use Somebody & 1.39496 & 1.62151 & 4 & 4 \\
\hline 8 & $\begin{array}{l}\text { Somebody That I } \\
\text { Used To Know }\end{array}$ & 1.38403 & 1.54539 & 4 & 4 \\
\hline 8 & Losing My Religion & 1.31389 & 1.49024 & 4 & 5 \\
\hline 8 & Sex on Fire & 1.28298 & 1.49204 & 4 & 5 \\
\hline
\end{tabular}


Tabela 15: Resultados das predições e avaliações das músicas considerando a influência social

\begin{tabular}{|c|c|c|c|c|c|}
\hline $\begin{array}{l}\text { Coldstart } \\
\text { Id }\end{array}$ & Música & $\begin{array}{l}\text { Predição } \\
\text { sem SI }\end{array}$ & $\begin{array}{l}\text { Predição } \\
\text { com SI }\end{array}$ & R_system & R_user \\
\hline 8 & Yellow & 1.39106 & 1.51248 & 4 & 5 \\
\hline 8 & Mr. Brightside & 1.30093 & 1.52366 & 4 & 4 \\
\hline 8 & Do I Wanna Know? & 1.30635 & 1.53072 & 4 & 5 \\
\hline 8 & Viva La Vida & 1.32669 & 1.53794 & 4 & 5 \\
\hline 8 & $\begin{array}{l}\text { Wonderwall - Remas- } \\
\text { tered }\end{array}$ & 1.45809 & 1.60671 & 4 & 4 \\
\hline 9 & Little Talks & 0.522339 & 0.559208 & 2 & 3 \\
\hline 9 & Use Somebody & 0.476128 & 0.554776 & 2 & 2 \\
\hline 9 & The Scientist & 0.502911 & 0.546171 & 2 & 3 \\
\hline 9 & Losing My Religion & 0.491041 & 0.523358 & 2 & 4 \\
\hline 9 & Ho Hey & 0.454716 & 0.523035 & 2 & 3 \\
\hline 9 & Take Me To Church & 0.504443 & 0.567778 & 2 & 3 \\
\hline 9 & Radioactive & 0.530546 & 0.579443 & 2 & 3 \\
\hline 10 & Mr. Brightside & 1.22619 & 1.33735 & 3 & 2 \\
\hline 10 & The Pretender & 1.19016 & 1.32464 & 3 & 1 \\
\hline 10 & In the End & 1.25082 & 1.32566 & 3 & 2 \\
\hline 10 & Numb & 1.25718 & 1.34704 & 3 & 2 \\
\hline 10 & Viva La Vida & 1.18858 & 1.3903 & 3 & 4 \\
\hline 10 & My Hero & 1.16358 & 1.47449 & 3 & 1 \\
\hline 10 & Use Somebody & 1.16769 & 1.48938 & 4 & 1 \\
\hline 10 & Everlong & 1.25079 & 1.53904 & 4 & 1 \\
\hline 11 & The Scientist & 1.93812 & 2.11847 & 5 & 5 \\
\hline 11 & Viva La Vida & 1.82154 & 2.17023 & 5 & 5 \\
\hline 11 & Linger & 1.76011 & 2.19633 & 5 & 5 \\
\hline 11 & $\begin{array}{l}\text { Wonderwall - Remas- } \\
\text { tered }\end{array}$ & 1.93854 & 2.24147 & 5 & 5 \\
\hline 11 & Use Somebody & 1.86035 & 2.15152 & 5 & 5 \\
\hline 11 & Losing My Religion & 2.08604 & 2.26332 & 5 & 5 \\
\hline 11 & Mr. Brightside & 2.00118 & 2.27029 & 5 & 5 \\
\hline 12 & Little Talks & 0.507747 & 0.630482 & 2 & 3 \\
\hline 12 & Radioactive & 0.48688 & 0.673084 & 2 & 5 \\
\hline
\end{tabular}


Tabela 15: Resultados das predições e avaliações das músicas considerando a influência social

\begin{tabular}{|c|c|c|c|c|c|}
\hline $\begin{array}{l}\text { Coldstart } \\
\text { Id }\end{array}$ & Música & $\begin{array}{l}\text { Predição } \\
\text { sem SI }\end{array}$ & $\begin{array}{l}\text { Predição } \\
\text { com SI }\end{array}$ & R_system & R_user \\
\hline 12 & Demons & 0.494328 & 0.636188 & 2 & 5 \\
\hline 12 & The Scientist & 0.514469 & 0.62895 & 2 & 5 \\
\hline 12 & Do I Wanna Know? & 0.448623 & 0.615726 & 2 & 2 \\
\hline 12 & Ho Hey & 0.481912 & 0.610383 & 2 & 5 \\
\hline 12 & $\begin{array}{l}\text { Somebody That I } \\
\text { Used To Know }\end{array}$ & 0.457916 & 0.608112 & 2 & 5 \\
\hline 13 & Psychosocial & 1.00221 & 1.24979 & 3 & 2 \\
\hline 13 & Losing My Religion & 1.13147 & 1.42509 & 3 & 5 \\
\hline 13 & Come As You Are & 0.986232 & 1.37708 & 3 & 5 \\
\hline 13 & $\begin{array}{l}\text { Nirvana smells like } \\
\text { teen spirit - remix }\end{array}$ & 1.00733 & 1.34837 & 3 & 5 \\
\hline 13 & The Scientist & 1.00529 & 1.24744 & 3 & 5 \\
\hline 13 & Numb & 1.03499 & 1.2906 & 3 & 5 \\
\hline 13 & Enter Sandman & 1.02991 & 1.28163 & 3 & 5 \\
\hline 13 & Chop Suey! & 1.07781 & 1.25683 & 3 & 1 \\
\hline 13 & Mr. Brightside & 1.04271 & 1.25002 & 3 & 5 \\
\hline 13 & $\begin{array}{l}\text { Wonderwall - Remas- } \\
\text { tered }\end{array}$ & 1.017 & 1.33796 & 3 & 5 \\
\hline 14 & Before I Forget & 0.113341 & 0.148793 & 1 & 5 \\
\hline 14 & In the End & 0.118437 & 0.154281 & 1 & 5 \\
\hline$\overline{15}$ & Use Somebody & 0.935577 & 1.27019 & 3 & 5 \\
\hline 15 & Losing My Religion & 0.959362 & 1.20963 & 3 & 5 \\
\hline 15 & Pumped Up Kicks & 0.89519 & 1.20405 & 3 & 2 \\
\hline 15 & The Scientist & 1.05724 & 1.18214 & 3 & 5 \\
\hline 15 & Mr. Brightside & 1.01851 & 1.17303 & 3 & 5 \\
\hline 15 & Scar Tissue & 0.893756 & 1.13926 & 3 & 5 \\
\hline 15 & $\begin{array}{l}\text { When You Were } \\
\text { Young }\end{array}$ & 0.903674 & 1.15468 & 3 & 5 \\
\hline 16 & Rolling in the Deep & 0.128417 & 0.156599 & 1 & 5 \\
\hline 16 & LoveGame & 0.124451 & 0.164562 & 1 & 5 \\
\hline 16 & Scar Tissue & 0.124581 & 0.167279 & 1 & 5 \\
\hline
\end{tabular}


Tabela 15: Resultados das predições e avaliações das músicas considerando a influência social

\begin{tabular}{|c|c|c|c|c|c|}
\hline $\begin{array}{l}\text { Coldstart } \\
\text { Id }\end{array}$ & Música & $\begin{array}{l}\text { Predição } \\
\text { sem SI }\end{array}$ & $\begin{array}{l}\text { Predição } \\
\text { com SI }\end{array}$ & R_system & R_user \\
\hline 16 & Californication & 0.124456 & 0.181435 & 1 & 5 \\
\hline 16 & Bad Romance & 0.142489 & 0.188077 & 1 & 5 \\
\hline 17 & The Scientist & 0.378373 & 0.422164 & 2 & 4 \\
\hline 17 & $\begin{array}{l}\text { Somebody That I } \\
\text { Used To Know }\end{array}$ & 0.337273 & 0.355375 & 2 & 4 \\
\hline 17 & $\begin{array}{l}\text { Wonderwall - Remas- } \\
\text { tered }\end{array}$ & 0.314525 & 0.358821 & 2 & 4 \\
\hline 17 & Creep & 0.309816 & 0.360538 & 2 & 4 \\
\hline 17 & Viva La Vida & 0.331383 & 0.351656 & 2 & 4 \\
\hline 17 & Yellow & 0.381242 & 0.419383 & 2 & 4 \\
\hline 17 & Clocks & 0.344016 & 0.37086 & 2 & 4 \\
\hline 17 & $\begin{array}{l}\text { Coldplay - Fix You } \\
\text { (Remix) }\end{array}$ & 0.341342 & 0.366146 & 2 & 1 \\
\hline 17 & Paradise & 0.313167 & 0.365137 & 2 & 4 \\
\hline 17 & Use Somebody & 0.314936 & 0.362038 & 2 & 4 \\
\hline 18 & Viva La Vida & 0.32377 & 0.406049 & 2 & 4 \\
\hline 18 & The Scientist & 0.360127 & 0.437069 & 2 & 5 \\
\hline 18 & Numb & 0.366434 & 0.439107 & 2 & 5 \\
\hline 18 & Rolling in the Deep & 0.348638 & 0.435482 & 2 & 3 \\
\hline 18 & Diamonds & 0.35551 & 0.434444 & 2 & 2 \\
\hline 18 & In the End & 0.324589 & 0.407308 & 2 & 5 \\
\hline 18 & Chandelier & 0.29539 & 0.399969 & 2 & 3 \\
\hline 18 & Mirrors & 0.298433 & 0.407777 & 2 & 4 \\
\hline 19 & Do I Wanna Know? & 1.07939 & 1.40601 & 3 & 4 \\
\hline 19 & $\begin{array}{l}\text { Wonderwall - Remas- } \\
\text { tered }\end{array}$ & 1.12413 & 1.38866 & 3 & 4 \\
\hline 19 & Viva La Vida & 1.07206 & 1.3722 & 3 & 5 \\
\hline 19 & Use Somebody & 1.08109 & 1.42742 & 3 & 4 \\
\hline 19 & Mr. Brightside & 1.20033 & 1.42877 & 3 & 5 \\
\hline 19 & The Scientist & 1.15847 & 1.44356 & 3 & 4 \\
\hline 19 & Pumped Up Kicks & 1.03633 & 1.39439 & 3 & 5 \\
\hline
\end{tabular}


Tabela 15: Resultados das predições e avaliações das músicas considerando a influência social

\begin{tabular}{|c|c|c|c|c|c|}
\hline $\begin{array}{l}\text { Coldstart } \\
\text { Id }\end{array}$ & Música & $\begin{array}{l}\text { Predição } \\
\text { sem SI }\end{array}$ & $\begin{array}{l}\text { Predição } \\
\text { com SI }\end{array}$ & R_system & R_user \\
\hline 19 & $\begin{array}{l}\text { Somebody That I } \\
\text { Used To Know }\end{array}$ & 1.08989 & 1.4509 & 3 & 5 \\
\hline 19 & Losing My Religion & 1.1708 & 1.46749 & 3 & 5 \\
\hline 19 & Sex on Fire & 1.09205 & 1.49917 & 4 & 4 \\
\hline 20 & Chop Suey! & 0.151295 & 0.221644 & 1 & 4 \\
\hline 20 & Psychosocial & 0.134372 & 0.211348 & 1 & 2 \\
\hline 20 & Bad Romance & 0.140972 & 0.208099 & 1 & 2 \\
\hline 20 & Crawling & 0.157575 & 0.205192 & 1 & 4 \\
\hline 20 & Going Under & 0.143172 & 0.222967 & 1 & 4 \\
\hline 20 & In the End & 0.17195 & 0.239755 & 1 & 4 \\
\hline 20 & Wait and Bleed & 0.137581 & 0.218452 & 1 & 2 \\
\hline 20 & Duality & 0.142617 & 0.213761 & 1 & 2 \\
\hline
\end{tabular}

